\title{
Ion Sensitive Field Effect Transistors
}

\author{
Applied to the Measurement \\ DOE/ID/12945-T3 \\ of the $\mathrm{pH}$ of Brines \\ DE93 005209
}

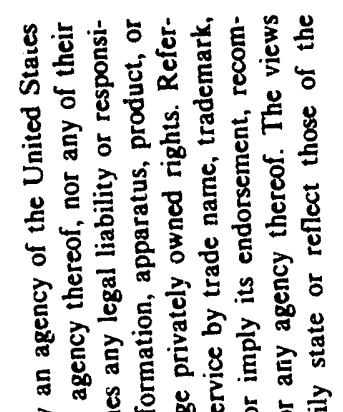

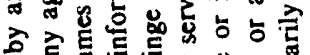

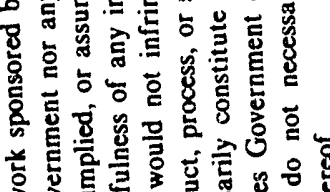

\section{A Thesis}

Presented to

The Graduate Faculty of

The University of Southwestern Louisiana

In Partial Fulfillment of the

Requirements for the Degree

Master of Science

FG07.40ID 12945

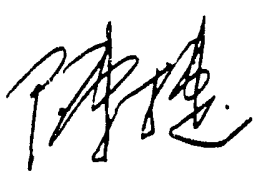

Jie Chen

Summer 1991 


\section{Ion Sensitive Field Effect Transistors}

Applied to tine Measurement

of the $\mathrm{pH}$ of Brines

Jie Chen

Approved:

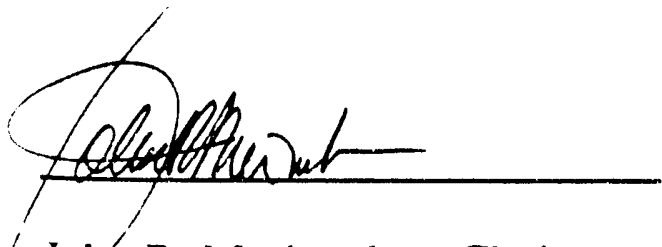

Johŕn R. Meriwether, Chairman

Professor of Physics

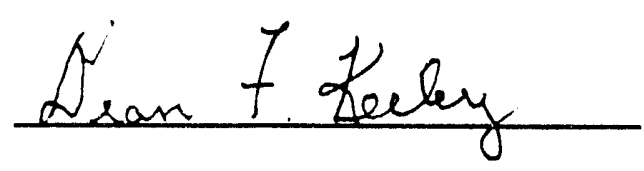

Dean F. Keeley

Professor of Chemistry
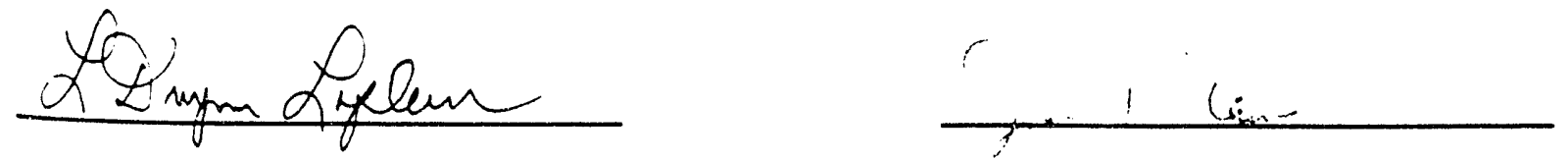

L. Dwynn Lafleur

Joan T. Cain

Professor of Physics

Dean, Graduate School 


\section{ACKNOWLEDGEMENTS}

I would like to thank all of those people who helped me to complete my masters work while here at USL. Many thanks go out from the bottom of my heart to all of my committee members, Dr. John R. Meriwether, Dr. Dean F. Keeley and Dr. L. Dwynn Lafleur, other faculty members, and especially Mr. William K. Koon, without whom I would not have been able to complete my work.

Sincere appreciation is expressed to Dr. John R. Meriwether for his direction of my study and research as well as the preparation of this thesis. 
ACKNOWLEDGMENTS ii

TABLE OF CONTENTS

LIST OF TABLES $\quad v$

LIST OF FIGURES vi

CHAPTER 1. INTRODUCTION

\$1.1. The Purpose of the Research 1

§1.2. Historical Review of the Development of the ISFET 1

§1.3. The Research 5

ChAPTER 2. THE ISFET

\$2.1. The Structure of an ISFET 6

1. The Ideal MIS Structure $\quad 7$

2. The Threshold Voltage of the Non-Ideal MIS Structure 11

§2.2. The Operational Principles of the IGFET and the ISFET 12

1. The IGFET 12

2. The ISFET $\quad 16$

§2.3. ISFET Selectivity 21

CHAPTER 3. EXPERIMENTAL

§3.1. The $\mathrm{pH}$ Probe 23

1. Reference Electrode 23

2. The ISFET Probe 24 
§3.2. Pressure and Temperature Control System 26

1. Pressure Control System 26

2. Temperature Control System 29

§3.3. Measurement System 29

1. Amplifier 29

2. Data Collecting System 32

\$3.4. Experiment $\quad 32$

1. Stability Tests of the ISFET 33

2. ISFET Output as a Function of Temperature 34

$\therefore$ ISFET Output as a Function of Pressure 34

§3.5. Data Analysis 36

1. Linear Regression 36

2. Analysis 38

Chapter 4. CONClusion

§4.1. Conclusions 41

§4.2. Suggestions for Improvements in Future Experiments 43

REFERENCES

ABSTRACT

BIOGRAPHICAL SKETCH 
Table 1. Stability Test of ISFET 3

Table 2. Stability Test of ISFET 3039

Table 3. Probe R Output as a Function of Temperature 46

Table 4. ISFET 3021 Output as a Function of Temperature 46

Table 5. ISFET 3041 Output as a Function of Pressure $(6 / 7 / 90)$

Table 6. ISFET 3041 Output as a Function of Pressure (6/13/90) 47

Table 7. ISFET 3041 Output as a Function of Pressure (6/15/90) 48

Table 8. ISFET 3049 Output as a Function of Pressure (8/15/90) 48

Table 9. ISFET 3041 Output as a Function of Pressure at

Constant Temperatures $(7 / 6 / 90) \quad 49$

Table 10. ISFET 3049 Output as a Function of Pressure at Constant Temperatures $(8 / 16 / 90) \quad$. 49

Table 11. Calibration of the Pressure Transducer 50

Table 12. Calibration of the Thermocouple 50

Table 13. ISFET 3039 Output as a Function of $\mathrm{pH}$ Value 51

Table 14. Confidence Range of Correlation Coefficient $R \quad 52$ 
Figure 2.1. The ISFET

Figure 2.2. MIS Structure

Figure 2.3. Energy Band Diagram of an MIS Structure for p-type Semiconductor

Figure 2.4. The Energy Band Diagrams of an MIS Structure for p-type Semiconductor for Different Biasing Condition

Figure 2.5. Schematic Diagram of an IGFET

Figure 2.6. IGFET Channel

Figure 2.7. IGFET Saturation

Figure 2.8. Characteristic Curve of the ISFET

Figure 2.9. Charge, Field, and Potential Profiles of the ISFET Gate

Figure 3.1. Preparation of the $\mathrm{Ag} / \mathrm{AgCl}$ Reference Electrode

Figure 3.2. The $\mathrm{pH}$ Probe

Figure 3.3. The Pressure and Temperature Control System

Figure 3.4. The High Pressure Cell

Figure 3.5. High Pressure Cell with ISFET, Pressure Transducer and Thermocouple

Figure 3.6. Schematic of Circuit Diagram for Constant $V_{g}$ Operation 30

Figure 3.7. Principal Circuit Diagram of the Amplifier

Figure 3.8. Calibration of the Pressure Transducer

Figure 3.9. Calibration of the Thermocouple

Figure 3.10. Stability Test of ISFET 3 in $\mathrm{pH} 4.05$ Buffer Solution

Figure 3.11. Stability Test of ISFET 3039 in pH 5.29 Buffer Solution

Figure 3.12. ISFET Output as a Function of Temperature $(\mathrm{pH}=4.05)$

Figure 3.13. ISFET Output as a Function of Temperarure $(\mathrm{pH}=5.26)$

Figure 3.14. ISFET Output as a Function of Pressure (6/7/90; pH6.84) 
Figure 3.15. ISFET Output as a Function of Pressure (6/13/90; pH5.26)

Figure 3.16. ISFET Output as a Function of Pressure (6/13/90; pH6.27)

Figure 3.17. ISFET Output as a Function of Pressure $(6 / 13 / 90 ; \mathrm{pH} 7.29)$

Figure 3.18. ISFET Output as a Function of Pressure (6/15/90; pH5.26)

Figure 3.19. ISFET Ourput as a Function of Pressure (6/15/90; pH6.27)

Figure 3.20. ISFET Output as a Function of Pressure $(6 / 15 / 90 ; \mathrm{pH} 7.29)$

Figure 3.21. ISFET Output as a Function of Pressure (8/15/90; pH6.27)

Figure 3.22. ISFET Output as a Function of Pressure at $40^{\circ} \mathrm{C}$

Figure 3.23. ISFET Output as a Function of Pressure at $50^{\circ} \mathrm{C}$

Figure 3.24. ISFET Output as a Function of Pressure at $60^{\circ} \mathrm{C}$

Figure 3.25. ISFET Output as a Function of Pressure at $70^{\circ} \mathrm{C}$

Figure 3.26. ISFET Output as a Function of Pressure at $26^{\circ} \mathrm{C}$

Figure 3.27. ISFET Output as a Function of Pressure at $37^{\circ} \mathrm{C}$

Figure 3.28. ISFET Output as a Function of $\mathrm{pH}$ (1)

Figure 3.29. ISFET Output as a Function of $\mathrm{pH}$ (2)

Figure 3.30. ISFET Output as a Function of $\mathrm{pH}$ (3) 75

Figure 3.31. ISFET Output as a Function of $\mathrm{pH}(4)$ 76

Figure 3.32. ISFET Output as a Function of $\mathrm{pH}(5)$ 77

Figure 3.33. ISFET Output as a Function of $\mathrm{pH}(6)$

Figure 3.34. Stability Test of ISFET 3039 in pH 5.29 Buffer Solution (analyzed by binomial regression) 


\section{ChAPTER 1. INTRODUCTION}

\section{§1.1. The Purpose of the Research}

The ability to measure the $\mathrm{pH}$ (the negative logarithm of the hydrogen ion activity) of harsh fluids such as geothermal oil field brines is important, since $\mathrm{pH}$ is a fundamental property; as one chemist stated: "very often $\mathrm{pH}$ is a critical test because its accuracy lays the foundation for other measurements" [1]. In our research, we focus on the analysis of brines similar to those found in underground geothermal reservoirs. Sirice the brines are deep under the ground, the values of the pressure and the temperature are high (up to 14 $\mathrm{MPa}$ and $150^{\circ} \mathrm{C}$ ); therefore the usual methods of $\mathrm{pH}$ measurement, e.g., glass electrode, are not applicable. The hydrogen ion sensitive ISFET (Ion Selective Field Efrect Transistor) was studied as a $\mathrm{pH}$ sensor in this research. An ISFET can detect the electrochemical potential difference between the solution and the semiconductor due to the concentration of $\mathrm{H}^{+}$ions in the solution. Because of its solid state construction, an ISFET should work properly under high pressure and high temperature conditions. Earlier results [2], [3], [4], have indicated that it is possible to use ISFETs under the harsh conditions presented by geothermal brines.

\section{\$1.2. Historical Review of the Development of the ISFET}

From the historical perspective, electrical engineers and solid state physicists are the pioneers of the field of the CSSD (chemically sensitiv semiconductor device). Later, electro-analytical chemists and bioengineers joined in and contributed to the development of this area. There are certain 
advantages which are inherent in solid state chemical sensors: they respond rapidly, have small size, and because of their solid state fabrication, they are very stable.

The ISFET is a kind of CHEMFET (Chemically Sensitive Field Effect Transistor) which belongs to the family of CSSDs. The first report on the CHEMFET can be traced back to 1970 when Bergveld published his short communication [5]. One year later, Matsuo, Esashi, and Iinuma [6]. reported a similar device. In 1972, Bergveld [7] published the first full description of an ISFET sensitive to hydrogen and sodium ions, in which he stated, "The device makes it possible to measure ion activities without using a reference electrode." He used the device for measurement of $\mathrm{pH}$ and sodium ion activity and for recording physiological transient action potentials. He also presented the electronic circuit and detailed results of the measurement of $\mathrm{Na}^{+}$and $\mathrm{H}^{+}$ ion activities. Matsuo and Wise described another pH-sensitive ISFET in 1974 [8], which basically is an n-channel depletion mode MOSFET (Metal-Oxide Field Effect Transistor). Their paper reported the preliminary data on a field-offset structure which was used for recording and monitoring ion concentrations. In Matsuo's device, there were two layers, one was thermally grown $\mathrm{SiO}_{2}$ and the other was pyrolytically deposited $\mathrm{Si}_{3} \mathrm{~N}_{4}$, while in Bergveld's device there was only one thermally grown $\mathrm{SiO}_{2}$ layer. The existence of pinholes in the $\mathrm{SiO}_{2}$ layer caused a degradation of its insulating properties [9] and further made it difficult to formulate a coherent model of operation of these devices. The difference between Matsuo's and Bergveld's models caused a significant discussion which was important in the development of these devices. Bergveld did not use an external reference electrode, and he claimed the reference electrode was not needed for the operation of an ISFET 
[7]. It was proved theoretically and generally accepted later that the external electrode reference is required for proper operation of a CHEMFET. Other reports describing $\mathrm{pH}, \mathrm{pK}, \mathrm{pNa}$ and $\mathrm{pCa}$ ISFETs [4] have appeared.

Zemel wrote the first review of chemically sensitive semiconductor devices [10] in 1975. He addressed the principles of the operation and relationships of MOSFETs, CSSD, ISFETs, Heterojunction and Schottky Barrier Structures. Another review focusing on ISFETs was written by Janata and Moss [11] in 1975. In this article, they presented the theory of operation and the structure of a potassium sensitive fieid effect transistor, and compared its performance with the corresponding conventional PVC-type ion selective electrodes. They characterized the FET's performance as a solid state field effect device and as an electrochemical sensor. They stated: "The transistor operates satisfactorily in the presence of proteins and it has been used for deterritination of potassium ion concentration in blood serum.". In 1977, Revesz [12] presented another paper which dealt particularly with the role of the surface states in the mechanism of the operation of ISFET. A theoretical analysis of the solution/membrane/insulator/semiconductor structure, supplemented by a thorough experimental study of the system, was published by Buck and Hackleman [13]. The promising features of CHEMFETs have attracted many scientists and research groups to the field, e.g., J. N. Zemel, J. Janata and R. P. Buck in the USA., P. Bergveld in the Netherlands, T. Matsuo and T. Akiyama in Japan, A. Sibbald in England, Yu. G. Vlasov in the USSR., K. Nagy and T. A. Fjeldy in Norway.

In 1984, Morf, Oggenfuss, and Simon [14] reported a "unified approach to the theory of ion-selective liquid membrane electrodes". In their paper, the 
potential response and selectivity behavior towards monovalent cations and anions was described for membranes containing different ion-exchange sites and neutral carriers. In the same year, Janata gave a lecture [15] on the application of CHEMFETs in analytical and physical chernistry, and reviewed the technology of the preparation of CHEMFETs. At that time the average lifetimes of membrane-based ISFETs had exceecied sixty days. Later, in 1987, Van Der Schoot and Bergveld [16] in a short communication on the pH-Static Enzyme Sensor, reported an ISFET-based urea sensor combined with a noble-metal electrode which provided for continuous coulometric titration of an enzymatic reaction. In 1989, Alear. Kirkpatrick and Hertz [2] published a paper which described a method for $\mathrm{ir}_{i}$-situ $\mathrm{pH}$ monitoring of rainfall and the compensation for the effect of temperature. In 1990, Knauss, Wolery, and Jackson [3] published a letter which proposed an operational and theoretical approach to dealing with $\mathrm{pH}$ in brines and other concentrated aqueous solutions. They used several different ion selective electrodes corresponding to different types of ions. The potential measured was proportional to $\mathrm{pHCl}=\mathrm{pH}+\mathrm{pCl}$ or $\mathrm{pH} / \mathrm{Na}=$ $\mathrm{pH}-\mathrm{pNa}$ depending on the type of the other electrodes. Then they used the Pitzer equation to compute a thermodynamic model of the solution, as they stated "A $\mathrm{pH}$ scale convention is then used to decouple $\mathrm{pH}$ from $\mathrm{pCl}, \mathrm{pNa}, \mathrm{pBr}$, etc.". The direct coupling of chemical and electric fields in the gate opens new classes of sensors. Thus, changes in electron work function can be analytically utilized and the work function of various materials can be directly measured.

Recently, other applications have been made in biomedical science [17], [18], geological science [3], [4], chemical engineering, physical chemistry [15] and many other fields. As the technology improved [1], [19], [20], [21], 
[22] more sophisticated, sbes have been designed for more specific tasks. The progress of the materials selection and deposition technique of ion-selective membranes [14], [20] has improved the stability and ion selectivity, and further expanded the applications of ISFETs. The desire for in-line monitoring of the ion concentrations and development of multi-species probes [17], [18], [23] appears to be the trend in the development of ISFETs. Durability, fast response time, and small size are the advantages that the ISFET brings to these problems.

\section{§1.3. The Research}

In our research, we used ISFETs in $\mathrm{NaCl}$ solutions of varying $\mathrm{pH}$ values and measured the ISFET output signal which was amplified by a linear amplifier. A heated pressure cell was designed and built to simulate the high temperature and high pressure conditions found in the geothermal brines. The pressure cell can generate a pressure more than $176 \mathrm{MPa}$ and the heater can heat the sample to over $240^{\circ} \mathrm{C}$. We have measured the $\mathrm{pH}$ of brine solution as a function of pressure to $40 \mathrm{MPa}$ and temperature to $70^{\circ} \mathrm{C}$. 


\section{CHAPTER 2. ISFET}

\section{§2.1. The Structure of ISFET}

The structure of an ISFET is shown in Figure 2.1. " is is an n-channel depletion mode FET. A conducting channel is formed by the interface of a semiconductor and an insulatur on the semiconductor side in response to ions passing through the membrane. The source region is ty lectron supplier and the ele:trons drain from the drain region. It is the membrane covering the ISFET which provides the device its ionic selectivity.

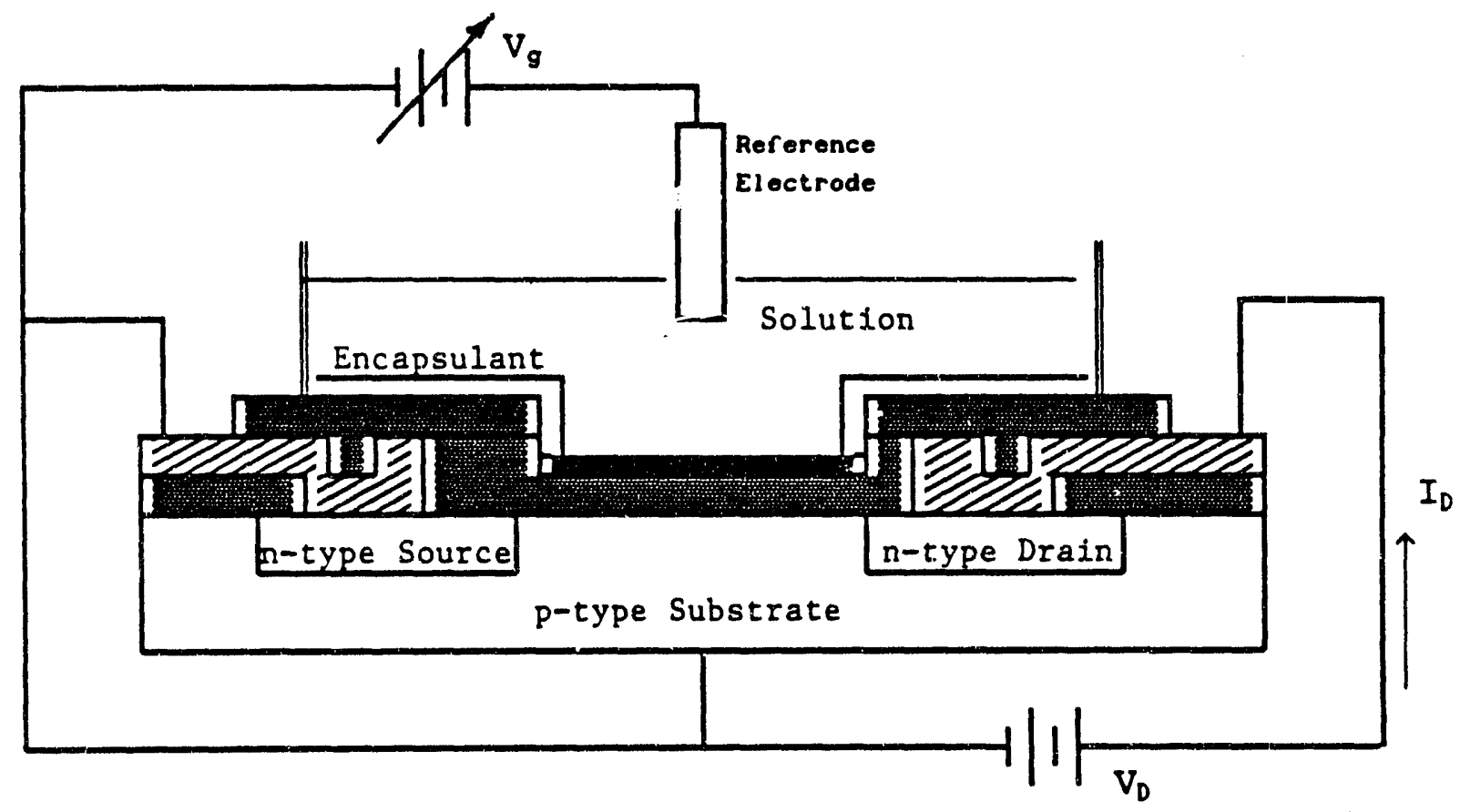

Figure 2.1 ISFET. , insulator; 立, metal; 1 , membrane

The structure of an ISFET is

metal (external electrode reference)/membrane/insulator/semiconductor.

It can be simplified to a metal/insulator/semiconductor (MIS) structure, the 
most basic structure of IGFETs (Insulated Gate Field Effect Transistor). The purpose of this chapter is to discuss the MIS structure then extend it to IGFETs and finally to include ISFETs.

\section{The Ideal MIS Structure}

Figure 2.2 shows the MIS structure. The characteristics of the ideal MIS structure is defined as:

(1) The electron work functions $W_{w}$ of the metal and $W_{s}$ of the semiconductor are equal, i.e., $W_{m s}=W_{m}-W_{s}=0$.

(\%) The insulator is a perfect insulator, thus, there is no charge distribution in the insulator and no charge transport through the insulator.

(3) There are no surface states for semiconductor, i.e., the ideal semiconductor band structure extends to the surface.

For the ideal MIS structure, when no voltage is applied on the gate $\left(\mathrm{V}_{\mathrm{g}}=\right.$ 0 ), the ensisgy band structure of the semiconductor is flat, as shown in Figure 2.3. But if $\mathrm{V}_{\mathrm{g}} \neq 0$, the band structure of the semiconductor will be bent, and the Fermi levels of metal and semiconductor separated by $\mathrm{qV}_{\mathrm{g}}$ as shown in Figure 2.4.

There are three biasing conditions $\left(V_{g}<0, V_{g}>0\right.$, and $\left.V_{g} \gg 0\right)$ which are described below (We consider the p-type semiconductor here; the n-channel FET will be discussed later).

(1). Accumulation: For $\mathrm{V}_{\mathrm{g}}<0$, additional holes are attracted to the semiconductor-insulator interface on the semiconductor side. The semiconductor behaves like a conductor. 


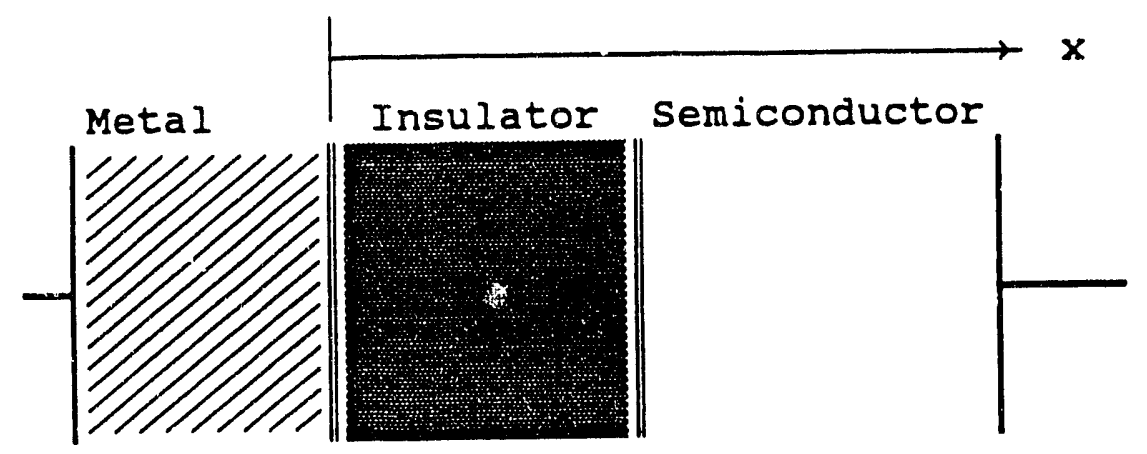

Figure 2.2 MIS Structure

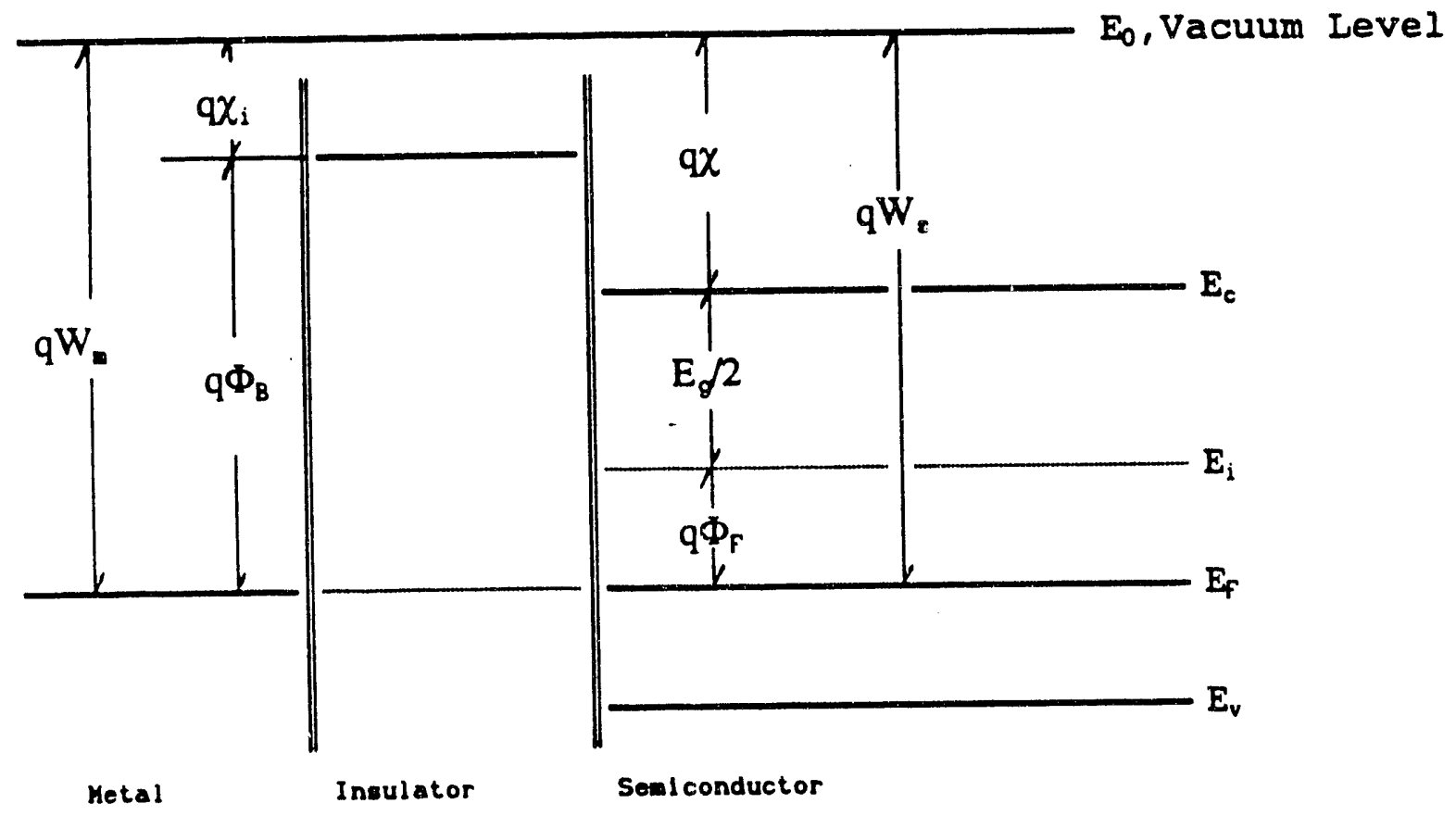

Figure 2.3 Energy Band Diagram of an MIS Structure for p-type Semiconductor $q$, the electron charge; $W_{-}$, the metal work function; $W_{s}$, the semiconductor work function; $\Phi_{B}$, the barrier potential; $\Phi_{F}$, Fermi potential; $E_{g}$ band-gap energy; $\chi$, electron affinity of the semiconductor, $\chi_{i}$, insulator electron affinity; $E_{c}$, semiconductor's conducting band; $E_{i}$, semiconductor's intrinsic band; $E_{v}$, semiconductor's valence band 

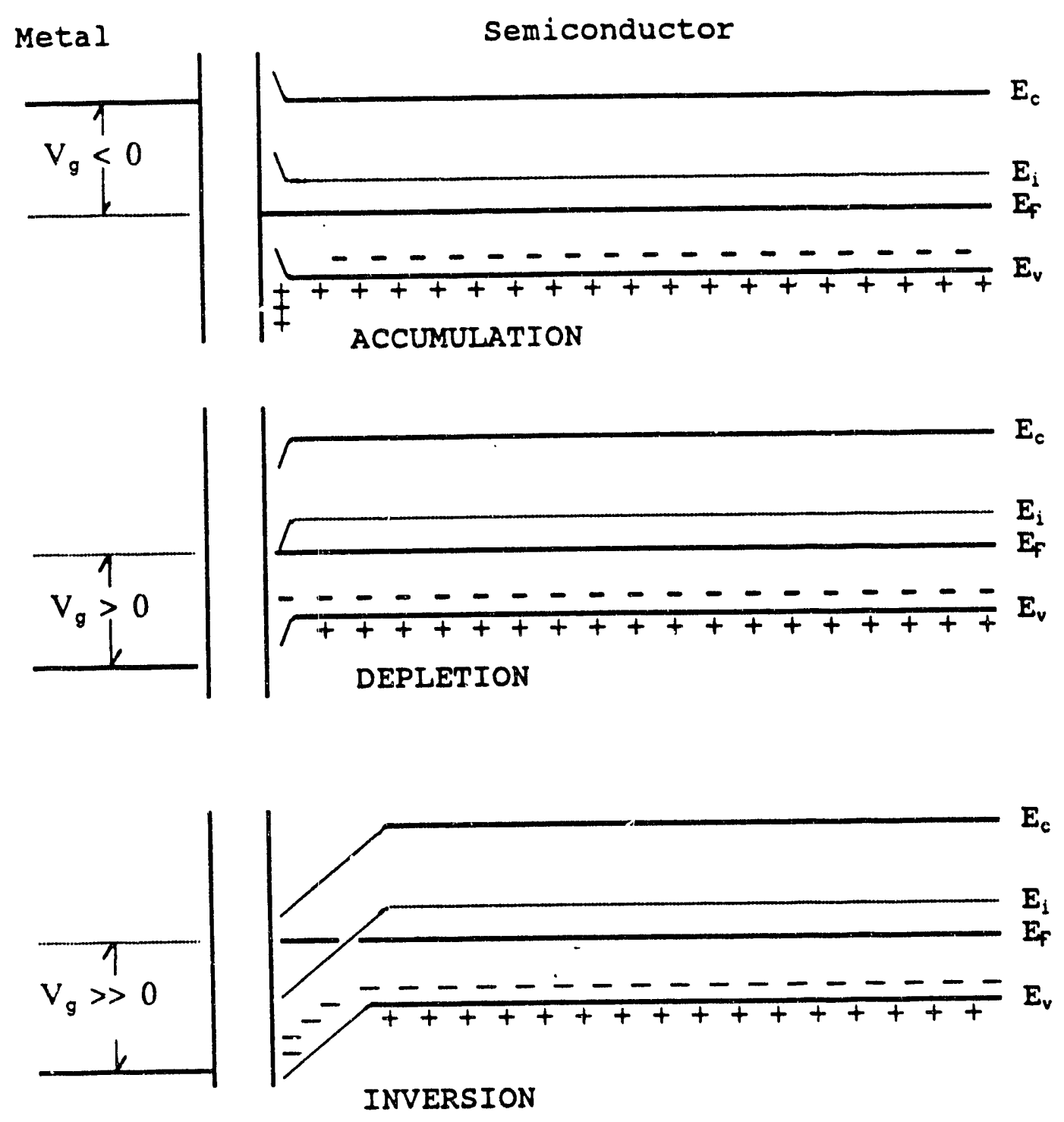

Figure 2.4 The Energy Band Diagrams of an MIS Structure with p-type Semiconductor Different Biasing Conditions

(2). Depletion: For $\mathrm{V}_{\mathrm{g}}>0$, holes are repelled from the semiconductorinsulator interface and immobile negative charge accepter atoms are left. Thus the semiconductor behaves much like an insulator. According to electrostatic theory, the energy bands of the semiconductor shift up, as shown in Figure 


\section{4 .}

(3). Inversion: For $\mathrm{V}_{g} \gg 0$, when $\mathrm{V}_{g}$ is sufficiently large, the energy bands of the semiconductor will be bent so much that the intrinsic level, $E_{1}$, will cross the Fermi level, $E_{F}$. That means $E_{F}-E_{i}>0$ near the insulator. In general, the hole density, $\rho_{h}$, and the electron density, $\rho_{e}$, depend exponentially on the value of $\pm\left(E_{i}-E_{F}\right)$, that is,

$$
\begin{aligned}
& \rho_{h} \propto \exp \left[\left(E_{i}-E_{F}\right) / 2 K T\right], \text { and } \\
& \rho_{e} \propto \exp \left[\left(E_{F}-E_{i}\right) / 2 K T\right] .
\end{aligned}
$$

When $E_{F}-E_{i}>0$, the electron density is so great that $\rho_{e}$ will exceed $\rho_{h}$ near the semiconductor insulator interface. The band displacement, $E_{F}-E_{i}$, reaches its maximum value, $q \Phi_{F}$, at the interface. Here $q$ is the charge of the electron and $\Phi_{\mathrm{F}}$ is the Fermi potential. Thus, a conducting 'electron layer' exists on the semiconductor side of the semiconductor-insulator interface. Now, the p-type semiconductor behaves like a n-type semiconductor. This is called "semiconductor inversion". When the band displacement reaches $2 \Phi_{\mathrm{F}}$ the condition is called the 'strong inversion'. The voltage $\mathrm{V}_{\mathrm{g}}$ producing strong inversion is called the 'threshold voltage', labeled $\mathrm{V}_{\mathrm{T}}$. This is an important parameter because under strong inversion, the band displacement of the semiconductor reaches its maximum value. When $\mathrm{V}_{\mathrm{g}}>\mathrm{V}_{\mathrm{T}}$, the electron density at the semiconductor-insulator interface increases as $V_{g}$ increases but the band displacement will not. This inversion biasing condition is emphasized because the FET works under this condition.

For the ideal MIS structure, $V_{T}$ is given as $\quad V_{T}=-\frac{Q_{B}}{C_{0}}+2 \Phi_{F}$, 
where $Q_{B}$ is the surface charge density of the charge region and $C_{0}$ is the capacitance per unit area of the capacitor formed by the metal and semiconductor in the MIS structure.

\section{The Threshold Voltage of Non-Ideal MIS Structure}

In the non-ideal MIS structure, there are three non-ideal effects which must be considered:

(1) $W_{m s}=W_{m}-W_{s} \neq 0$, i.e., there is a work function difference between metal and semiconductor. It means there is a charge flow that exists between metal and semiconductor. (2) Since the insulator is non-ideal, there is a charge distribution of density $\rho^{\prime}(x)$ in the insulator which induces an image charge distribution in both metal and semiconductor. (3) There is a dense pcsitive charge layer, $Q_{s s}$, at the insulator side of the insulator-semiconductor interface. This $Q_{s s}$ is due to the non-ideal effect of the MIS structure.

$\rho^{\prime}(x)$ can be written as

$$
\rho^{\prime}(x)=\rho(x)+\delta(d) Q_{s s}
$$

where $\delta(d)$ is a delta function.

Considering these non-ideal effects, the threshold voltage can be modified as

where

$$
\mathrm{V}_{\mathrm{T}}=\mathrm{V}_{\mathrm{FB}}+2 \Phi_{\mathrm{F}}-\frac{\mathrm{Q}_{\mathrm{B}}}{\mathrm{C}_{0}}
$$

$$
V_{F B}=-\frac{1}{C_{0}} \int_{0}^{d} \frac{x}{d} \rho(x) d x+\frac{W_{m s}}{e}-\frac{Q_{s s}}{C_{0}}
$$

$d$ is the thickness of the insulator, and $x$ the position along the axis shown in Figure 2.2. 
$V_{F B}$ is the non-ideal-effects modification term. If $V_{F B}$ were applied to a non-ideal MIS structure, then its band structure could be considered equivalent to a flat band structure without any applied external voltage. The subscript FB implies the Flat Rand.

\section{§2.2. The Operational Principle of the IGFET and the ISFET}

\section{The IGFET}

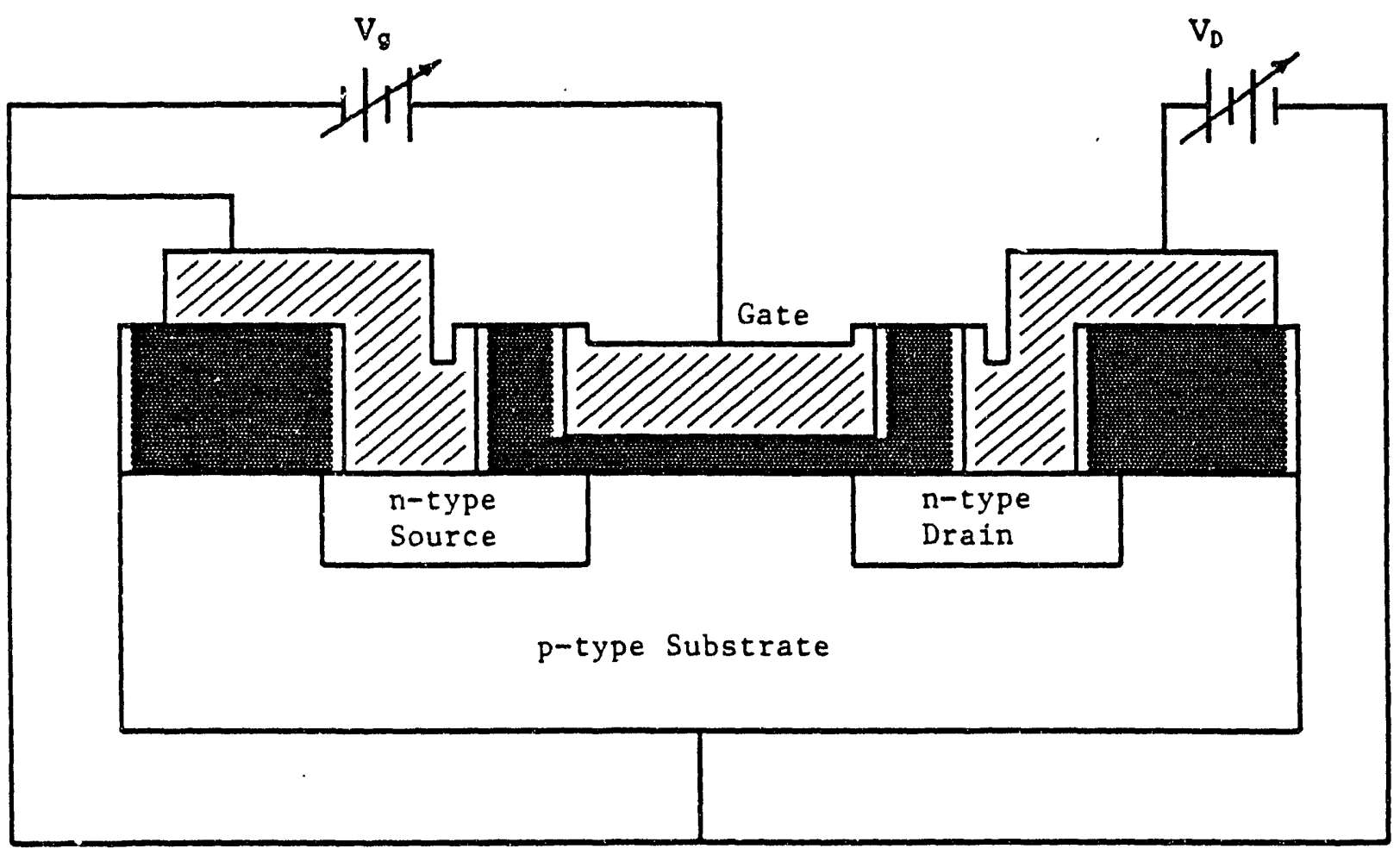

Figure 2.5 Schematic Diagram of an IGFET. 立, metal; , insulator

The structure of an IGFET is shown by Figure 2.5. It is essentially an MIS structure. From the analysis of the MIS structure in $\$ 2.1$, we know that the operational principle of the IGFET is the modulation of electrical 
conductivity of the surface channel by the applied voltage $\mathrm{V}_{g}$

As shown in Figure 2.5, both the drain and the source regions of the IGFET are $n$-type semiconductors. They form $p-n$ junctions on the interfaces with the p-type semiconductor substrate. Under depletion or accumulation biasing conditions, there is no electric current between drain and substrate or between source and substrate because of the reverse biased $p-n$ junction, so drain-source current is zero. Only when $\mathrm{V}_{\mathrm{g}}$ is sufficiently large to make the semiconductor invert is the conducting channel formed (Figure 2.6), and the drain voltage $V_{D}$ iapplied between drain and source causes drain current $I_{D}$ to flow in the conducting channel.

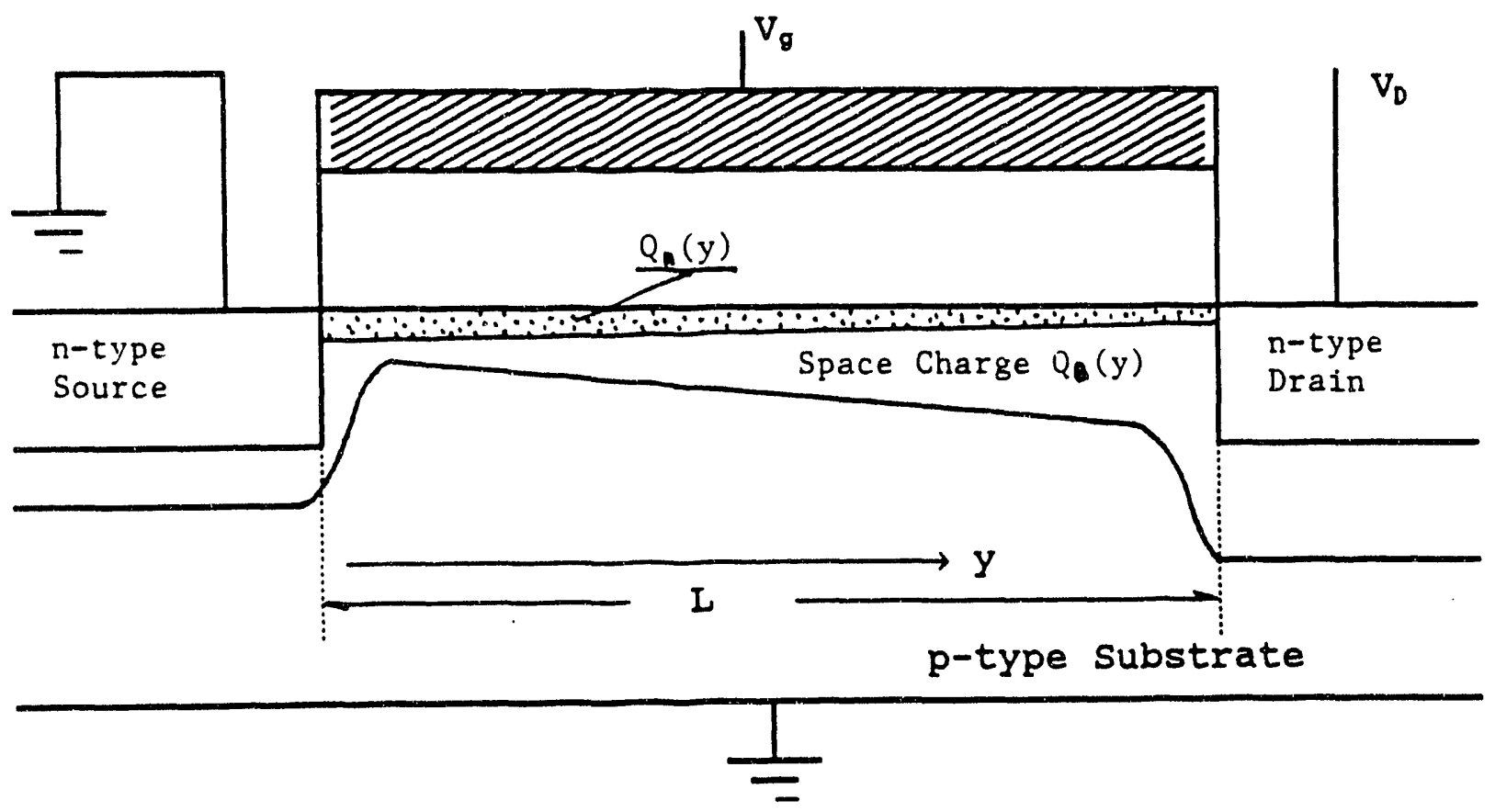

Figure 2.6 IGFET Conducting Channel. 立 indicates the metal indicates the conducting channel 
According to Ohm's law, the potential difference $\mathrm{dV}$ across an infinitesimal distance dy between the source and drain is given by

$$
d V=I_{D} d R=\frac{I_{D} d y}{b \mu_{n} Q_{n}(y)}
$$

where $d R$ is the resistance across $d y, b$ is the width of the channel, $\mu_{n}$ is the electron mubility in the channel, and $Q_{n}(y)$ is the charge density of mobile electrons in the conducting channel.

In addition to the mobile electrons. there are also ionized dopant atoms of charge density $Q_{B}(y)$ in the surface charge region. We thus have a total surface charge density $Q_{s}(y)$ given by

$$
Q_{s}(y)=Q_{n}(y)+Q_{B}(y)
$$

As a result,

$$
V_{g}-V_{F B}=-\frac{Q_{s}}{C_{0}}+\Phi_{s}
$$

where $\Phi_{s}$ is the surface potential of the semiconductor. Hence,

$$
Q_{n}(y)=-\left[V_{g}-V_{F B}-\Phi_{s}(y)\right] C_{0}-Q_{B}(y)
$$

For strong inversion,

$$
\Phi_{s}(y)=V(y)+2 \Phi_{F}
$$

where $V(y)$ is the voltage drop along the channel.

Under the depletion approximation, which assumes that there are no mobile charges in the space-charge regions, $Q_{B}(y)$ can be written as

$$
Q_{B}(y)=-\left\{2 K_{s} \varepsilon_{0} q N_{A}\left[V(y)+2 \Phi_{F}\right]\right\}^{1 / 2}
$$


where $K_{s}$ is the dielectric constant of the semiconductor and $N_{A}$ is the number of the dopant atoms per unit volume. Then $Q_{n}(y)$ becomes

$$
Q_{n}(y)=-\left[V_{g}-V_{F B}-V(y)-2 \Phi_{F}\right] C_{0}+\left\{2 K_{s} \varepsilon_{0} q N_{A}\left[V(y)+2 \Phi_{F}\right]\right\}^{1 / 2}
$$

Note that

$$
\mathrm{V}_{\mathrm{T}}=\mathrm{V}_{\mathrm{FB}}+2 \Phi_{\mathrm{F}}-\frac{\mathrm{Q}_{\mathrm{B}}}{\mathrm{C}_{0}} ; \text { thus } \mathrm{V}_{\mathrm{FB}}+2 \Phi_{\mathrm{F}}=\mathrm{V}_{\mathrm{T}}-\frac{\mathrm{Q}_{\mathrm{B}}}{\mathrm{C}_{0}}
$$

and

$$
Q_{n}(y)=-\left[V_{g}-V_{T}^{\prime}-V(y)\right] C_{0}
$$

The mobile electron density, $Q_{n}(y)$, in the inversion layer surface thus becomes a linear function of $\left(V_{g}-V_{T}\right)$ when $V_{g}>V_{T}$, the latter given by the equation (6).

From Ohm's law,

$$
d V=\frac{I_{D} d y}{b \mu_{n} Q_{n}(y)}
$$

Combining the two previous equations and integrating (note that in most cases $V_{T}$ can be treated as a constant although it is a function of $y$ ), we have

$$
I_{D}=\mu_{n} C_{0} \frac{b}{L}\left[\left(V_{g}-V_{T}\right) V_{D}-\frac{V_{D}^{2}}{2}\right]\left[V_{D}<V_{D S A T}\right]
$$

for drain voltages below saturation, and

$$
I_{D}=\mu_{n} C_{0} \frac{b\left(V_{g}-V_{T}\right)^{2}}{2 L} \quad\left[V_{D}>V_{D S A T}\right]
$$

above saturation. In Equation (7)-(8), $\mathrm{L}$ is the le. 'gth of the channel.

Further, $V_{T}=V_{F B}+2 \Phi_{F}-\frac{Q_{B}}{C_{0}}$ and $V_{F B}=\Phi_{m s}-\frac{Q_{S s}}{C_{0}}$; thus, $V_{D S A T}=V_{g}-V_{T}$. 
where $V_{D S A T}$ is the threshold voltage of the saturation of the IGFET. Saturation means that when $V_{D}$ is sufficiently large, $V_{D} \geq V_{D S A T}, I_{D}$ will not increase as $V_{D}$ does. Figure 2.7 illustrates the saturation condition of the IGFET and Figure 2.8 shows the $I_{D}-V_{D}$ characteristics curve of the IGFET.

\section{The ISFET}

Compare Figure 2.1 (the structure of the ISFET) and Figure 2.5 (the structure of the IGFET). The differences between them are that the gate in the IGFET is replaced by a 'remote' reference electrode in ISFET, and there is an ion-sensitive membrane on the top of the insulator and an encapsulant which protects the ISFET. A potential difference between the membrane and the semiconductor must be considered.

The ISFET can be considered to have six phases in a single mutiphase system. From the Gibbs' equation,

$$
\sum \mathrm{dn}_{\mathrm{i}} \tilde{a}_{j}=0,
$$

where $\mathrm{dn}_{1}$ is the number of species $\mathrm{i}$ which are transported across each of the interfaces, $\tilde{a}_{i}$ is the electrochemical potential of species $i$. At equilibrium,

$$
\tilde{\mathrm{a}}_{1} \equiv \tilde{\mathrm{a}}_{2} \equiv \tilde{\mathrm{a}}_{3} \equiv \tilde{\mathrm{a}}_{6} \equiv \tilde{\mathrm{a}}_{5} .
$$




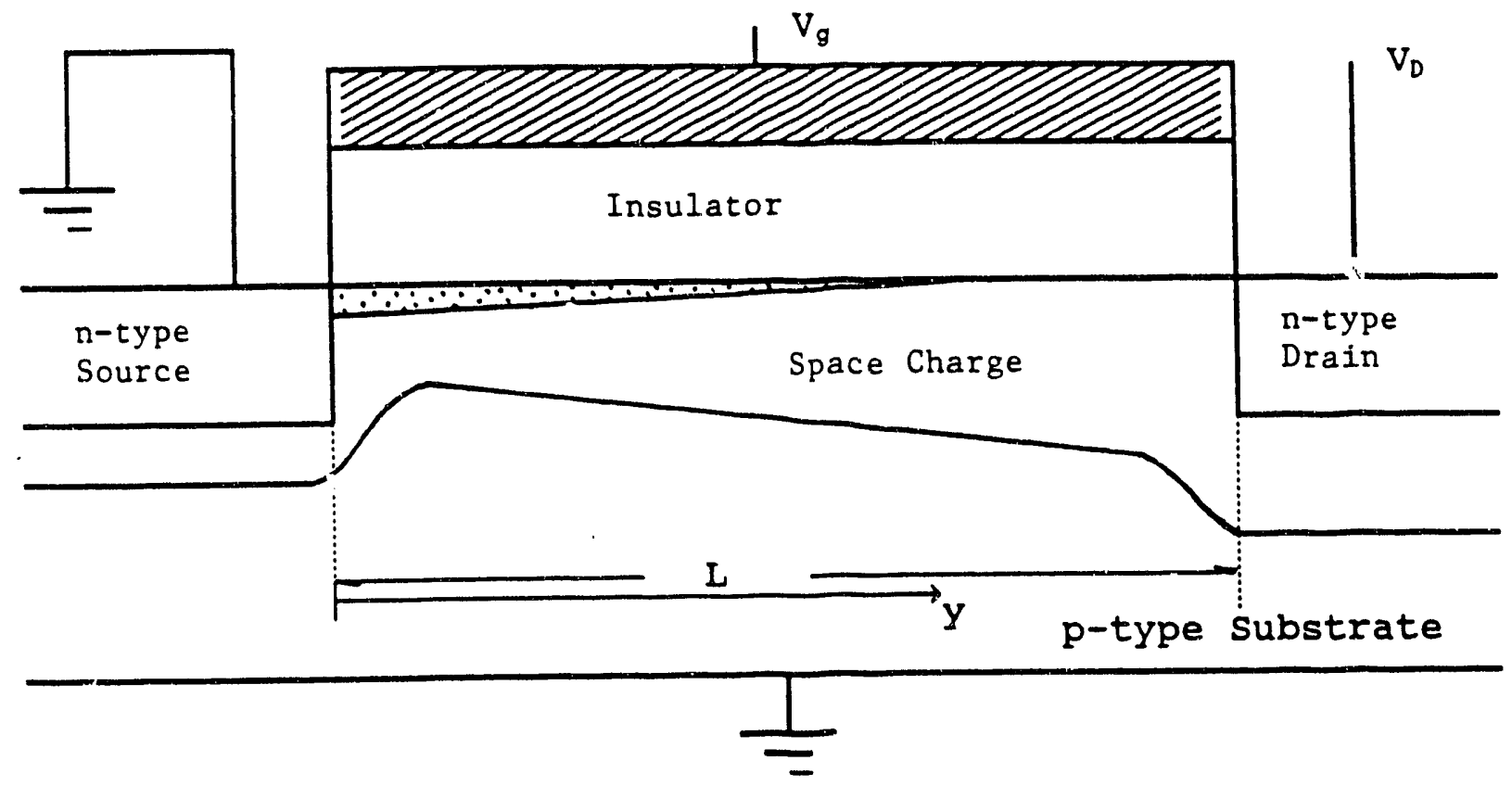

Figure 2.7 IGFET Saturation

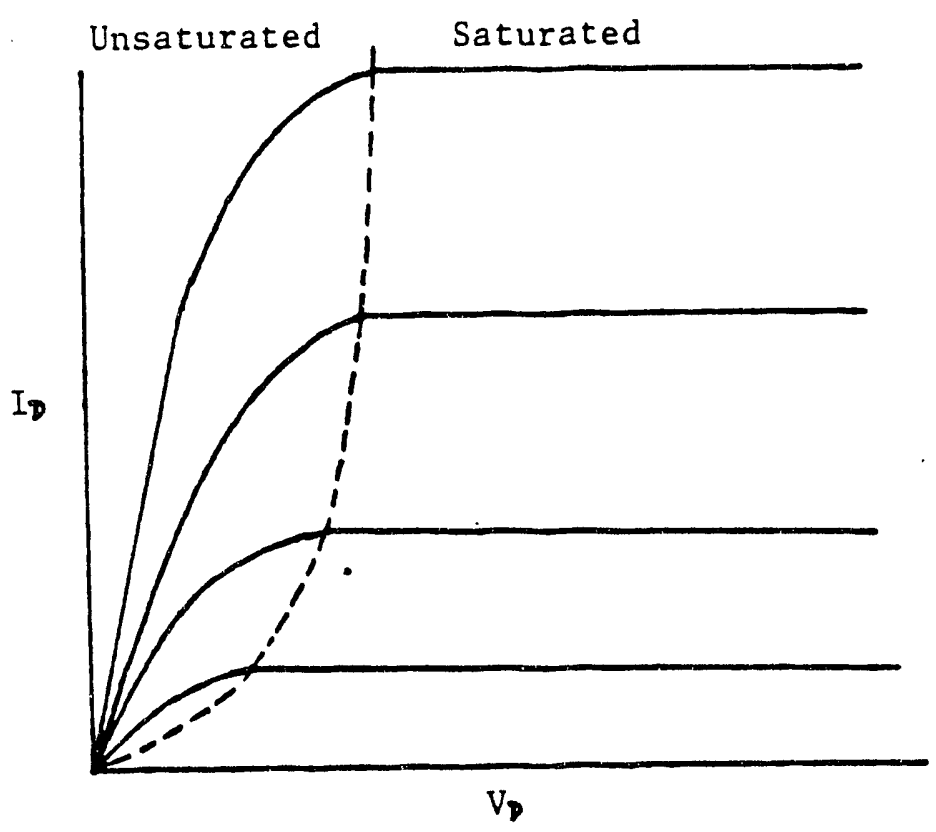

Figure $2.8 I_{D} / V_{D}$ Curve of the ISFET 


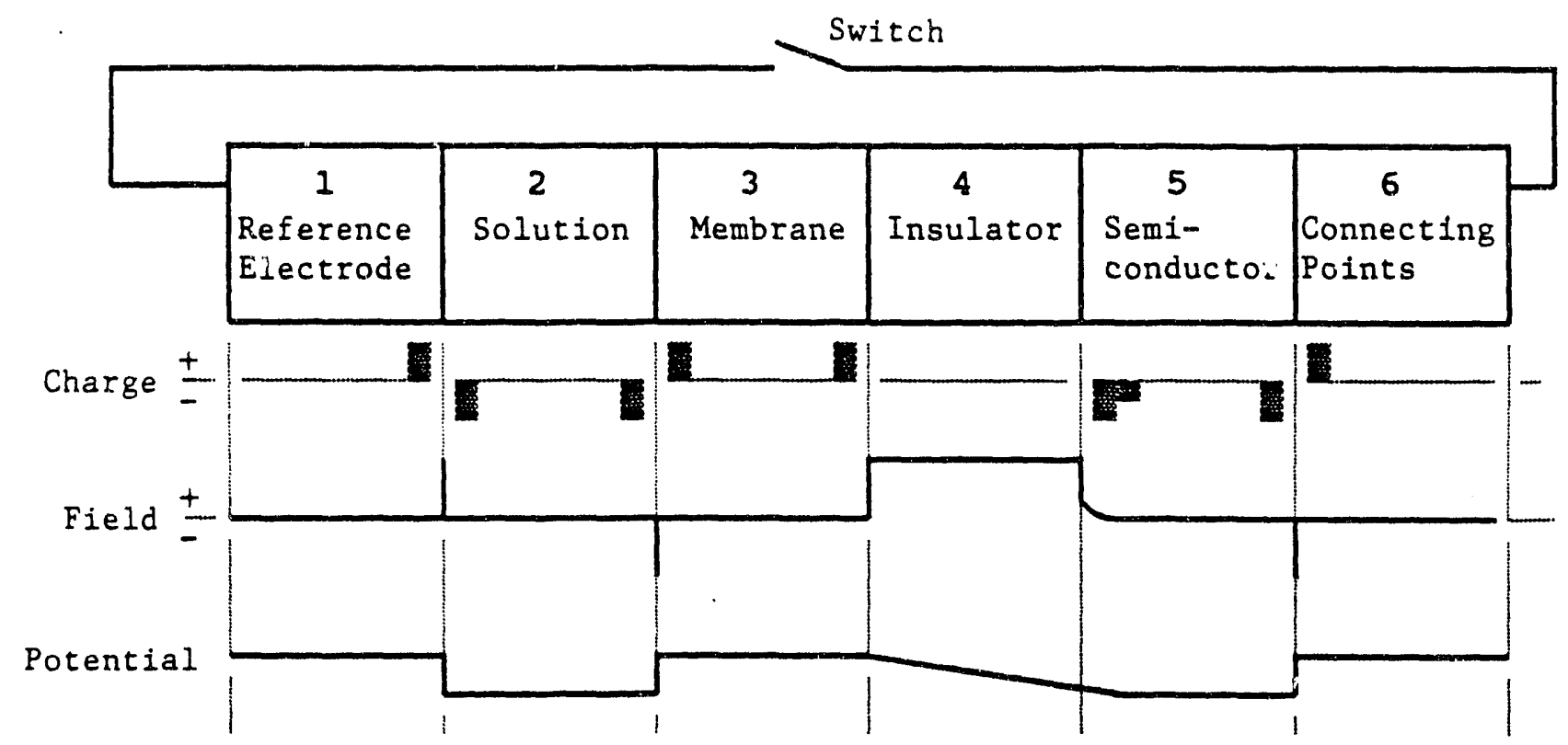

Figure 2.9 Charge, Field and Potential Profiles of the ISFET Gate

In Figure 2.9, box 1 represents the reference electrode, a metal which is described by the equilibrium equation:

$$
M=M^{+}+e^{-} \text {, }
$$

Box 2 stands for the solution which contains the ions to be detected. Box 3 is the membrane which is on the top of the insulator. Box 4 is the insulator which is assumed to be an ideal insulator. Box 5 indicates the semiconductor such as silicon. Box 6 is the metal that forms the connecting points of the drain and source poles.

Note that in Equation (9), $\tilde{a}_{4}$ is missing, since there is no electrochernical potential in the ideal insulator. Equation (9) can only exist (the equilibrium state) when the switch (in Figure 2.9) is closed. If the switch is open, which means the absence of the electrode reference, there is no way to let $\tilde{a}_{3}$ equal to $\tilde{a}_{5}$, therefore, the system cannot reach equilibrium, 
this means that the FET cannot operate. Thus, a reference electrode is the basic requirement for the operation of an ISFET.

The inner potential of the semiconductor is

$$
U_{5}=\frac{1}{F}\left(a_{5}^{e}-\tilde{a}_{5}^{e}\right) .
$$

The superscript $e$ indicates the electron, $a_{5}^{e}$ is the electron-lattice interaction energy in the semiconductor, $\bar{a}_{5}^{c}$ is the electrochemical potential of an electron in phase 5, the Fermi level, and F is the Faraday constant.

The inner potential of the membrane $\mathrm{U}_{3}$ is

$$
U_{3}=\frac{1}{Z^{i} F}\left(\bar{a}_{3}^{i}-a_{3}^{i}\right)
$$

where the $Z^{i}$ is the number of elementary charges, it is positive for cations and negative for anions. $a_{3}^{i}$ and $a_{3}^{i}$ are the electrochemical and the chemical potentials respectively of species $i$ in phase 3 .

Therefore, the potential difference of the space-charge regions across the insulator is

$$
\Delta \Phi_{53}=\Delta U_{53}=U_{5}-U_{3}=\frac{1}{F}\left[\left(a_{5}^{e}-\tilde{a}_{5}^{e}\right)-\frac{1}{Z^{i}}\left(\tilde{a}_{3}{ }^{i}-a_{3}^{i}\right)\right] .
$$

Since ion $\mathrm{i}$ can transfer from the solution to the membrane, at equilibrium we have

$$
\tilde{a}_{3}^{i}=\tilde{a}_{2}^{i}=a_{2}^{i}+Z^{i} F U_{2} \text {, and } \tilde{a}_{5}^{e}=\tilde{a}_{1}^{e}=a_{1}^{e}-F U_{1} \text {, }
$$

Since $M_{1}=M_{1}^{+}+e^{-}, a_{1}^{M}=a_{1}^{M^{+}}+a_{1}^{e}$, hence $a_{1}^{e}=a_{1}^{M}-a_{1}^{M^{+}}$.

Substituting $a_{1}^{e}$ in to equation (11), we have 


$$
\bar{a}_{5}^{e}=a_{1}^{M}-a_{1}^{M}-F U_{1} .
$$

Combining equations (10), (11) and (12) yields

$$
\Delta U_{53}=\frac{1}{F}\left(a_{5}^{e}-a_{1}^{M}+a_{1}^{M^{+}}\right)-\frac{1}{Z^{i} F}\left(a_{2}^{i}-a_{3}^{i}\right)+\left(U_{2}-U_{1}\right) .
$$

Note that

$$
\frac{1}{F}\left(a_{5}^{e}-a_{1}^{M}+a_{1}^{M^{+}}\right)=\frac{1}{F}\left(a_{5}^{e}-a_{1}^{e}\right)=U_{5}-U_{1}=-\Delta \Phi_{c},
$$

so the first term of equation (13) is the negative value of the contact potential, $-\Delta \Phi_{c}$, between the semiconductor and the metal. By using the Nernst equation, the second term of equation (13) can be written as

$$
\frac{1}{Z^{i} F}\left(a_{2}^{i}-a_{3}^{i}\right)=E_{0}^{i}+\frac{R T}{Z^{i} F} \ln \alpha_{2}^{i} .
$$

Where $\alpha_{2}^{i}$ is the ion activity in the solution. The ion activity of the membrane, $\alpha_{3}^{i}$, is assumed to be constant and is included in $E_{0}^{i}$.

The last term of equation (13), $\left(U_{1}-U_{2}\right)$, is the reference electrode potential $E_{\text {ref. }}$ Thus, rewriting equation (13), we have

$$
\Delta U_{53}=-\Delta \Phi_{c}-E_{0}^{i}-\frac{R T}{Z^{i} F} \ln \alpha_{2}^{i}+E_{r e f}
$$

Since $\Delta U_{53}$ is the potential difference between the membrane and the semiconductor, $\Delta \mathrm{U}_{35}=-\Delta \mathrm{U}_{53}$ should be added to $\mathrm{V}_{9}$, when we consider the relationship between the drain current and the drain voltage. Then equation (7) becomes

$$
I_{D}=\frac{\mu_{n} C_{0} b V_{D}}{L}\left(V_{g}+\Delta \Phi_{c}+E_{0}^{i}+\frac{R T}{Z^{i} F} \ln \alpha_{2}^{i}-E_{r e f}+\frac{Q_{s s}}{C_{0}}-2 \Phi_{F}+\frac{Q_{B}}{C_{0}}-\frac{V_{D}}{2}\right)
$$


and the threshold voltage of the ISFET is re-defined as

$$
\mathrm{V}_{\mathrm{T}}=-\Delta \Phi_{\mathrm{c}}-\mathrm{E}_{0}{ }^{\mathrm{i}}-\frac{\mathrm{Q}_{\mathrm{ss}}}{\mathrm{C}_{0}}+2 \Phi_{\mathrm{F}}-\frac{\mathrm{Q}_{\mathrm{B}}}{\mathrm{C}_{0}}
$$

The final equation for the drain current of the ISFET sensitive to the activity of ions $i$ is

$I_{D}=\frac{\mu_{n} C_{0} b V_{D}}{L}\left(V_{g}-V_{T} \pm \frac{R T}{Z^{i} F} \ln \alpha_{2}^{i}-E_{\text {ref }}-\frac{V_{D}}{2}\right),\left[V_{D}<V_{D S A T}\right]$

and $\quad I_{D}=\frac{\mu_{n} C_{0} b}{2 L}\left(V_{g}-V_{T} \pm \frac{R T}{Z^{i} F} \ln \alpha_{2}^{i}-E_{\text {ref }}\right),\left[V_{D}>V_{D S A T}\right]$.

\section{§2.3. ISFET Selectivity}

Selectivity refers to the fact that the sensor has the ability to respond primarily to only one species of ions while there are other species of ions present. The sensor output is a combination of the contributions of the interactions of several different kinds of ions. The primary contribution is from one dominate species $S$, and the effects of the other species of ions (interfering species) can often to be minimized. This may be represented by the expression

$$
\mathrm{V}_{\text {oUT }}=\mathrm{V}\left(\mathrm{S}, \Sigma_{\mathrm{k}} \mathrm{S}_{\mathrm{k}}\right)
$$

In the case of an ISFET, ion selectivity results from the ion selective membrane. The membrane has a permeability to certain kinds of ions. When the electrochemical potentials of the ions are the same on each side of the membrane, the system reaches equilibrium. The partitioning of the ions between the solution and the membrane results in a potential difference, $E_{\text {out }}$, between 
these two phases. So, $E_{\text {out }}$ is related to the activities of the partitioning ions rather than to their concentrations. Generally, $E_{\text {OuT }}$ can be expressed by the Eisenmann-Nikolskij equation [24]

$$
E_{\text {out }}=\frac{R T}{Z_{j} F} \ln \left(\alpha_{j}+\sum_{k} K_{j, k} \alpha_{j}{ }_{j} Z_{k}\right)
$$

where $R$ is the gas constant, $T$ is the absolute temperature, $K_{J, k}$ is the selectivity coefficient, a unitless constant that may be determined by the comparison of the electrode response to a solution containing only the primary ion at activity $\alpha_{j}$ with that containing $\alpha_{k}$ of the interference as well as $\alpha_{j}$ of the primary ion. $j$ and $k$ indicate the dominate and interfering species of ions, respectively. $Z_{j}$ is the charge number of the species $j$ io the ionic activity of $j$ ions. $E_{\alpha u T}$ is superimposed over the reference electrode potential. It is this term that brings ion selectivity.

The $I_{D}-V_{D}$ relationship thus can be expressed as

$$
I_{D}=\frac{\mu_{n} C_{0} b V_{D}}{L}\left[V_{g}-V_{T}-E_{r e f}-\frac{V_{D}}{2}+\frac{R T}{Z_{j} F} \ln \left(\alpha_{j}+\sum_{k} K_{j, k} \alpha_{j}{ }^{z_{j} / Z_{k}}\right)\right]
$$

When temperature is fixed, $E_{0}^{i}$ is a constant, thus $V_{T}$ is a constant. Assuming that $\alpha_{\mathrm{Cl}^{-}}$in the solution does not change, then $E_{\mathrm{ref}}$ becomes a constant [25]. Under constant $I_{D}$ and $V_{D}$ operations,

$$
\begin{aligned}
& V_{\text {out }}=V_{g}=\beta-\frac{R T}{Z_{j} F} \ln \left(\alpha_{j}+\sum_{k} K_{j, k} \alpha_{j}^{z_{j} / Z_{k}}\right) \\
& \text { where } \beta=\frac{I_{D} L}{\mu_{n} C_{0} b V_{D}}+V_{T}+E_{r e f}+\frac{V_{D}}{2} \text { is a constant. }
\end{aligned}
$$

It is this $V_{\text {out }}$ that is measured in the experiments that follow. 


\section{Chapter 3. EXPERIMENTAL}

This chapter describes three main systems: (1) The ISFET pH probe which consisted of a $\mathrm{Ag} / \mathrm{AgCl}$ reference electrode and an ISFET. This part will be described in \$3.1. (2) The temperature and pressure control systems whose function was to provide the high temperature and high pressure conditions in a test cell. Since the $\mathrm{pH}$ value is a function of temperature and pressure, it is a very important part of the experiment, and will be described in \$3.2. (3) The data collecting system which consisted of an amplifier and a precision multimeter (Fluke); they will be discussed in \$3.3.

Three groups of experiments were performed. They were measurements of the ISFET's output as a function of (1) time at fixed $\mathrm{pH}$; (2) temperature at atmospheric pressure; (3) pressure at several temperatures.

\section{§3.1. The pH Probe}

\section{Reference Electrode}

The $\mathrm{Ag} / \mathrm{AgCl}$ reference electrodes were prepared from a silver wire (one millimeter in diameter) which was electrochemically coated with silver chloride. The fabrication procedure consisted of two steps:

(1). An apparatus was set up as shown below:

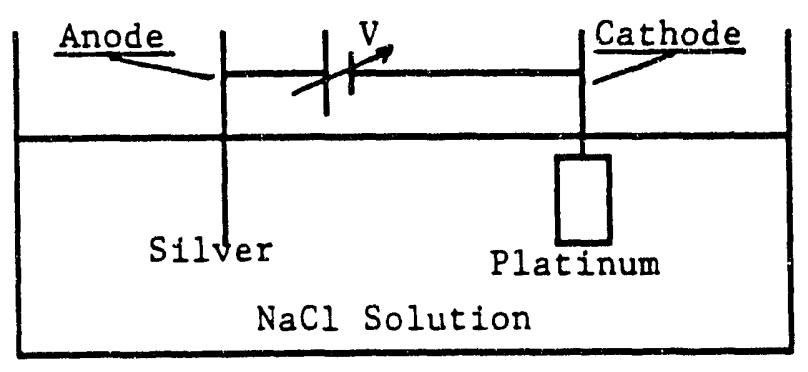

Figure 3.1 Preparation of the $\mathrm{Ag} / \mathrm{AgCl}$ Reference Electrode 
(2). The voltage $\mathrm{V}$ was increased very slowly until tiny $\mathrm{H}_{2}$ bubbles appeared on the platinum cathode. The reaction was allowed to proceed at this voltage until the silver wire was uniformly coated with $\mathrm{AgCl}$. This completed the electroplating.

The anode reaction is

$$
2 \mathrm{Ag}_{(s)}+2 \mathrm{H}_{(g)}^{+}+2 \mathrm{Cl}_{(g)}^{-} \longrightarrow 2 \mathrm{AgCl}_{(s)}+\mathrm{H}_{2(g)}
$$

\section{The ISFET Probe}

As shown in Figure 3.1, the ISFET and the $\mathrm{Ag} / \mathrm{AgCl}$ reference electrode were mounted together to form a probe. Epoxy resin was used to fix the ISFET and $\mathrm{Ag} / \mathrm{AgCl}$ reference electrode in the shell of the probe. The epoxy was applied in such a manner that it covered every part of the lead wires of drain and source poles but not any part of the membrane of the ISFET. If the lead wires were exposed to the solution, thermal expansion would loosen the sealant between the wire and the physical part of the ISFET, allowing solution to enter the ISFET and destroy it. If any epoxy was put on the membrane of the ISFET, it would prevent contact between the membrane and the solution. The epoxy forms the pressure seal for the probe. A three lead connector was used to connect the $\mathrm{Ag} / \mathrm{AgCl}$ reference electrode, the drain and source leads of the ISFET. To reduce the noise, shielded wires were used to connect the probe to the amplifier. 


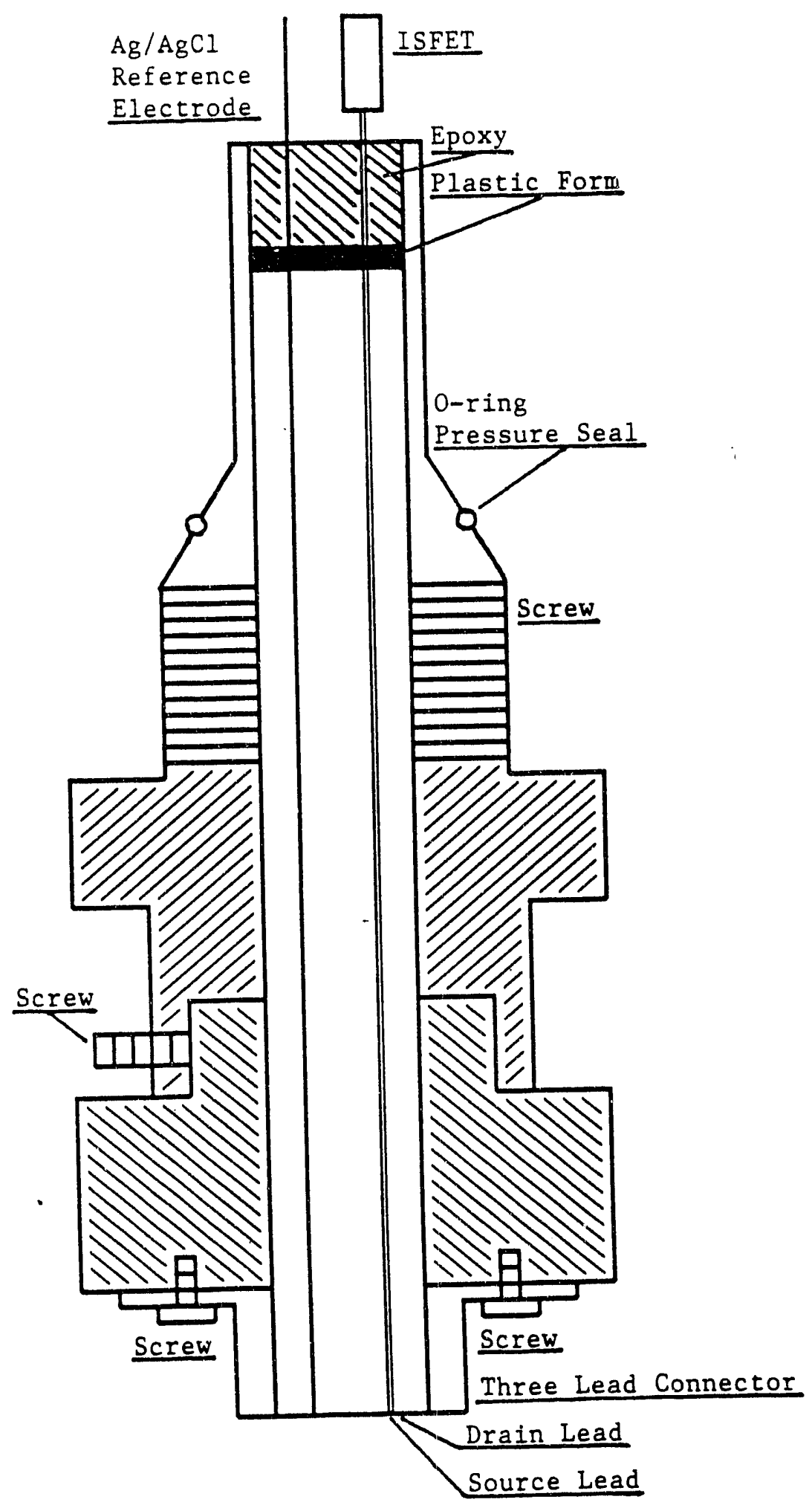

Figure 3.2 The $\mathrm{pH}$ Probe 


\section{§3.2. The Pressure and Temperature Control System}

These system were used to control the temperature and the pressure of test solutions. The system is shown in a block diagram below:

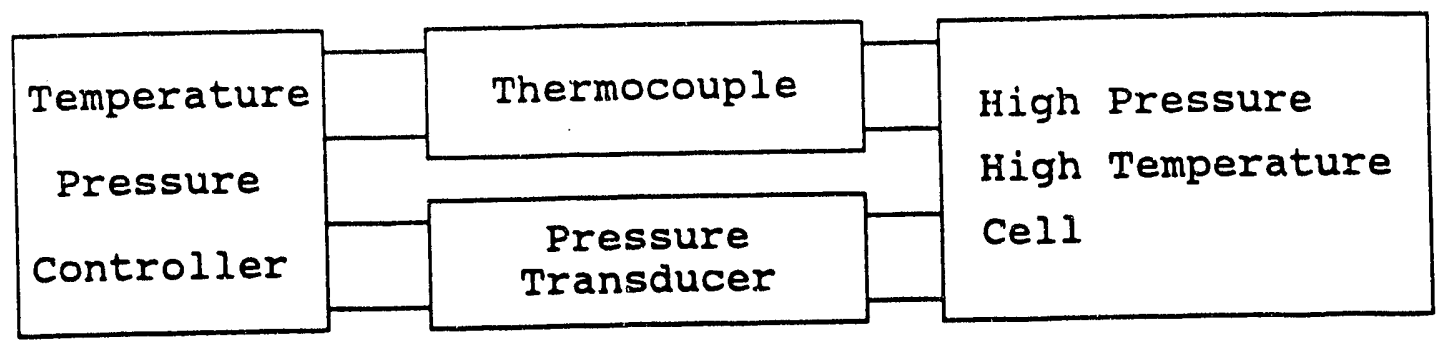

Figure 3.3 The Pressure and Temperature Control System

\section{Pressure Control System}

(1). The high pressure and high temperature cell:

A high pressure/high temperature cell was designed by Dr. D. F. Keeley and made as shown in Figure 3.3. The diameter of the piston is one and half inches (about 0.0381 meter). There are four ports in the wall of the cell which were used to put an ISFET probe, a pressure transducer and the other kinds of sensors in the cell as needed. An Omega iron/constantan J type thermocouple was put in a small hole in the wall of the cell. A channel and a screw on the piston were used to bleed the solution so that any air in the solution can be forced out of the cell. Figure 3.4 shows the high pressure cell with pressure transducer and thermocouple assembly. 


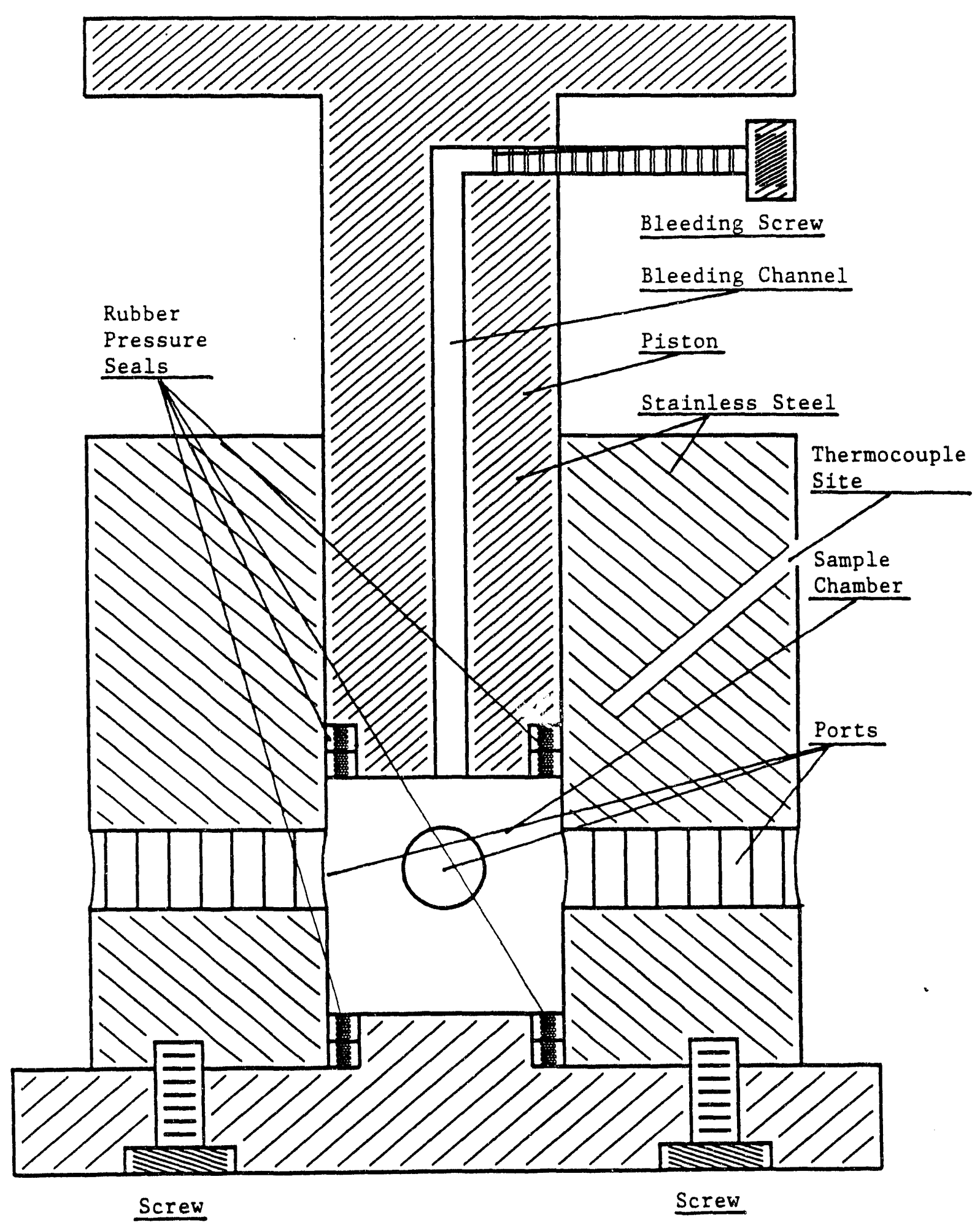

Figure 3.4 The High Pressure Cell 


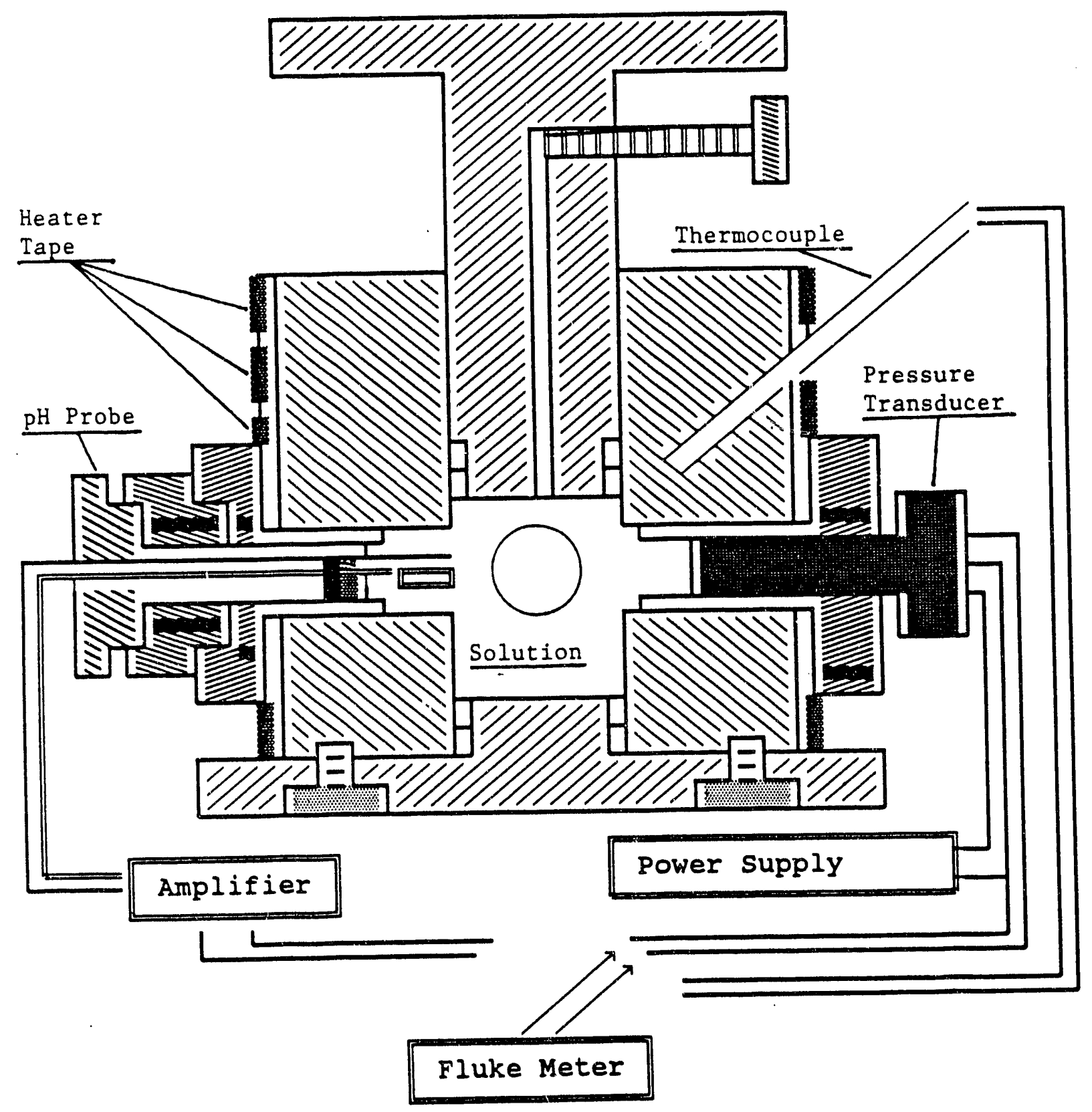

Figure 3.5 High Pressure Cell with ISFET, Pressure Transducer and Thermocouple 
(2) Pressure generator

A Carver Laboratory Press (Model: $M$ ) with an adjusting range from zero to $200 \mathrm{kN}$ was applied to the piston to produce the high pressure, thus the high pressure cell can generate a pressure of more than $176 \mathrm{MPa}$. A hydraulic controller preset and automatically maintained the pressure. An Omega PX303-10K65V pressure transducer was put in the high pressure cell in order to measure the pressure. The pressure transducer was calibrated by M-Tec/Rise, Inc. using dead weight test, and the curve is shown in Figure 3.8.

\section{The Temperature Control System}

A heating tape and an Omega CN7100 temperature controller were used to raise and control the temperature of the cell. The tape was wound on the high pressure cell and a thermocouple was put in the small hole on the high pressure cell as shown in Figure 3.5. The temperature could be adjusted over the range of the experiment (from room temperature to $250^{\circ} \mathrm{C}$ ). The thermocouple was calibrated by a CMS precision thermometer and the calibration data and curve are shown in Table 12 and Figure 3.9.

\section{§3.3. The Measurement System}

\section{Amplifier}

The function of the measuring circuit is to detect and amplify the electrochemical potential changes between the semiconductor and the solution. The ISFET should work under maximum ion sensitivity, i.e., a every small change in ion concentration of the solution should be reflected in a drain current change of the ISFET. This requires that the ISFET is unsaturated and under strong inversion since when the ISFET is saturated, $I_{D}$ will be a 
constant no matter how $V_{D}$ changes. On the hand, when the FET is strongly inverted, the semiconductor yields the maximum number of mobile electrons, and the channel has the maximum conductivity. Under this situation a change in the activity of the ions in the solution will be reflected as a change in the number of mobile charge carriers in the conducting channel (field effect).

There are two types of measuring methods: (1) constant gate voltage $\mathrm{V}_{g}$ operation: the gate voltage $\mathrm{V}_{\mathrm{g}}$ is held constant and the change of drain current is measured directly; and (2) constant drain current $I_{D}$ operation: varying the gate voltage such to hold drain current constant.

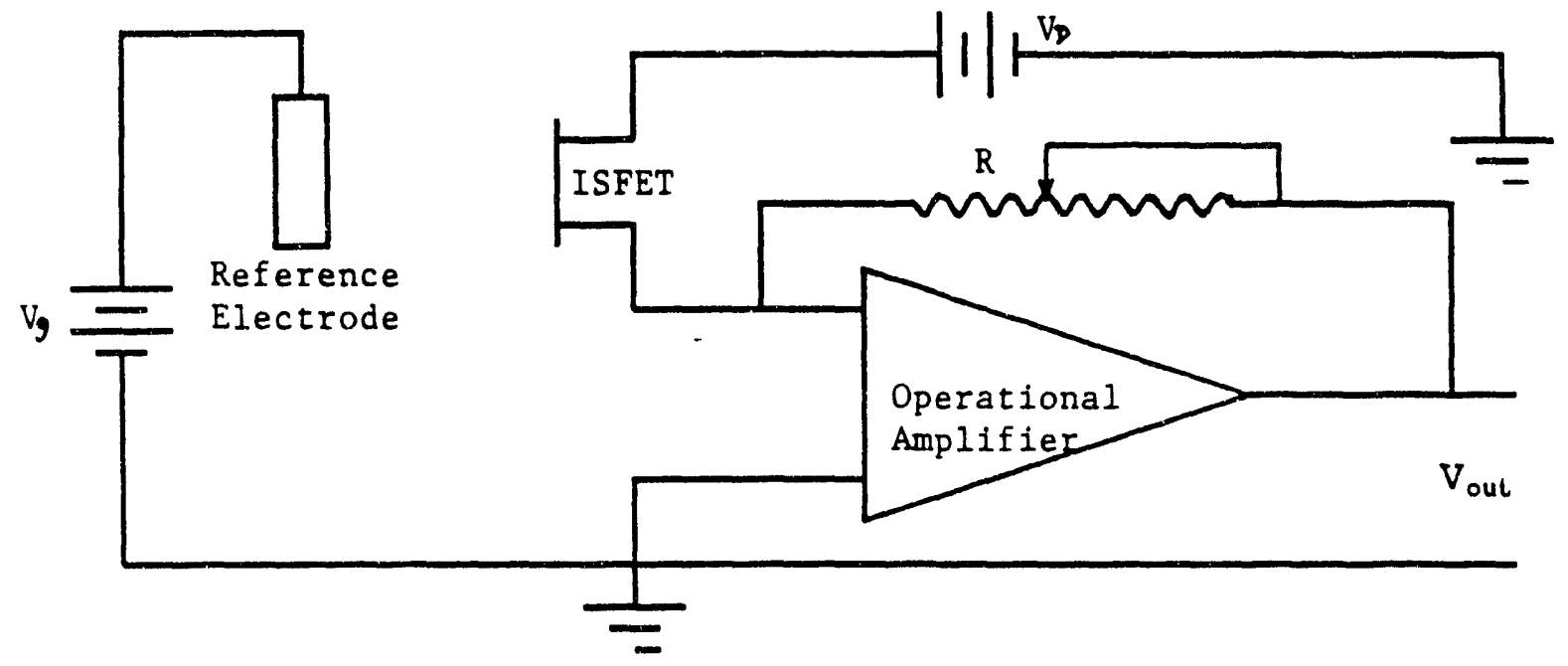

Figure 3.6 Schematic of Circuit Diagram for Constant $\mathrm{V}_{\mathfrak{g}}$ Operation Amplifier

(1). Constant Gate Voltage Operation

The circuit diagram is shown in Figure 3.6. Although the technique is simple, this design has a disadvantage in that the ISFET is not an ideal device, non-ideal effects will cause the relation between the drain current and system voltages to be different from that predicted by the Equation 15 in 
Chapter 2. This requires a calibration over its total operating range. For any different configuration, the different calibration is needed.

(2). Constant Drain Current Operation

In this mode of operation, the change of electrochemical potential between the solution and semiconductor is read out directly. Using an operational amplifier with a feedback loop, a change of voltage resulting from the change of ionic activity will be reflected as a change of gate voltage, thus the drain current can be held constant. In this situation, any non-ideal effect will be held constant, so the calibration is not necessary for every design. The circuit diagram of constant drain current operation is shown in Figure 3.7.

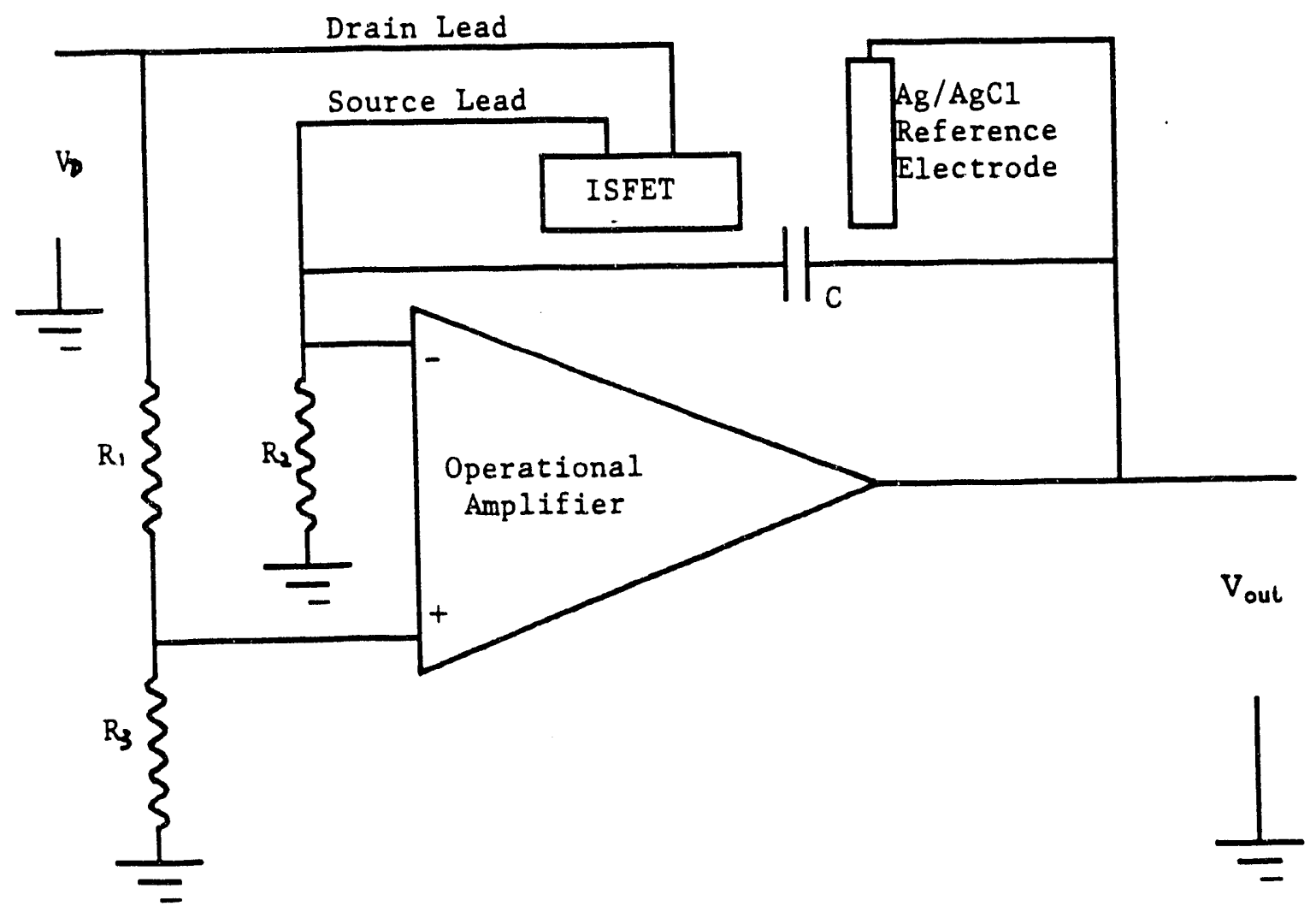

Figure 3.7 Principal Circuit Diagram of the Amplifier 
In our experiment, the ISFET output signal is processed by an amplifier which was bought from Chemfet Corp.. The amplifier, shown in Figure 3.7, operates with a constant drain current.

\section{Data Collecting System}

At the beginning of the research, we used a computer data collecting system. The system consisted a DAS-8PGA eight-channel data interface board and LABTECH Acquire software which was run by an AT personal computer. The advantages of this system are that sampling rates can be precisely set and that all data acquisition and data analysis was part of or read into the software. We found that there were some disadvantages of the system. There was some unknown noise which was difficult to eliminate, and with the Acquire software there was a nine hours and six minutes running limit (no matter how the sampling frequency was set). We wished to run a much longer term of measurement. With these disadvantages, we abandoned this system and used a precision multimeter to measure the output voltages.

\section{\$3.4 Experiment}

A series of sodium chloride solutions buffered to $\mathrm{pH}$ values ranging from 4 to 10 were prepared using $\mathrm{NaH}_{2} \mathrm{PO}_{6} \cdot \mathrm{H}_{2} \mathrm{O}$ as the acid and $\mathrm{Na}_{2} \mathrm{HPO}_{4} \cdot 7 \mathrm{H}_{2} \mathrm{O}$ as the base. The concentration of the reference salt $\mathrm{NaCl}$ was $0.1 \mathrm{M}$. The buffer strength was $0.05 \mathrm{M}$. A CORNING pH meter (model 10) was used as a calibration device.

The first five ISFETs received from Chemfet Corp. were labeled 1-5 and were calibrated using the buffer solutions. The results are shown below. A later group we received had a manufacturer's reference number which was used 
to identify them.

$\begin{array}{ll}\text { FET No: } & \text { Slope }\left(\mathrm{V}_{\text {out }}(\mathrm{V}) / \mathrm{pH} \text { unit }\right) \\ 1 & 0.0464 \\ 2 & 0.0434 \\ 3 & 0.0469 \\ 4 & 0.0470 \\ 5 & 0.0467\end{array}$

The results for the calibration of ISFET 3039 is in Tab!s 13 and Figure 3.28-33. Data analysis was perfori.ed and the results are shown on this figures. The data indicates a linear relationship between the ISFET output and the pHI value.

\section{Stability Tests of the ISFE:T:}

The first long term test (labeled $S-1$ ) was made from Jan. 9, to Jan. 19, 1990, using ISFET 3 in a $\mathrm{pH} 4.05$ buffered solution. The sampling frequency was eight hours. The temperature of the solution was maintained at $25^{\circ} \mathrm{C}$ in a thermostated constant temperature bath. A precision multimeter was used to measure the ISFET output $\mathrm{V}_{\text {out }}$. The result is presented in Table 1 and Figure 3.10 .

The second, longer stability test (labeled S-2) using ISFET 3039 was made from Dec. 18, 1990 to Mar. 13, 1991, in a pH 5.29 buffered solution, sampling about every twelve hours. The buffered solution was put in the high pressure cell but was neither pressured nor thermostated. The results are shown in Table 2 and Figure 3.11. 


\section{ISFET Output as a Function of Temperature:}

These experiments were performed at atmospheric pressure. The temperature of the solution was controlled by a constant temperature bath. Due to the ISFETs' failures during these experiments, we did not obtain much data under these conditions. The malfunction of the ISFET may have been due to improper fabrication of the ISFET, the drain and source leads of the ISFET may have opened due to thermal expansion or the solution may have entered the physical part of the ISFET and shorted it.

Experiment $T-1$ : A pH probe (labeled $\mathrm{R}$ ) which was provided by Chemfet Corp. was used in this experiment with $\mathrm{pH} 4.05$ buffered solution. The result was tabulated by Table 3 and Figure 3.12 .

Experiment T-2: ISFET 3021 was used with $\mathrm{pH} 5.26$ buffered solution. The result was shown in Table 4 and Figure 3.13.

\section{ISFET Output as a Function of Pressure:}

There are two sub-groups of experiments:

(1). The temperature of the buffered solutions were not thermostated. The experiments were performed at room temperature, around $25^{\circ} \mathrm{C}$.

A precision multimeter was used to measure the outputs of the ISFET probe and pressure transducer. ISFETs 3041 and 3049 were used in these experiments. Different $\mathrm{pH}$ values of buffered solutions, $\mathrm{pH}=5.26,6.27$ and 7.29 , were tested under room temperature using ISFET 3041 and the experiments were repeated.

In an another experiment, the output of ISFET (3041) in a $\mathrm{pH} 6.84$ buffered solution was measured as a function of pressure, and the results are shown in Table 5 and Figure 3.14. Table 8 and Figure 3.21 show the experiments with ISFET 3049 in a pH 6.27 buffered solution.

The experiments are listed in following table: 


\begin{tabular}{lll}
\hline Label & Experiment & \multicolumn{1}{c}{ Results shown in } \\
\hline P-1 & ISFET 3041, pH 6.84,6/190 & Table 5, Figure 3.14 \\
P-2 & ISFET 3041, pH 5.26, 6/13/90 & Table 6, Figure 3.15 \\
P-3 & ISFET 3041, pH 6.27,6/13/90 & Table 6, Figure 3.16 \\
P-4 & ISFET 3041, pH 7.29,6/13/90 & Table 6, Figure 3.17 \\
P-5 & ISFET 3041, pH 5.26, 6/15/90 & Table 7, Figure 3.18 \\
P-6 & ISFET 3041, pH 6.27,6/15/90 & Table 7, Figure 3.19 \\
P-7 & ISFET 3041, pH 7.29,6/15/90 & Table 7, Figure 3.20 \\
P-8 & ISFET 3049, pH 6.27, 8/15/90 & Table 8, Figure 3.21 \\
\hline
\end{tabular}

(2). The temperature of the test solutions in the high pressure cell were set and maintained by the temperature controller. At six different temperatures, between $26^{\circ} \mathrm{C}$ and $70^{\circ} \mathrm{C}$, the ISFET output was measured as a function of pressure, The $\mathrm{pH}$ of the solutions was either 5.26 or 6.27 . The results of the experiments are shown below:

\begin{tabular}{lll}
\hline Label & Experiment & \multicolumn{1}{c}{ Results shown in } \\
\hline PT-1 & ISFET $3041, \mathrm{pH} 5.26,40^{\circ} \mathrm{C}, 7 / 6 / 90$ & Table 9, Figure 3.22 \\
PT-2 & ISFET 3041, pH 5.26,50 C,7/6/90 & Table 9, Figure 3.23 \\
PT-3 & ISFET 3041, pH 5.26,60 C,7/6/90 & Table 9, Figure 3.24 \\
PT-4 & ISFET 3041, pH 5.26,70 C,7/6/90 & Table 9, Figure 3.25 \\
PT-5 & ISFET 3049, pH 6.27, 26 $\mathrm{C}, 8 / 16 / 90$ & Table 10, Figure 3.26 \\
PT-6 & ISFET 3049, pH 6.27, 37 C, 8/16/90 & Table 10, Figure 3.27 \\
\hline
\end{tabular}

\section{§3.5 Data Analysis}

Since the measurement devices were not ideal devices, there were 
measurement errors in the data. Therefore, all of the data was considered to be random variables. We used linear regression to analyze these data since they seem to be linear from the graphics. The statistical results confirm this.

In order to show these linear relationships analytically, we employ two statistical tests: coefficient of correlation $R$ and t-test.

\section{Linear Regression}

This method of curve fitting is one of a number of processes in mathematics which use finite differences. We can find a best fit straight line for a set of sample points by using this method. Suppose that we have $n$ points $\left(X_{1}, X_{2}, \ldots X_{n}\right.$ and $\left.Y_{1}, Y_{2}, \ldots Y_{n}\right)$ and want to fit them into a straight line,

$$
Y=a+b X \text {, }
$$

to them. $\delta_{i}$ is defined as

$$
\delta_{1}=Y_{1}-\left(a+b X_{1}\right)
$$

So

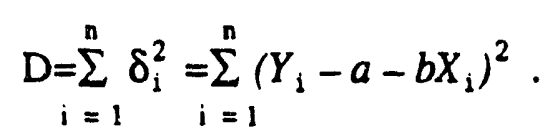

We can then choose $a$ and $b$ to yield a minimum $D$, such that $Y=a-b X$ is the best fit straight line of these $n$ points $\left\{X_{1}, Y_{1}\right\}_{n^{*}}$ The minimization is performed by setting

$$
\frac{\partial D}{\partial a} \underset{i=1}{n}-2\left(Y_{i}-a-b X_{i}\right)=0 \text {, }
$$

and

$$
\frac{\partial D}{\partial b}=\sum_{i=1}^{n}-2 X_{i}\left(Y_{1}-a-b X_{1}\right)=0
$$


and

$$
\mathrm{n} a+b \sum_{\mathrm{i}=1}^{\mathrm{n}} X_{\mathrm{i}}=\sum Y_{\mathrm{i}}
$$$$
a \sum_{i=1}^{n} X_{i}+b \sum_{i=1}^{n} X_{i}^{2}=\sum_{=1}^{n} X_{i} Y_{i} .
$$

Then, we have

$$
b=\frac{S S X Y}{S S X^{2}},
$$

and

$$
a=\bar{Y}-b \bar{X},
$$

where

$$
\begin{aligned}
& \bar{X}=\sum_{i=1}^{n} X_{i} / n \text {, and } \bar{Y}=\sum_{i=1}^{n} Y_{i} / n \text {, } \\
& S S X Y=\sum_{i=1}^{n} X_{i} Y_{i}-\frac{\sum X_{i} \sum Y_{i}}{n}=\sum_{i=1}^{n} X_{i} Y_{i}-\sum_{i=1}^{n} \sum_{i=1} Y_{i}, \\
& S S X^{2}=\sum_{i=1}^{n} X_{i}^{2}-\frac{\left(\Sigma X_{i}\right)^{2}}{n}=\sum_{i=1}^{n} X_{i}^{2}-\bar{X} \sum_{i=1}^{n} X_{i} .
\end{aligned}
$$

The Standard Deviation of the Estimated $Y$ is defined as

$$
s(Y)=\left[\frac{\sum_{\mathrm{i}=1}^{\mathrm{n}}\left(Y_{\mathrm{i}}-a-b X_{\mathrm{i}}\right)}{\mathrm{n}-1}\right]^{1 / 2},
$$

and the Variance of Slope $b$ is

$$
s^{2}(b)=s^{2}(Y) / S S X^{2},
$$

and the Variance of Mean of $Y$ is

$$
s^{2}(\bar{Y})=s^{2}(Y) / n .
$$

The Coefficient of Correlation is defined as 


$$
R=\frac{S S X Y}{\sqrt{S S X^{2} S S Y^{2}}}
$$

So, if $R^{2}=0.9$, we can say that $90 \%$ of the variation in the data is explained by the line $Y=a+b X$. We also can check with a correlation coefficient table, Table 14 [26], to see if there is a correlation between $X$ and $Y$.

The confidence limits of the, say, mean of the $Y$ 's is:

$$
\bar{Y}=\bar{Y} \pm t_{A} s(\bar{Y}) \text {, }
$$

where $t_{A}$ can be obtained from $t$-table [27] and $A$ is the percent confidence range.

\section{Analysis}

A confidence range $95 \%, A=0.05$, was chosen in data analysis below. Details of the calculations are shown under stability tests and only in tabular form there after.

(1). Calibration of ISFET $3039^{\circ}$

In Figures 3.28-3.33, we can see that $R^{2}>0.98$ for all of six sets of data. So, we say that over $98 \%$ of the data were presented by the best fit lines. Since $R>0.99$, from Table 14 , we know that for two degrees of freedom we say with $99 \%$ confidence that the output of the ISFET has a linear relationship with the $\mathrm{pH}$ value.

\section{(2). Stability Tests of ISFET}

Using the data in Figure 3.9 and Table 1 and performing a regression analysis, we have $R^{2}=0.83, R=0.91, n=29$. According to Table 14 , we are over $99.9 \%$ confident that the relationship between the ISFET output and time is a linear function; $83 \%$ of the data points are presented by the best fit line: 


$$
V_{\text {out }}(v)=9.88964 \times 10^{-5} t+3.1489
$$

Choose $A=0.05$, that is, $95 \%$ of confidence, the degrees of freedom, $n-1=28$. Refer to a $t$-value table of a statistics book [26], $t_{A}=2.05$, thus the confiderive limit of $\mathrm{V}_{\text {out }}$ is:

$$
\begin{aligned}
& \delta \mathrm{V}_{\text {out }}=t_{A} s\left(\mathrm{~V}_{\text {out }}\right)=2.05 \times 0.003705=0.00769 \mathrm{~V}, \\
& \delta b=\mathrm{t}_{A} s(b)=2.05 \times 0.000009=1.845000 \times 10^{-5} \mathrm{~V} / \text { hours . }
\end{aligned}
$$

So, we can say with $95 \%$ confidence that:

$$
\mathrm{V}_{\text {out }}=9.88964 \times 10^{-5} \mathrm{t}+3.1489 \pm 0.00769 \mathrm{~V}
$$

and

$$
b=(9.88964 \pm 1.84500) \times 10^{-5} \text { V/hours. }
$$

\begin{tabular}{lcccccc}
\hline E.N.* & $n$ & $R^{2}$ & $\delta \mathrm{V}_{\text {out }}(\mathrm{V})$ & $\delta b$ (V/hours) & $\%^{* *}$ & Best fit line \\
\hline S-1 & 29 & 0.830 & 0.00769 & $1.845 \times 10^{-5}$ & 99.9 & $\mathrm{~V}_{\text {out }}=0.00010 \mathrm{t}+3.14890$ \\
$\mathrm{~S}-2$ & 160 & 0.991 & 0.00172 & $1.980 \times 10^{-6}$ & 99.9 & $\mathrm{~V}_{\text {out }}=0.00015 \mathrm{t}+2.17270$ \\
\hline
\end{tabular}

\begin{tabular}{|c|c|c|c|c|c|c|}
\hline E.N. & $n$ & $R^{2}$ & $\delta \mathrm{V}_{\text {out }}(\mathrm{V})$ & $\delta b(\mathrm{~V} / \mathrm{C})$ & $\%$ **** & Best fit line \\
\hline $\mathrm{T}-1$ & 8 & 0.976 & 0.02272 & 0.00070 & 99.9 & $V_{\text {out }}=-0.00459 \mathrm{~T}+3.26355$ \\
\hline T-2 & 13 & 0.983 & 0.00419 & 0.00012 & 99.9 & $V_{\text {out }}=-0.00141 \mathrm{~T}+3.25390$ \\
\hline
\end{tabular}

* E.N. is the experiment label defined in $\$ 3.4$.

** \% represents the percentages of confidence in the linear relationship between $\mathrm{V}_{\text {out }}$ and time $\mathrm{t}$.

(3). ISFET Output as a Function of Temperature

(4) ISFET Output as a Function of Pressure

(A). For those experiments performed in unthermostated buffer solutions: 


\begin{tabular}{lcccccc}
\hline E.N. & $n$ & $R^{2}$ & $\delta \mathrm{V}_{\text {out }}(\mathrm{V})$ & $\delta b(\mathrm{~V} / \mathrm{MPa})$ & $\%^{*}$ & Best fit line \\
\hline P-1 & 14 & 0.988 & 0.00078 & 0.00002 & 99.9 & $\mathrm{~V}_{\text {out }}=-0.00028 \mathrm{P}+2.51940$ \\
P-2 & 10 & 0.971 & 0.00153 & 0.00005 & 99.9 & $\mathrm{~V}_{\text {out }}=-0.00034 \mathrm{P}+2.61836$ \\
P-3 & 10 & 0.847 & 0.00273 & 0.00009 & 99.9 & $\mathrm{~V}_{\text {out }}=-0.00027 \mathrm{P}+2.66397$ \\
P-4 & 10 & 0.968 & 0.00138 & 0.00004 & 99.9 & $\mathrm{~V}_{\text {out }}=-0.00028 \mathrm{P}+2.72272$ \\
P-5 & 10 & 0.683 & 0.00427 & 0.00013 & 99.0 & $\mathrm{~V}_{\text {out }}=-0.00024 \mathrm{P}+2.63516$ \\
P-6 & 10 & 0.941 & 0.00104 & 0.00004 & 99.9 & $\mathrm{~V}_{\text {out }}=-0.00017 \mathrm{P}+2.68909$ \\
P-7 & 10 & 0.681 & 0.00455 & 0.00014 & 99.0 & $\mathrm{~V}_{\text {out }}=-0.00026 \mathrm{P}+2.74772$ \\
P-8 & 10 & 0.703 & 0.00242 & 0.00006 & 99.0 & $\mathrm{~V}_{\text {out }}=-0.00012 \mathrm{P}+2.68798$ \\
\hline
\end{tabular}

(B). For the experiments taken in thermostated buffer solutions:

\begin{tabular}{lllllll}
\hline E.N. & $n$ & $R^{2}$ & $\delta \mathrm{V}_{\text {out }}(\mathrm{v})$ & $\delta b(\mathrm{v} / \mathrm{MPa})$ & $\% *$ & Best fit line \\
\hline PT-1 & 11 & 0.964 & 0.00390 & 0.00011 & 99.9 & $\mathrm{~V}_{\text {out }}=-0.00077 \mathrm{P}+3.25249$ \\
PT-2 & 11 & 0.877 & 0.00520 & 0.00014 & 99.9 & $\mathrm{~V}_{\text {out }}=-0.00052 \mathrm{P}+3.16325$ \\
PT-3 & 11 & 0.856 & 0.00486 & -0.00014 & 99.9 & $\mathrm{~V}_{\text {out }}=-0.00045 \mathrm{P}+3.08956$ \\
PT-4 & 11 & 0.938 & 0.00379 & 0.00011 & 99.9 & $\mathrm{~V}_{\text {out }}=-0.00057 \mathrm{P}+3.05324$ \\
PT-5 & 7 & 0.673 & 0.01642 & 0.00053 & 95.0 & $\mathrm{~V}_{\text {out }}=-0.00069 \mathrm{P}+2.69909$ \\
PT-6 & 6 & 0.915 & 0.00717 & 0.00024 & 98.0 & $\mathrm{~V}_{\text {out }}=-0.00061 \mathrm{P}+2.66953$
\end{tabular}

* \% represents the percentages of confidence in the linear relationships between $V_{\text {out }}$ and pressure $P$. 


\section{Chapter 4. Conclusions}

\section{\$4.1. Conclusions}

\section{The Relationship between $\mathrm{V}_{\text {out }}$ and $\mathrm{pH}$}

The ISFET Output in Figure 3.7, is equal to $V_{g}$

From Equation 15 in Chapter 2, when $I_{D}$ is a constant, the relationship between $V_{g}$ and $\alpha_{2}^{i}$ is

$$
\mathrm{V}_{9} \propto-\frac{\mathrm{RT}}{\mathrm{Z}^{\mathrm{i} F}} \ln \alpha_{2}^{\mathrm{i}}
$$

According to [25], $\alpha_{2}^{i}=f\left[\mathrm{H}^{+}\right]$, therefore,

$$
\mathrm{V}_{\text {out }}=\mathrm{V}_{9} \propto-\ln \left[\mathrm{H}^{+}\right]=-\frac{\log \left[\mathrm{H}^{+}\right]}{\log \mathrm{e}}
$$

hence, $\mathrm{V}_{\text {out }} \propto \mathrm{pH}$. So, theoretically speaking, there is a linear relationship between $\mathrm{V}_{\text {out }}$ and $\mathrm{pH}$ value.

Our experimental results (Table 13 and Figure 3.28-33) support this expectation. We are $99 \%$ confident that the relationship between $\mathrm{V}_{\text {out }}$ and $\mathrm{pH}$ value is linear from the experiment.

\section{The Relationship between $V_{\text {out }}$ and Temperature}

According to $\$ 3.5$ and. Figure 3.12 and 3.13 , the linear relationship between $\mathrm{V}_{\text {out }}$ and the temperature is over $99.9 \%$ sure. Furthermore, the data are over $97 \%$ represented by their best fit lines, we can therefore conclude that there is a linear relationship between $\mathrm{V}_{\text {out }}$ and the temperature from $25^{\circ} \mathrm{C}$ to $60^{\circ} \mathrm{C}$.

The slopes of the best fit lines are $-4.6\left(\mathrm{mv} / \mathrm{C}\right.$ ) and $-1.4\left(\mathrm{mv} /{ }^{\rho} \mathrm{C}\right)$ (Figure 
3.12 and 3.13). They are relatively small, comparing to those of $\mathrm{V}_{\text {out }} \mathrm{vs} \mathrm{pH}$ curves (about $40(\mathrm{mv} / \mathrm{pH}$ ) in Figure 3.28-3.33). Thus, we can conclude that the indicated $\mathrm{pH}$ value decreases slowly with a increasing temperature.

During these experiments, the ISFETs we had failed at a temperature around $60^{\circ} \mathrm{C}$. We suspect that this was caused by thermal expansion which separated drain and/or source leads from the ISFET. Although these sets of data have shown good linear functions, further experiments are needed to support the conclusion and extend it to a higher temperature.

\section{The Relationship between $V_{\text {out }}$ and Pressure}

Using the results from experiments $\mathrm{P}-1$ to $\mathrm{P}-8$, as shown in Table 5-8 and Figure 3.14-3.21, we can draw the conclusion that the relationship between $V_{\text {out }}$ and the pressure on the solution is a linear function with a small slope, around $-0.2 \mathrm{mv} / \mathrm{MPa}$, from $101 \mathrm{kPa}$ to $40 \mathrm{MPa}$. This conclusion is further supported by the results from the experiments performed under several fixed temperatures as shown in Figure 3.22-3.27 (the slope is about $-0.5 \mathrm{mv} / \mathrm{MPa}$ under this conditions).

An increase in pressure results in a small decrease in the indicated $\mathrm{pH}$. The linear relations of $\mathrm{pH}$ with pressure or temperature as indicated $\mathrm{pH}$ provide the basis upon which practical instruments can be designed to give corrected values of $\mathrm{pH}$ under various conditions.

\section{The Stability of $\mathrm{V}_{\text {out }}$}

From both of two stability tests, we are $99.9 \%$ confident that $\mathrm{V}_{\text {out }}$ changes slowly as a function of time. However, the second stability test (over 2,000 hours) indicates a more complicated relationship between $V_{\text {out }}$ and time. Rather than a linear function, the trend of $V_{\text {out }}$ can be more precisely 
predicted by adding a very small second order term:

$$
V_{\text {out }}=-1.95185 \times 10^{-8} t^{2}+0.00019 t+2.15961
$$

According to Figure 3.39, the coefficient of correlation $R \propto 1$. So, the relationship between $\mathrm{V}_{\text {out }}$ and time can be considered to be linear in a short time period, but for a long term measurement, this relationship should be modified by using a polynomial equation.

\section{§4.2. Suggestions for Improvements in Future Experiments}

In the future, experiments should focus on the operation of ISFETs at higher temperatures. If possible, ISFETs with different encapsulants and contact binding procedures should be considered and tested as a function of temperature.

The satisfactory performance of the ISFETs as indicators of $\mathrm{pH}$ at the pressures found in geothermal/geopressured reservoirs has been demonstrated. It remains to be seen, however, if the ISFETs can function at temperature to $150^{\circ} \mathrm{C}$. 


\begin{tabular}{|r|r|}
\hline \multicolumn{2}{|c|}{ Experiment S-1, 01/09/90 } \\
\hline Time (hours) & FET Output $(\mathrm{v})$ \\
\hline 0.000 & 3.14906 \\
8.085 & 3.14868 \\
16.026 & 3.14841 \\
32.101 & 3.15667 \\
40.123 & 3.14246 \\
48.062 & 3.15232 \\
56.030 & 3.15380 \\
64.101 & 3.15447 \\
72.066 & 3.15660 \\
88.324 & 3.15208 \\
96.124 & 3.15913 \\
$103.59,4$ & 3.16471 \\
111.582 & 3.16036 \\
119.599 & 3.16215 \\
127.589 & 3.16253 \\
135.621 & 3.15378 \\
151.947 & 3.16532 \\
159.581 & 3.16507 \\
167.502 & 3.16595 \\
175.468 & 3.16742 \\
183.548 & 3.16888 \\
191.538 & 3.16918 \\
199.379 & 3.17056 \\
207.608 & 3.17026 \\
215.514 & 3.17495 \\
223.502 & 3.17479 \\
231.567 & 3.17108 \\
239.531 & 3.16520 \\
240.517 & 3.17187 \\
\hline & \\
\hline
\end{tabular}

Table 1. Stability Test of ISFET 3

$$
\mathrm{pH}=4.05 ; \text { Temperature }=25^{\circ} \mathrm{C}
$$




\begin{tabular}{|c|c|c|c|c|c|c|c|c|c|}
\hline \multicolumn{10}{|c|}{ Experiment S-2; $\mathrm{pH}=5.29$; ISFET Output: volts; $12 / 18 / 90-03 / 13 / 91$} \\
\hline $\begin{array}{l}\text { Time } \\
\text { (hours) }\end{array}$ & \begin{tabular}{|l|} 
ISFET \\
Output
\end{tabular} & $\begin{array}{l}\text { Time } \\
\text { (hours) }\end{array}$ & \begin{tabular}{|l|} 
ISFET \\
Output
\end{tabular} & $\begin{array}{l}\text { Time } \\
\text { (hours) }\end{array}$ & \begin{tabular}{|l|} 
ISFET \\
Output
\end{tabular} & $\begin{array}{l}\text { Time } \\
\text { (hours) }\end{array}$ & \begin{tabular}{|l} 
ISFET \\
Output \\
\end{tabular} & \begin{tabular}{|l|} 
Time \\
(hours)
\end{tabular} & \begin{tabular}{|l|} 
ISFET \\
Output \\
\end{tabular} \\
\hline 0.00 & 2.170 & 381.78 & 2.219 & 764.95 & 2.299 & 1149.12 & 2.362 & 1649.12 & 2.426 \\
\hline 7.48 & 2.179 & 392.87 & 2.223 & 772.62 & 2.301 & 1157.12 & 2.361 & 1662.12 & 2.430 \\
\hline 19.73 & 2.182 & 404.62 & 2.227 & 788.28 & 2.302 & 1177.12 & 2.366 & 1673.12 & 2.432 \\
\hline 31.68 & 2.182 & 415.63 & 2.229 & 799.62 & 2.305 & 1185.62 & 2.367 & 1686.12 & 2.433 \\
\hline 43.62 & 2.183 & 429.70 & 2.231 & 811.62 & 2.308 & 1192.12 & 2.366 & 1703.12 & 2.432 \\
\hline 55.53 & 2.185 & 438.78 & 2.232 & 823.95 & 2.311 & 1204.12 & 2.368 & 1710.12 & 2.435 \\
\hline 67.78 & 2.186 & 453.62 & 2.235 & 833.95 & 2.312 & 1224.12 & 2.369 & 1714.12 & 2.435 \\
\hline 79.62 & 2.185 & 463.95 & 2.237 & 844.95 & 2.315 & 1229.12 & 2.370 & 1726.12 & 2.436 \\
\hline 91.80 & 2.187 & 475.95 & 2.239 & 863.62 & 2.318 & 1242.12 & 2.373 & 1739.12 & 2.438 \\
\hline 103.62 & 2.189 & 487.95 & 2.242 & 869.78 & 2.318 & 1339.12 & 2.386 & 1755.12 & 2.441 \\
\hline 115.78 & 2.190 & 499.63 & 2.244 & 886.62 & 2.322 & 1351.62 & 2.391 & 1770.12 & 2.442 \\
\hline 127.70 & 2.196 & 512.62 & 2.247 & 893.62 & 2.323 & 1370.12 & 2.391 & 1782.12 & 2.444 \\
\hline 140.08 & 2.197 & 526.78 & 2.249 & 906.28 & 2.326 & 1390.62 & 2.393 & 1794.12 & 2.447 \\
\hline 152.72 & 2.194 & 536.95 & 2.252 & 920.87 & 2.328 & 1400.12 & 2.397 & 1806.12 & 2.445 \\
\hline 163.47 & 2.191 & 548.95 & 2.254 & 932.12 & 2.330 & 1412.12 & 2.400 & 1810.12 & 2.445 \\
\hline 174.87 & 2.187 & 560.37 & 2.256 & 942.12 & 2.333 & 1442.12 & 2.402 & 1823.12 & 2.446 \\
\hline 189.87 & 2.190 & 574.37 & 2.259 & 957.12 & 2.335 & 1451.12 & 2.403 & 1834.12 & 2.450 \\
\hline 198.70 & 2.192 & 584.97 & 2.261 & 966.12 & 2.335 & 1464.12 & 2.403 & 1849.12 & 2.449 \\
\hline 214.37 & 2.195 & 598.12 & 2.263 & 980.12 & 2.336 & 1473.12 & 2.403 & 1860.12 & 2.452 \\
\hline 225.30 & 2.198 & 608.95 & 2.266 & 989.12 & 2.334 & 1488.12 & 2.406 & 1872.12 & 2.450 \\
\hline 237.28 & 2.199 & 622.95 & 2.267 & 1005.12 & 2.342 & 1496.62 & 2.407 & 1887.12 & 2.456 \\
\hline 248.53 & 2.200 & 632.95 & 2.271 & 1013.12 & 2.340 & 1508.62 & 2.410 & 1901.12 & 2.455 \\
\hline 262.05 & 2.202 & 646.12 & 2.273 & 1028.12 & 2.344 & 1520.12 & 2.411 & 1907.12 & 2.457 \\
\hline 274.20 & 2.204 & 656.38 & 2.277 & 1037.12 & 2.345 & 1541.12 & 2.417 & 1920.12 & 2.459 \\
\hline 285.78 & 2.205 & 670.37 & 2.278 & 1056.12 & 2.346 & 1547.12 & 2.415 & 1928.12 & 2.460 \\
\hline 298.62 & 2.205 & 681.95 & 2.284 & 1064.12 & 2.348 & 1559.12 & 2.417 & 1944.12 & 2.462 \\
\hline 309.78 & 2.207 & 693.95 & 2.282 & 1078.12 & 2.347 & 1571.12 & 2.418 & 1963.12 & 2.465 \\
\hline 318.95 & 2.210 & 704.12 & 2.288 & 1086.12 & 2.350 & 1584.12 & 2.418 & 1974.12 & 2.466 \\
\hline 333.95 & 2.208 & 717.03 & 2.289 & 1100.12 & 2.352 & 1595.12 & 2.424 & 1988.12 & 2.466 \\
\hline 342.62 & 2.211 & 728.62 & 2.291 & 1110.12 & 2.356 & 1602.12 & 2.424 & 2000.12 & 2.466 \\
\hline 357.37 & 2.214 & 740.62 & 2.294 & 1126.12 & 2.356 & 1613.12 & 2.425 & 2016.12 & 2.468 \\
\hline 368.03 & 2.216 & 753.45 & 2.296 & 1135.12 & 2.360 & 1637.12 & 2.427 & 2042.12 & 2.469 \\
\hline
\end{tabular}

Table 2. Stability Test of ISFET 3039; Temperature: $25^{\circ} \mathrm{C}$; Pressure: $101 \mathrm{KPa}$ 


\begin{tabular}{|c|c|}
\hline $\begin{array}{l}\text { Experiment T } \\
01 / 29 / 90\end{array}$ & $-1 ; \mathrm{pH}=4.05$ \\
\hline $\begin{array}{l}\text { Temperature } \\
\left({ }^{\circ} \mathrm{C}\right)\end{array}$ & $\begin{array}{l}\text { ISFET Output } \\
\text { (v) }\end{array}$ \\
\hline 25 & 3.136 \\
\hline 30 & 3.142 \\
\hline 35 & 3.110 \\
\hline 40 & 3.072 \\
\hline 45 & 3.052 \\
\hline 50 & 3.036 \\
\hline 55 & 3.011 \\
\hline 60 & 2.988 \\
\hline
\end{tabular}

Table 3. ISFET Output as a Function of Temperature. Using the $\mathrm{pH}$ Probe $\mathrm{R}$ Which was Provided by Chemfet Company; Pressure: $101 \mathrm{KPa}$

\begin{tabular}{|c|c|}
\hline \multicolumn{2}{|c|}{$\begin{array}{l}\text { Experiment } \mathrm{T}-2, \mathrm{pH}=5.26 \\
10 / 17 / 90\end{array}$} \\
\hline $\begin{array}{l}\text { Temperature } \\
\text { (C) }\end{array}$ & \begin{tabular}{|l} 
ISFET Output \\
(v)
\end{tabular} \\
\hline 25 & 3.217 \\
\hline 27 & 3.214 \\
\hline 31 & 3.212 \\
\hline 33 & 3.208 \\
\hline 35 & 3.207 \\
\hline 38 & 3.201 \\
\hline 41 & 3.196 \\
\hline 43 & 3.192 \\
\hline 45 & 3.190 \\
\hline 48 & 3.185 \\
\hline 51 & 3.178 \\
\hline 54 & 3.180 \\
\hline 55 & 3.177 \\
\hline
\end{tabular}

Table 4. ISFET 3021 Output as a Function of Temperature. Pressure: $101 \mathrm{KPa}$ 


\begin{tabular}{|c|c|c|c|c|c|}
\hline \multicolumn{2}{|c|}{$\begin{array}{l}\text { Experiment } \mathrm{P}-2 \\
\mathrm{pH}=5.26\end{array}$} & \multicolumn{2}{|c|}{$\begin{array}{l}\text { Experiment P-3 } \\
\mathrm{pH}=6.27\end{array}$} & \multicolumn{2}{|c|}{$\begin{array}{l}\text { Experiment } \mathrm{P}-4 \\
\mathrm{pH}=7.29\end{array}$} \\
\hline $\begin{array}{l}\text { Pressure } \\
(\mathrm{MPa})\end{array}$ & $\begin{array}{l}\text { FET (v) } \\
\text { Output }\end{array}$ & $\begin{array}{l}\text { Pressure } \\
(\mathrm{MPa})\end{array}$ & \begin{tabular}{|l} 
FET (v) \\
Output
\end{tabular} & $\begin{array}{l}\text { Pressure } \\
(\mathrm{MPa})\end{array}$ & $\begin{array}{l}\text { FET (v) } \\
\text { Output }\end{array}$ \\
\hline 6.16 & 2.615 & 8.64 & 2.660 & 6.59 & 2.720 \\
\hline 7.86 & 2.616 & 9.76 & 2.661 & 8.28 & 2.720 \\
\hline 10.57 & 2.615 & 11.52 & 2.662 & 10.14 & 2.720 \\
\hline 14.26 & 2.614 & 13.48 & 2.662 & 14.90 & 2.719 \\
\hline 17.91 & 2.612 & 16.94 & 2.660 & 17.66 & 2.718 \\
\hline 21.41 & 2.612 & 20.44 & 2.657 & 22.00 & 2.717 \\
\hline 25.56 & 2.610 & 24.25 & 2.657 & 26.59 & 2.716 \\
\hline 29.59 & 2.608 & 28.35 & 2.655 & 30.19 & 2.714 \\
\hline 33.86 & 2.607 & 32.04 & 2.655 & 34.42 & 2.713 \\
\hline 37.15 & 2.605 & 36.01 & 2.655 & 38.16 & 2.711 \\
\hline
\end{tabular}

Table 6. ISFET 3041 Output as a Function of Pressure. Date: June 13, 1990

\begin{tabular}{|c|c|}
\hline $\begin{array}{l}\text { Experiment } \\
\mathrm{pH}=6.84 ; 06\end{array}$ & $\begin{array}{l}-1 \\
07 / 90\end{array}$ \\
\hline $\begin{array}{l}\text { Pressure } \\
(\mathrm{MPa})\end{array}$ & $\begin{array}{l}\text { FET (v) } \\
\text { Output }\end{array}$ \\
\hline 0.21 & 2.519 \\
\hline 7.25 & 2.517 \\
\hline 7.43 & 2.517 \\
\hline 8.57 & 2.517 \\
\hline 9.44 & 2.517 \\
\hline 10.94 & 2.517 \\
\hline 13.54 & 2.516 \\
\hline 15.99 & 2.515 \\
\hline 19.68 & 2.514 \\
\hline 23.50 & 2.513 \\
\hline 27.19 & 2.512 \\
\hline 30.87 & 2.511 \\
\hline 34.83 & 2.509 \\
\hline 37.84 & 2.509 \\
\hline
\end{tabular}

Table 5. ISFET 3041 Output as a Function of Pressure. Temperature: $25^{\circ} \mathrm{C}$ 


\begin{tabular}{|c|c|c|c|c|c|}
\hline \multicolumn{2}{|c|}{$\begin{array}{l}\text { Experiment } \mathrm{P}-5 \\
\mathrm{pH}=5.26\end{array}$} & \multicolumn{2}{|c|}{$\begin{array}{l}\text { Experiment } \mathrm{P}-6 \\
\mathrm{pH}=6.27\end{array}$} & \multicolumn{2}{|c|}{$\begin{array}{l}\text { Experiment P-7 } \\
\mathrm{pH}=7.29\end{array}$} \\
\hline $\begin{array}{l}\text { Pressure } \\
(\mathrm{MPa})\end{array}$ & \begin{tabular}{|l|} 
ISFET \\
Output(v)
\end{tabular} & $\begin{array}{l}\text { Pressure } \\
(\mathrm{MPa})\end{array}$ & $\begin{array}{l}\text { ISFET } \\
\text { Output(v) }\end{array}$ & $\begin{array}{l}\text { Pressure } \\
(\mathrm{MPa})\end{array}$ & \begin{tabular}{|l} 
ISFET \\
Output(v) \\
\end{tabular} \\
\hline 6.72 & 2.635 & 9.58 & 2.687 & 7.58 & 2.743 \\
\hline 8.69 & 2.634 & 12.21 & 2.687 & 9.37 & 2.746 \\
\hline 12.14 & 2.633 & 15.87 & 2.686 & 11.99 & 2.743 \\
\hline 16.02 & 2.628 & 18.18 & 2.686 & 15.41 & 2.747 \\
\hline 19.30 & 2.628 & 22.31 & 2.686 & 18.11 & 2.744 \\
\hline 23.28 & 2.632 & 26.59 & 2.685 & 22.25 & 2.741 \\
\hline 27.23 & 2.628 & 29.89 & 2.684 & 26.23 & 2.743 \\
\hline 30.96 & 2.628 & 34.14 & 2.683 & 30.34 & 2.741 \\
\hline 34.59 & 2.628 & 37.99 & 2.682 & 34.63 & 2.738 \\
\hline 38.60 & 2.626 & & & 38.59 & 2.736 \\
\hline
\end{tabular}

Table 7. ISFET 3041 Output as a Function of Pressure. Date: June 15, 1990

\begin{tabular}{|r|r|}
\hline \multicolumn{2}{|l|}{$\begin{array}{l}\text { Experiment P-8 } \\
\text { pH=6.27 }\end{array}$} \\
\hline \begin{tabular}{r|r} 
Pressure \\
(MPa)
\end{tabular} & $\begin{array}{l}\text { ISFET } \\
\text { Output (v) }\end{array}$ \\
\hline 0.17 & 2.688 \\
15.34 & 2.687 \\
17.15 & 2.687 \\
22.41 & 2.685 \\
25.14 & 2.684 \\
29.10 & 2.683 \\
32.94 & 2.683 \\
37.15 & 2.685 \\
40.72 & 2.684 \\
43.98 & 2.683 \\
\hline
\end{tabular}

Table 8. ISFET 3049 Output as a Function of Pressure. Date: Aug. 15, 1990 


\begin{tabular}{|c|c|c|c|c|c|c|c|}
\hline \multicolumn{2}{|c|}{$\begin{array}{l}\text { Experiment PT }-1 \\
\text { Temperature }=40^{\circ} \mathrm{C}\end{array}$} & \multicolumn{2}{|c|}{$\begin{array}{l}\text { Experiment } \mathrm{PT}-2 \\
\text { Temperature }=50^{\circ} \mathrm{C}\end{array}$} & \multicolumn{2}{|c|}{$\begin{array}{l}\text { Experiment PT }-3 \\
\text { Temperature }=60^{\circ} \mathrm{C}\end{array}$} & \multicolumn{2}{|c|}{$\begin{array}{l}\text { Experiment PT }-4 \\
\text { Temperature }=70^{\circ} \mathrm{C}\end{array}$} \\
\hline $\begin{array}{l}\text { Pressure } \\
(\mathrm{MPa}) \\
\end{array}$ & $\begin{array}{l}\text { FET (v) } \\
\text { Output }\end{array}$ & $\begin{array}{l}\text { Pressure } \\
(\mathrm{MPa})\end{array}$ & $\begin{array}{l}\text { FET (v) } \\
\text { Output } \\
\end{array}$ & \begin{tabular}{|l} 
Pressure \\
$(\mathrm{MPa})$
\end{tabular} & $\begin{array}{l}\text { FET (v) } \\
\text { Output }\end{array}$ & $\begin{array}{l}\text { Pressure } \\
(\mathrm{MPa})\end{array}$ & \begin{tabular}{|l} 
FET (v) \\
Output
\end{tabular} \\
\hline 6.12 & 3.250 & 5.78 & 3.164 & 6.75 & 3.091 & 6.97 & 3.052 \\
\hline 8.5 & 3.246 & 8. & 3.161 & 10.00 & 3.085 & 9.95 & 3.048 \\
\hline 11.4 & 3.244 & 1.24 & 3.156 & 11.71 & 3.084 & 13.05 & 3.046 \\
\hline & 3.241 & & 3.154 & 15.53 & 3.081 & 14.77 & 3.044 \\
\hline & 3.238 & & 3.153 & 17.55 & 3.080 & 17.26 & 3.042 \\
\hline 20.35 & 3.235 & & 3.151 & 20.84 & 3.079 & 21.47 & 3.040 \\
\hline .91 & 3.234 & & 3.148 & 25.21 & 3.076 & 24.96 & 3.037 \\
\hline 28.39 & 3.232 & .35 & 3.147 & 28.90 & 3.075 & 28.83 & 3.036 \\
\hline .05 & 3.225 & 32.51 & 3.146 & 33.47 & 3.074 & 32.94 & 3.033 \\
\hline & 3.225 & 36.54 & 3.147 & 36.57 & 3.075 & 36.21 & 3.035 \\
\hline 38.93 & 3.225 & 39.27 & 3.145 & 39.56 & 3.074 & 39.88 & 3.032 \\
\hline
\end{tabular}

Table 9. ISFET 3041 Output as a Function of Pressure at Constant Temperatures Date: July 6, 1990; $\mathrm{pH}=5.26$

\begin{tabular}{|c|c|c|c|}
\hline $\begin{array}{l}\text { Experiment } \\
\text { Temperatur }\end{array}$ & $\begin{array}{l}\text { PT }-5 \\
e=26^{\circ} \mathrm{C}\end{array}$ & $\begin{array}{l}\text { Experiment } \\
\text { Temperatur }\end{array}$ & $\begin{array}{l}\text { PT }-6 \\
=37^{\circ} \mathrm{C} \\
\end{array}$ \\
\hline $\begin{array}{l}\text { Pressure } \\
(\mathrm{MPa})\end{array}$ & \begin{tabular}{|l|} 
FET (v) \\
Output
\end{tabular} & $\begin{array}{l}\text { Pressure } \\
(\mathrm{MPa})\end{array}$ & $\begin{array}{l}\text { FET (v) } \\
\text { Output }\end{array}$ \\
\hline 0.17 & 2.710 & 0.23 & 2.670 \\
\hline 7.65 & 2.686 & 8.32 & 2.666 \\
\hline 10.34 & 2.688 & 14.08 & 2.658 \\
\hline 17.59 & 2.685 & 20.84 & 2.655 \\
\hline 20.94 & 2.682 & 29.93 & 2.655 \\
\hline 27.76 & 2.681 & 35.87 & 2.646 \\
\hline 38.00 & 2.677 & & \\
\hline
\end{tabular}

Table 10. ISFET 3049 Output as a Function of Pressure at Constant Temperatures Date: Aug. 16, 1990; pH=6.27 


\begin{tabular}{|c|c|}
\hline \multicolumn{2}{|c|}{$\mathrm{P}=13.6519 \mathrm{~V}+7.0777$} \\
\hline $\begin{array}{l}\text { Pressure } \\
(\mathrm{MPa})\end{array}$ & $\begin{array}{l}\text { Transducer } \\
\text { Output (v) }\end{array}$ \\
\hline 0.10 & 0.524 \\
\hline 6.94 & 1.026 \\
\hline 13.77 & 1.527 \\
\hline 20.61 & 2.029 \\
\hline 27.44 & 2.530 \\
\hline 34.28 & 3.031 \\
\hline 41.12 & 3.529 \\
\hline 47.95 & 4.033 \\
\hline 54.79 & 4.533 \\
\hline 61.62 & 5.032 \\
\hline 68.46 & 5.530 \\
\hline
\end{tabular}

Table 11. Calibration of the Pressure Transducer. Performed by M-TEC/RISE, INC. Temperature: $26^{\circ} \mathrm{C}$; Date: Aug. 24, 1990

\begin{tabular}{|c|c|}
\hline $\mathrm{T}=19.6004 \mathrm{~V}$ & +1.31792 \\
\hline $\begin{array}{l}\text { Temperature } \\
\text { (C) }\end{array}$ & $\begin{array}{l}\text { Thermocouple } \\
\text { Output (v) }\end{array}$ \\
\hline 37.30 & 1.807 \\
\hline 41.90 & 2.057 \\
\hline 45.80 & 2.251 \\
\hline 50.49 & 2.501 \\
\hline 54.87 & 2.780 \\
\hline 60.15 & 3.030 \\
\hline 65.75 & 3.307 \\
\hline 69.30 & 3.502 \\
\hline 75.30 & 3.779 \\
\hline 80.50 & 4.030 \\
\hline 86.30 & 4.280 \\
\hline
\end{tabular}

Table 12. Calibration of the Thermocouple; Date: June 28, 1990; Voltage Measurement: Fluke Multimeter; Temperature Measurement: CMS Precision Thermometer 


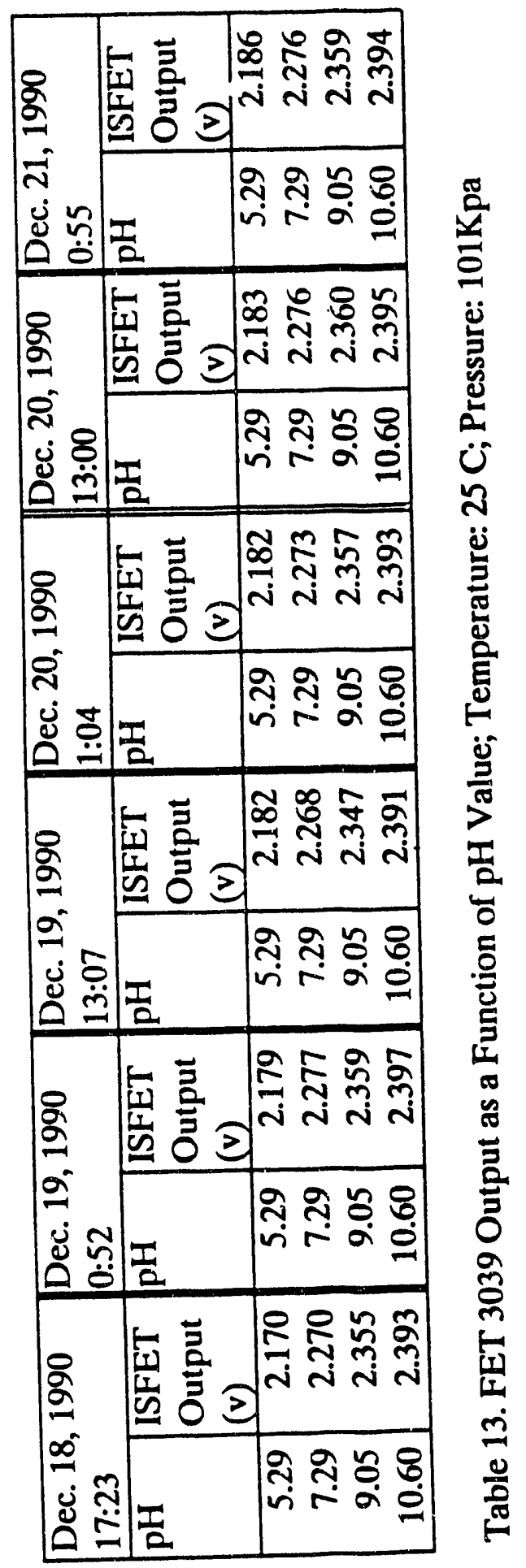




\begin{tabular}{|r|r|r|r|r|r|}
\hline \multicolumn{7}{|c|}{ Probability of a Larger Value of $\mathrm{R}$} \\
\hline $\mathrm{n}-2$ & $\mathrm{~A}=0.1$ & $\mathrm{~A}=0.05$ & $\mathrm{~A}=0.02$ & $\mathrm{~A}=0.01$ & $\mathrm{~A}=0.001$ \\
\hline 1 & 0.988 & 0.997 & 1.000 & 1.000 & 1.000 \\
2 & 0.900 & 0.950 & 0.980 & 0.990 & 1.000 \\
3 & 0.805 & 0.878 & 0.934 & 0.959 & 0.991 \\
4 & 0.729 & 0.811 & 0.882 & 0.917 & 0.974 \\
5 & 0.669 & 0.754 & 0.833 & 0.874 & 0.951 \\
6 & 0.622 & 0.707 & 0.789 & 0.834 & 0.925 \\
7 & 0.582 & 0.666 & 0.750 & 0.780 & 0.898 \\
8 & 0.549 & 0.632 & 0.716 & 0.765 & 0.872 \\
9 & 0.521 & 0.602 & 0.685 & 0.735 & 0.847 \\
10 & 0.497 & 0.576 & 0.658 & 0.708 & 0.823 \\
12 & 0.458 & 0.532 & 0.612 & 0.661 & 0.780 \\
14 & 0.426 & 0.497 & 0.574 & 0.623 & 0.742 \\
16 & 0.400 & 0.468 & 0.542 & 0.590 & 0.708 \\
18 & 0.378 & 0.444 & 0.516 & 0.561 & 0.679 \\
20 & 0.360 & 0.423 & 0.492 & 0.537 & 0.652 \\
25 & 0.323 & 0.381 & 0.445 & 0.487 & 0.597 \\
30 & 0.296 & 0.349 & 0.409 & 0.449 & 0.554 \\
35 & 0.275 & 0.325 & 0.381 & 0.418 & 0.519 \\
40 & 0.257 & 0.304 & 0.358 & 0.393 & 0.490 \\
45 & 0.243 & 0.288 & 0.338 & 0.372 & 0.465 \\
50 & 0.231 & 0.273 & -0.322 & 0.354 & 0.443 \\
\hline
\end{tabular}

Table 14. Confidence Range of Correlation Coefficient $R$ Refer to Reference 27 


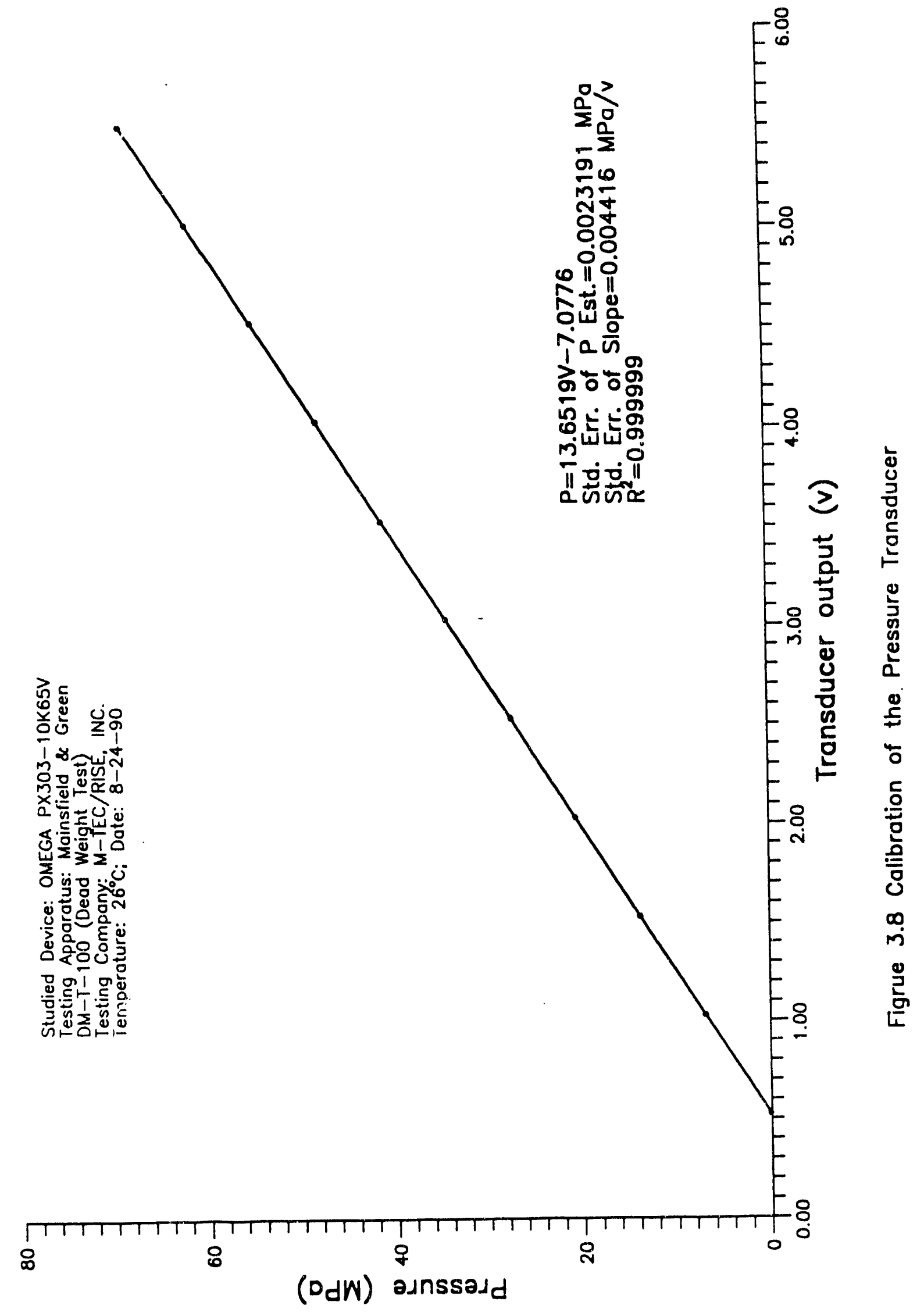



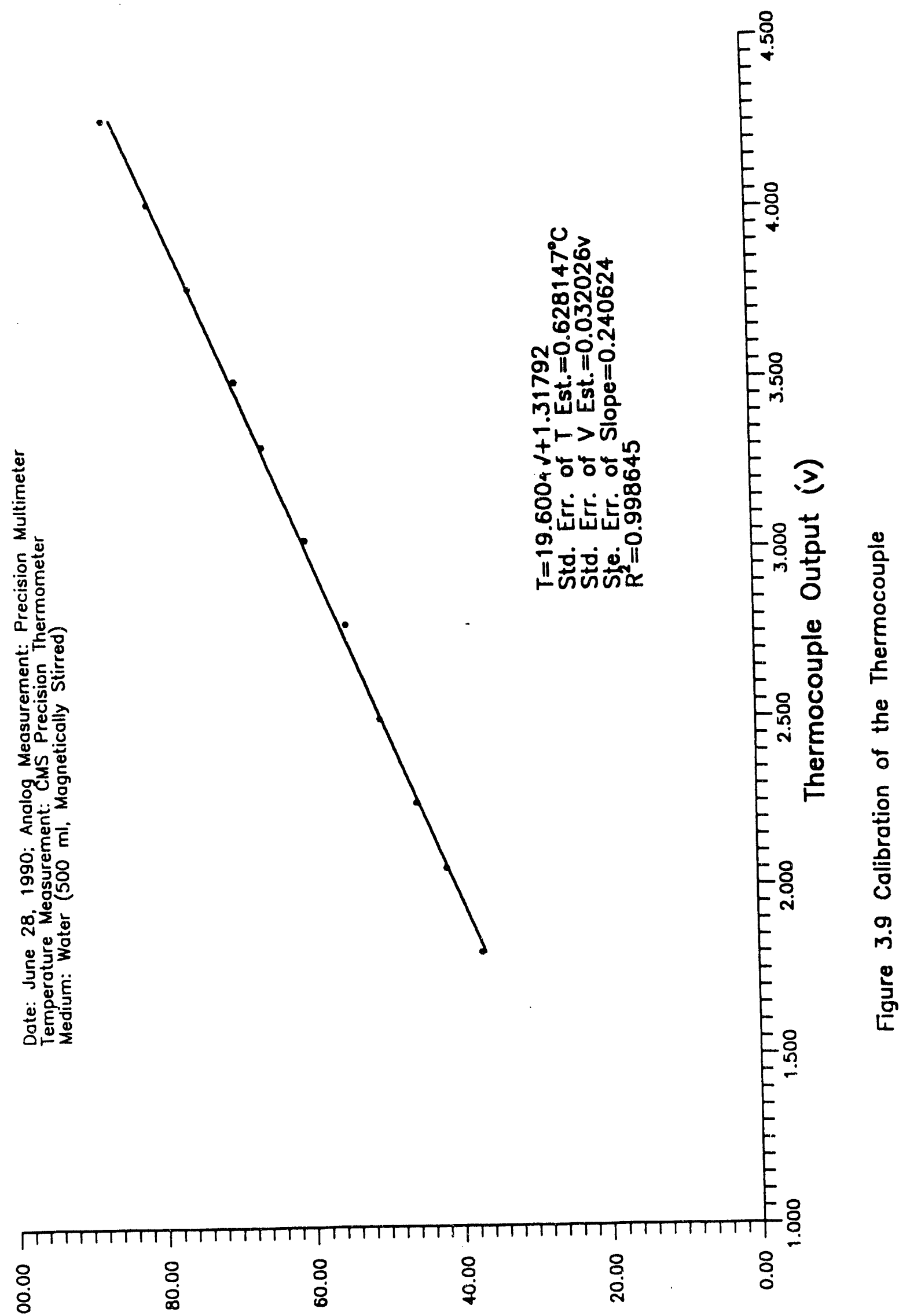

(O०) asnzosadual 


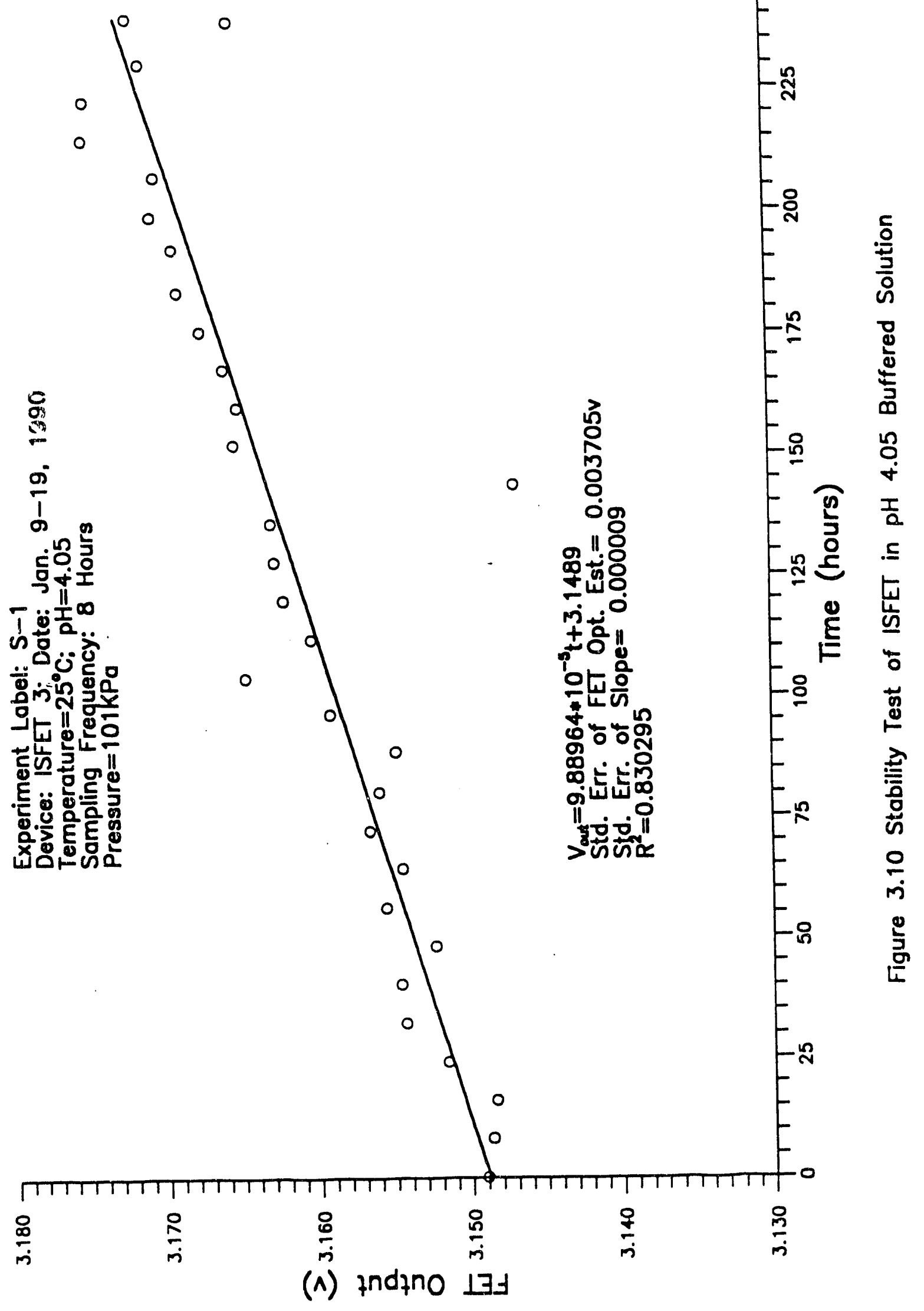




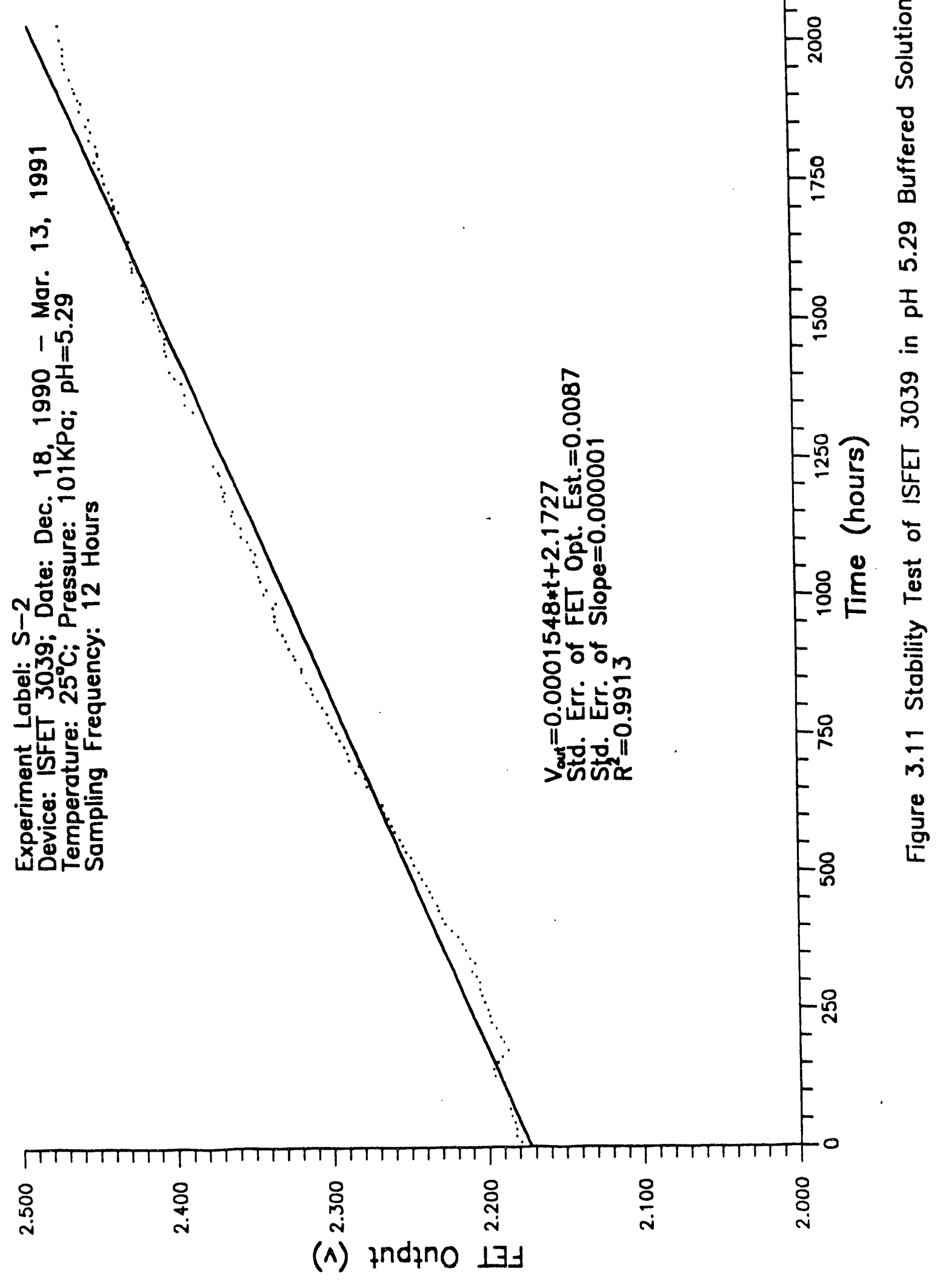




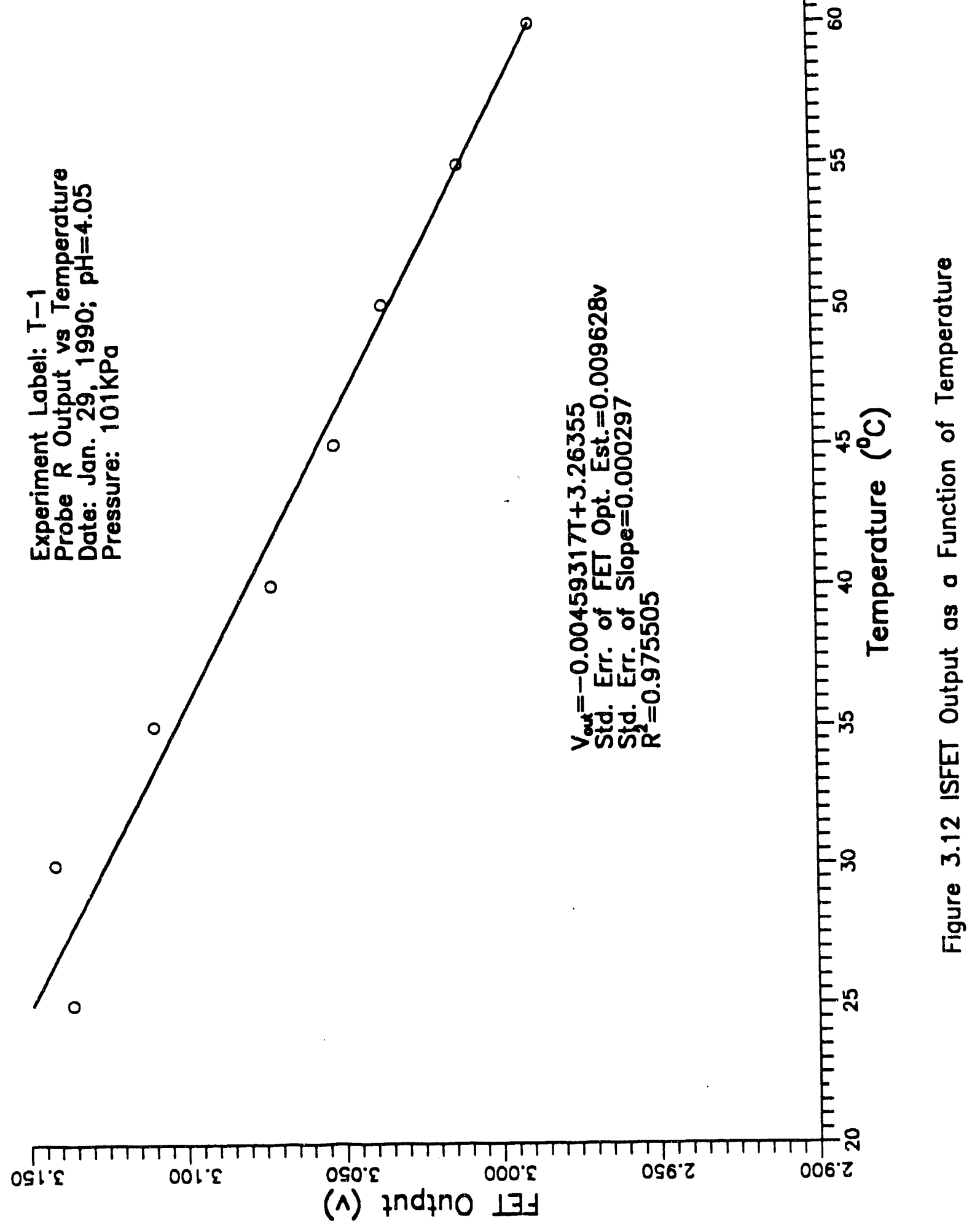




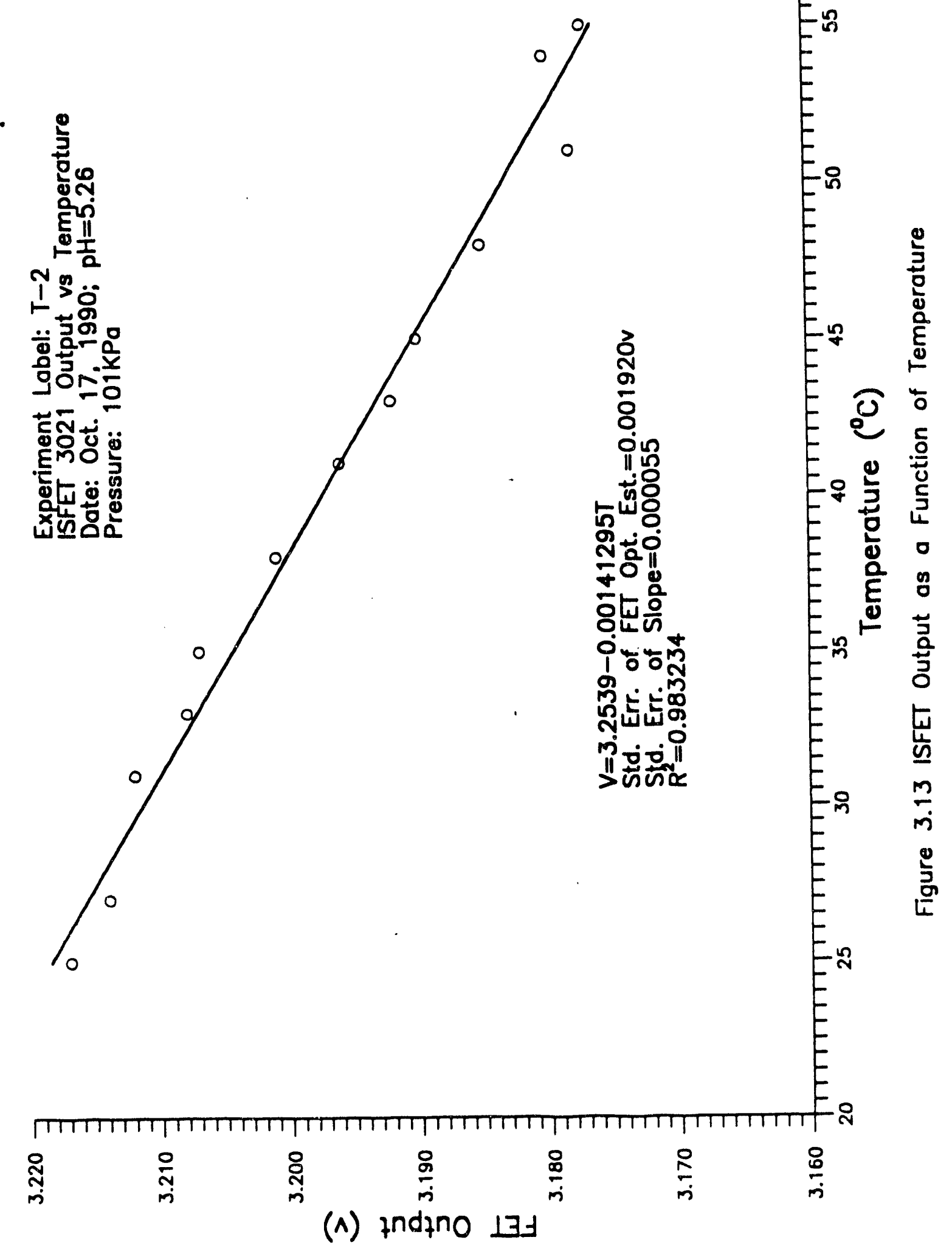




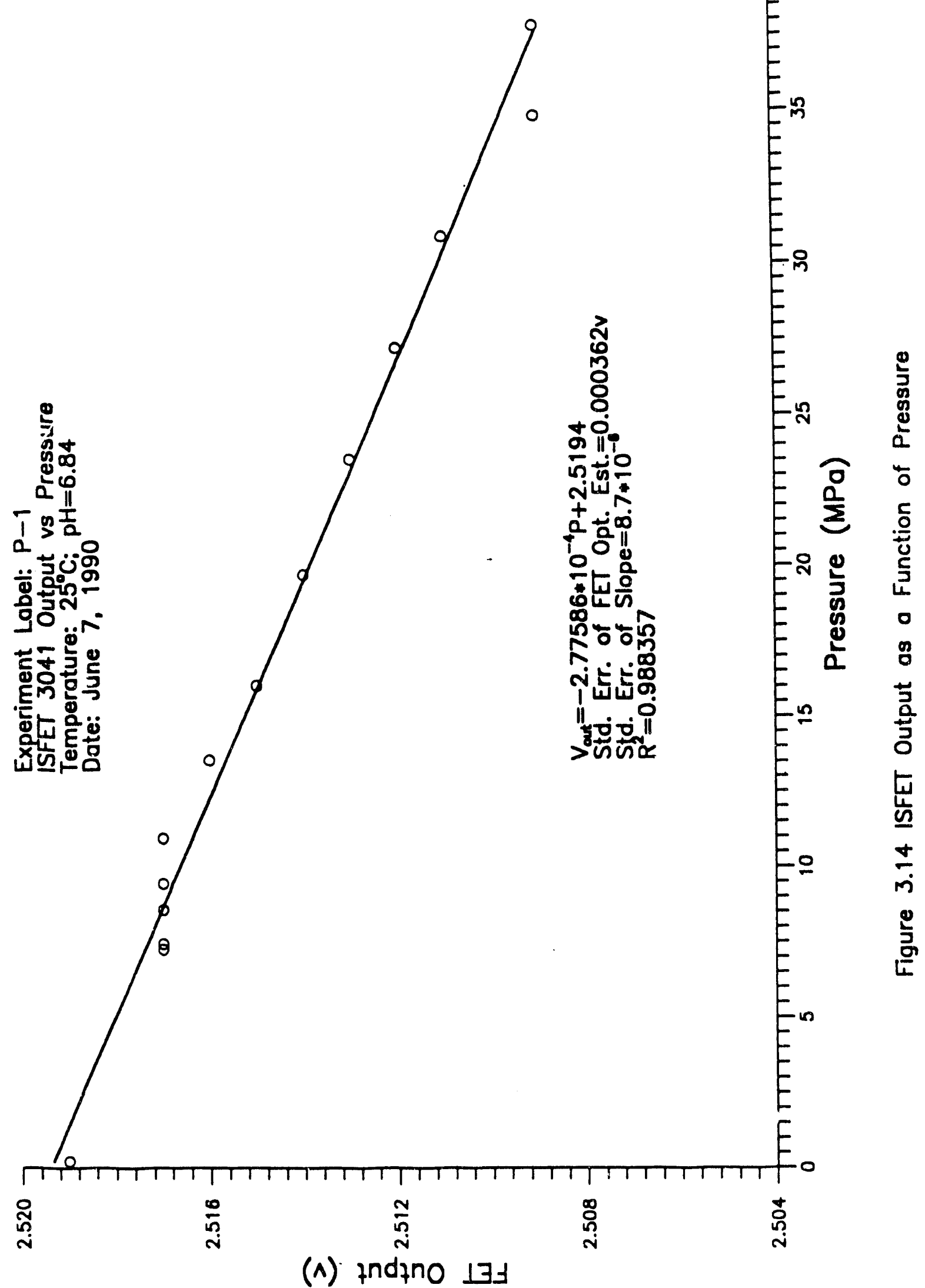




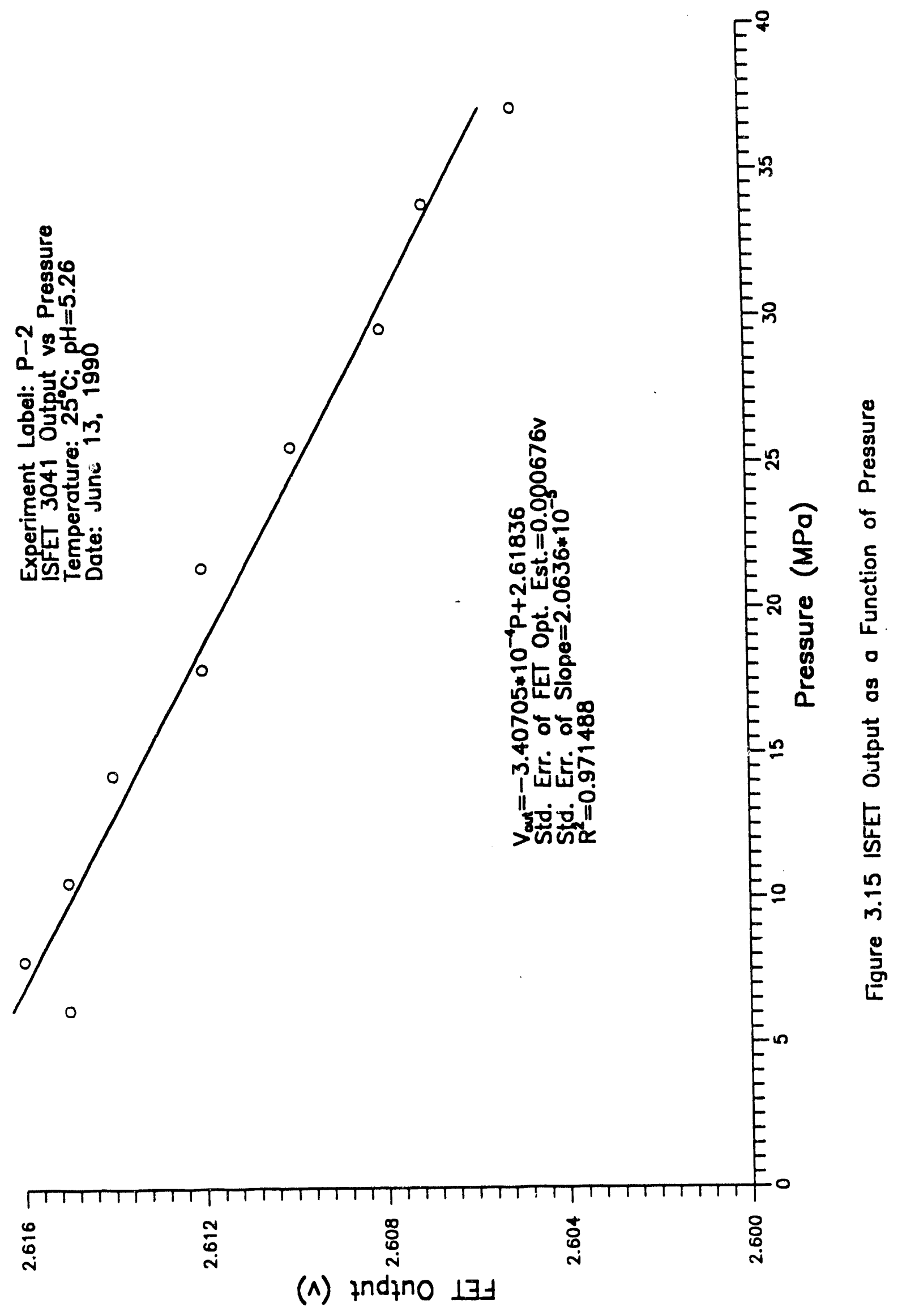




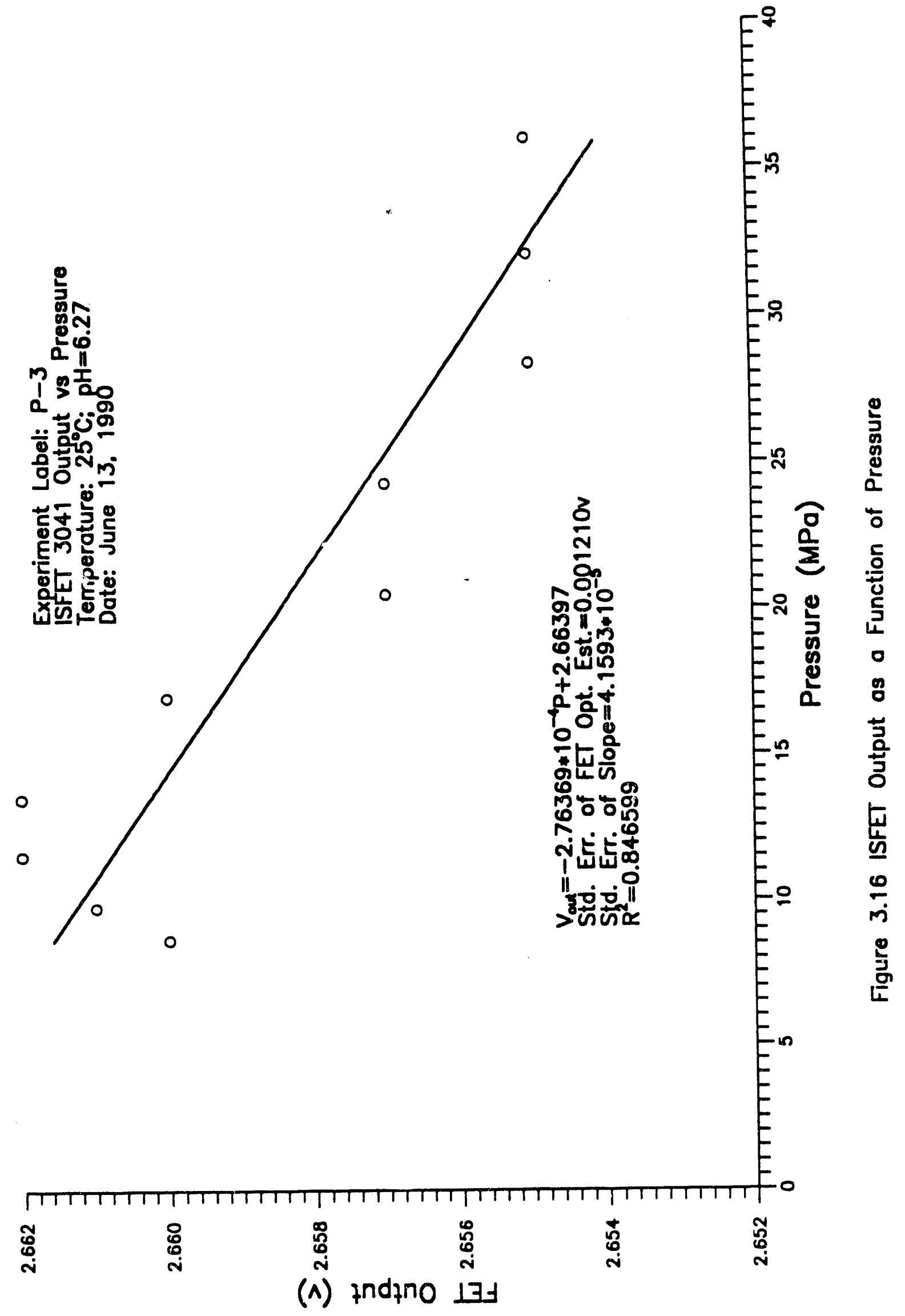




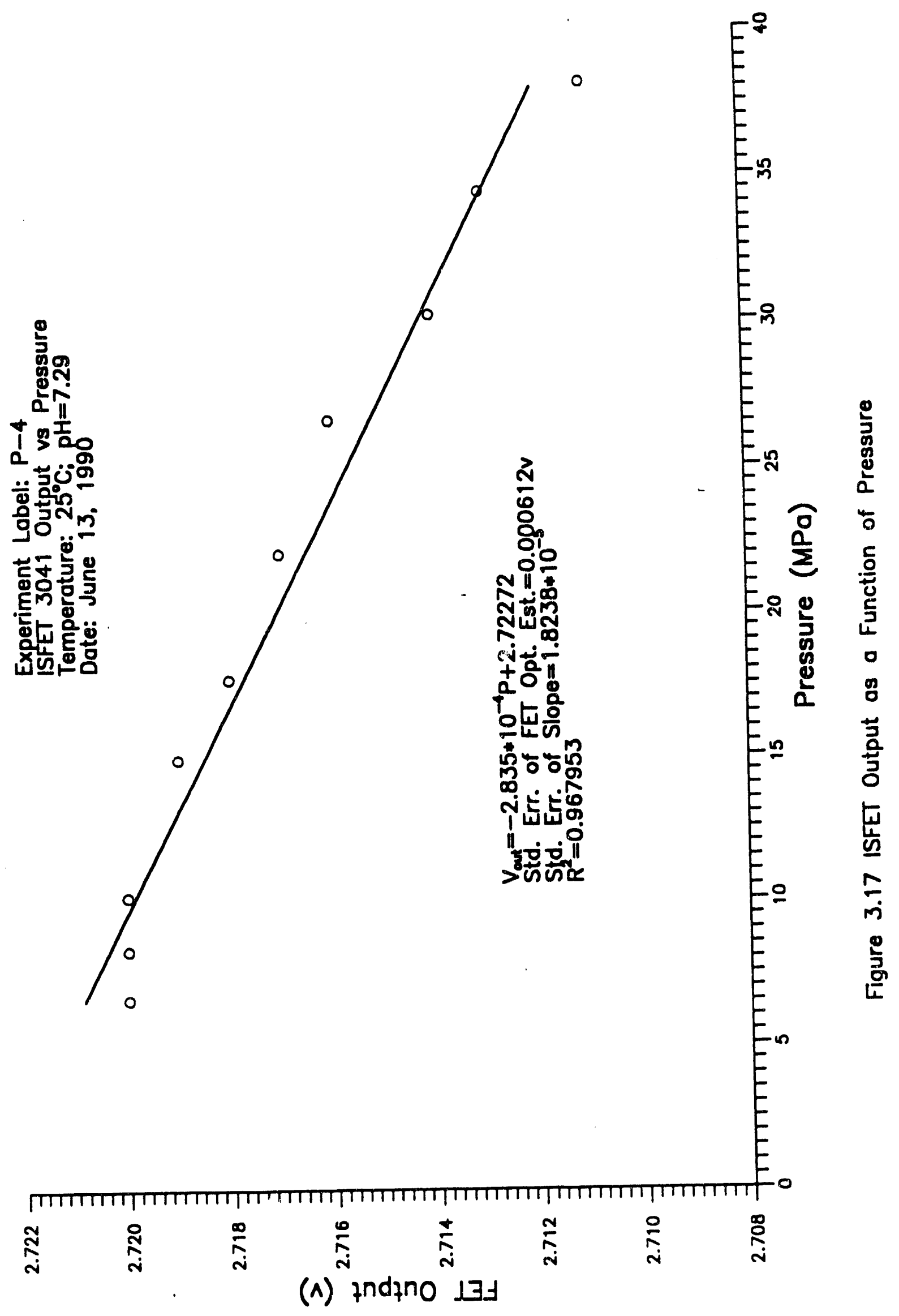




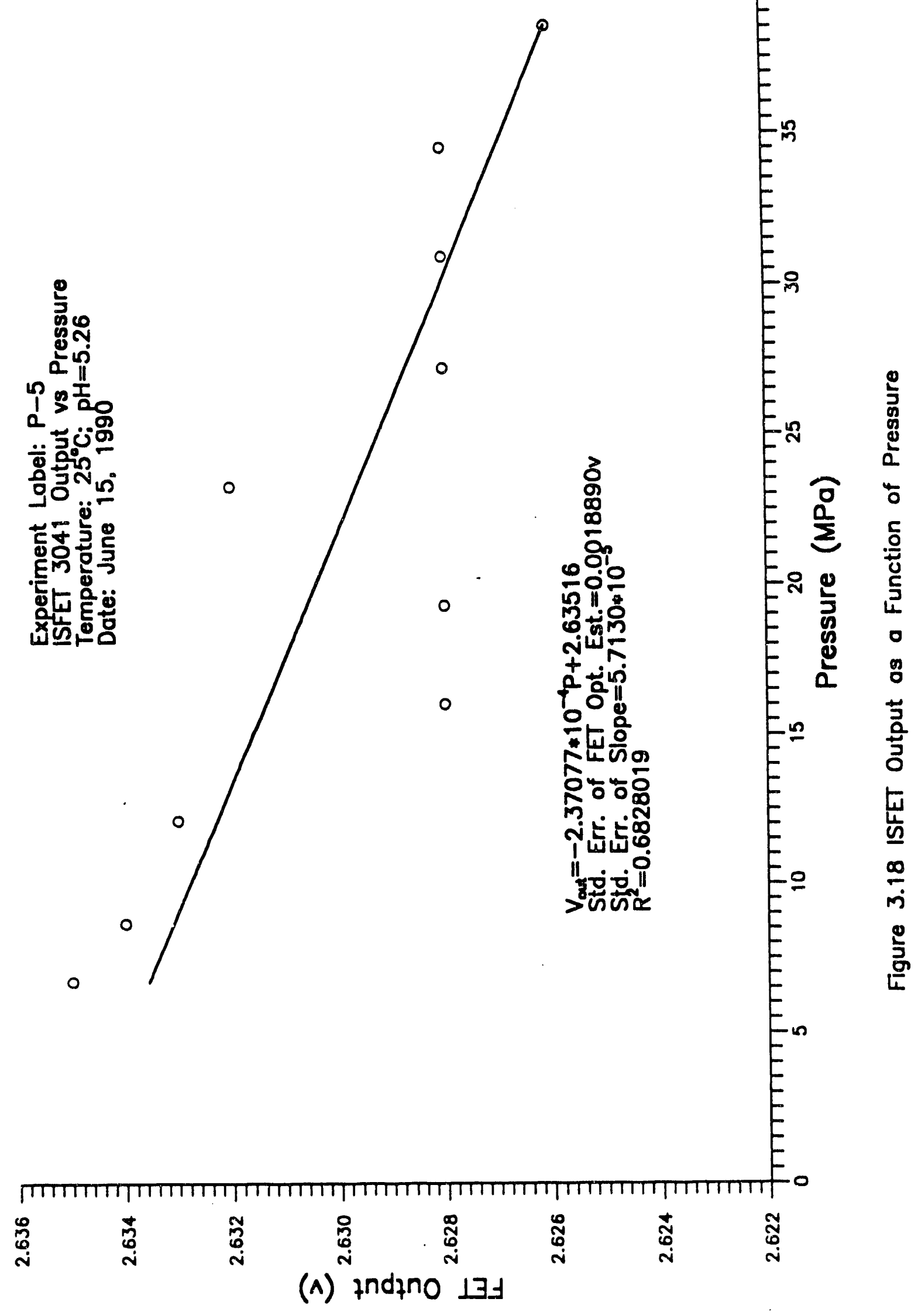




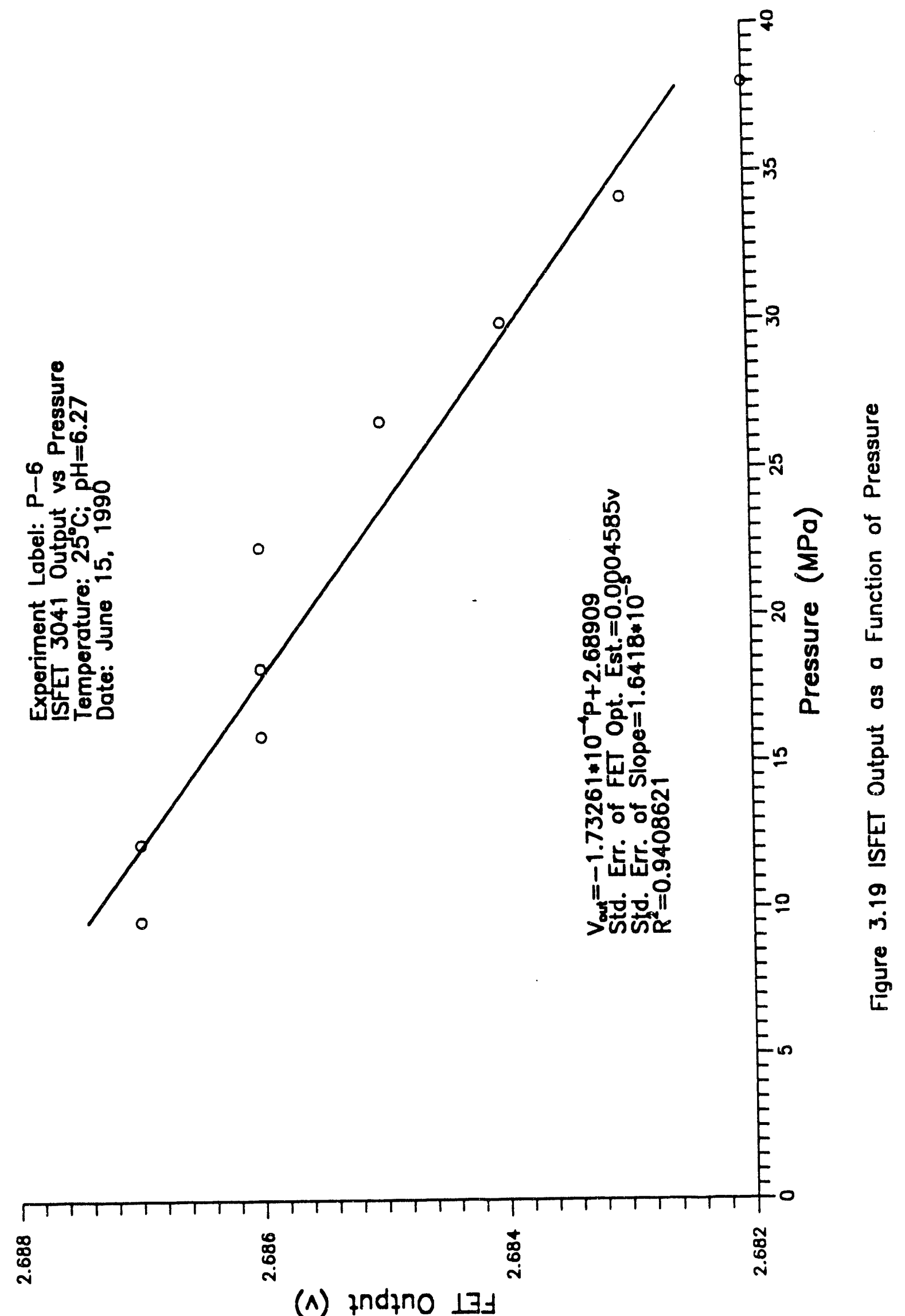



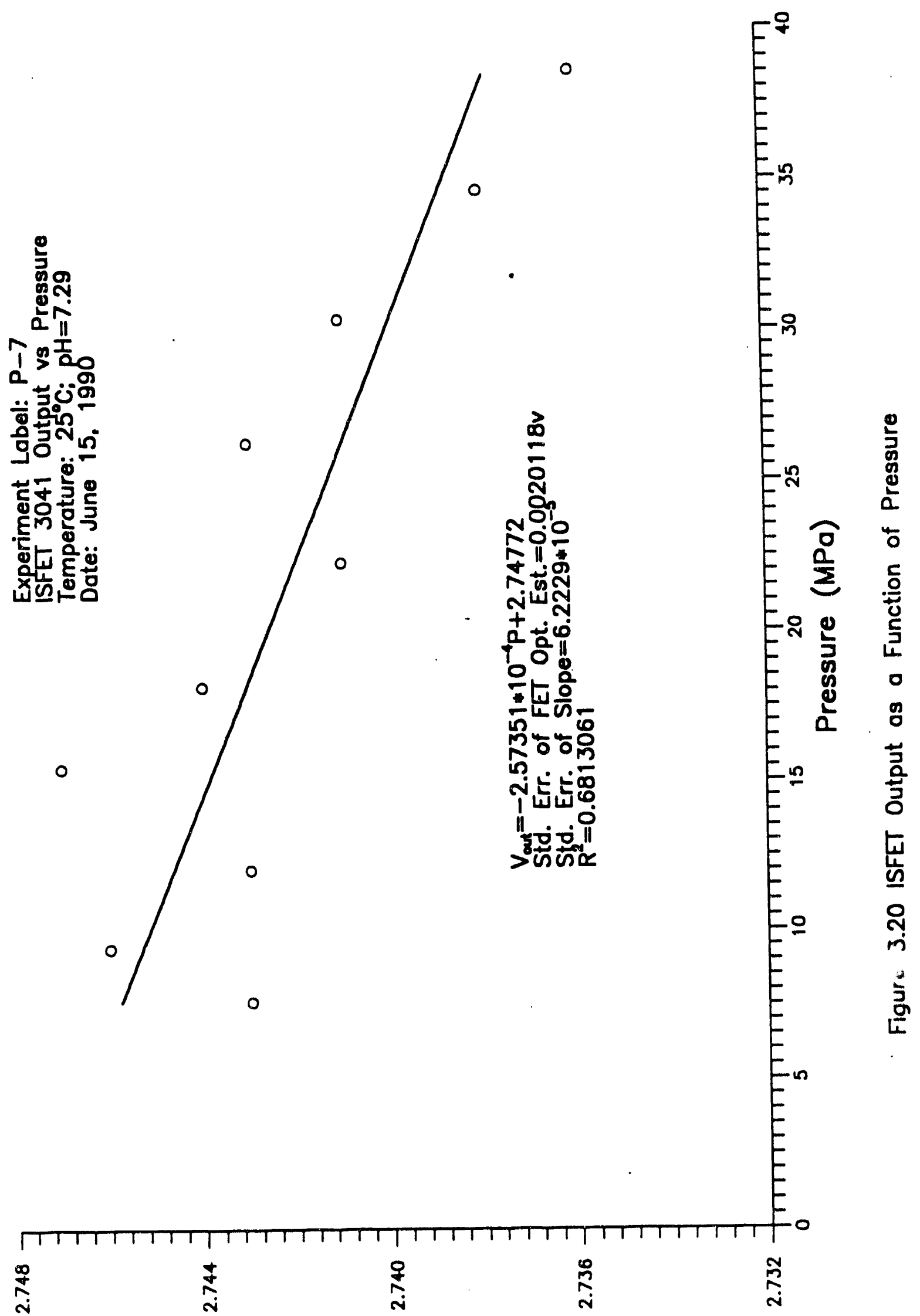

(A) zndino 1y 


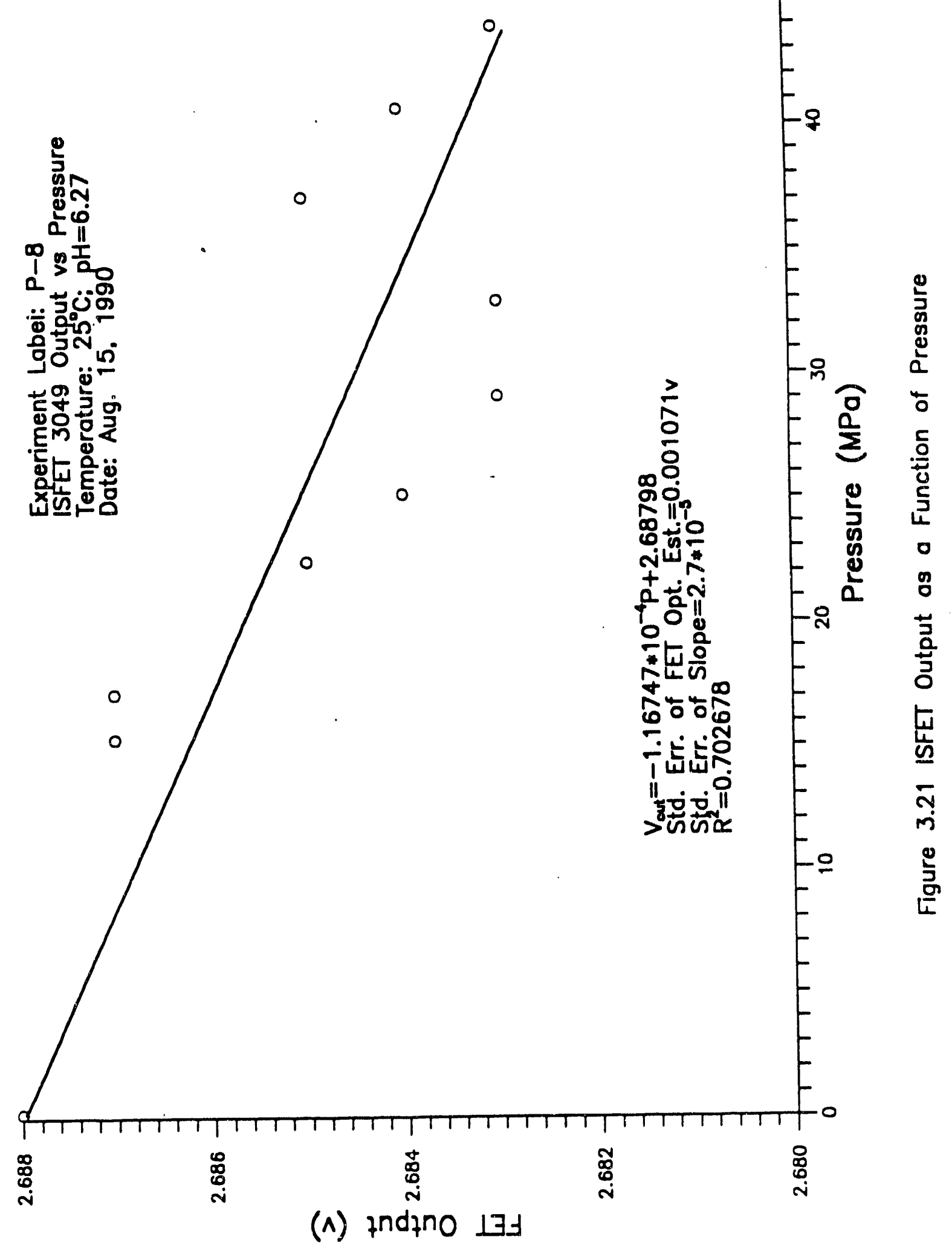




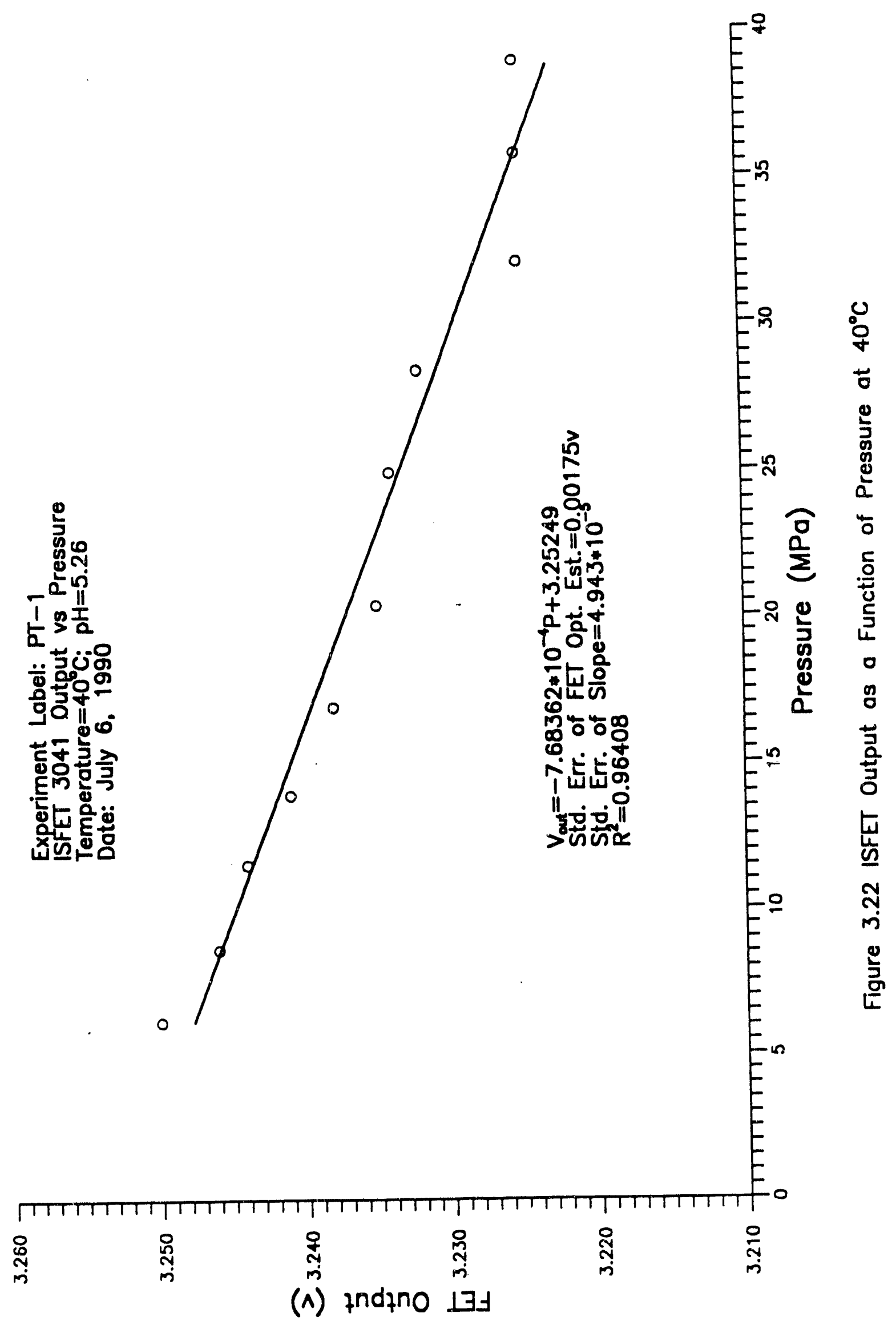




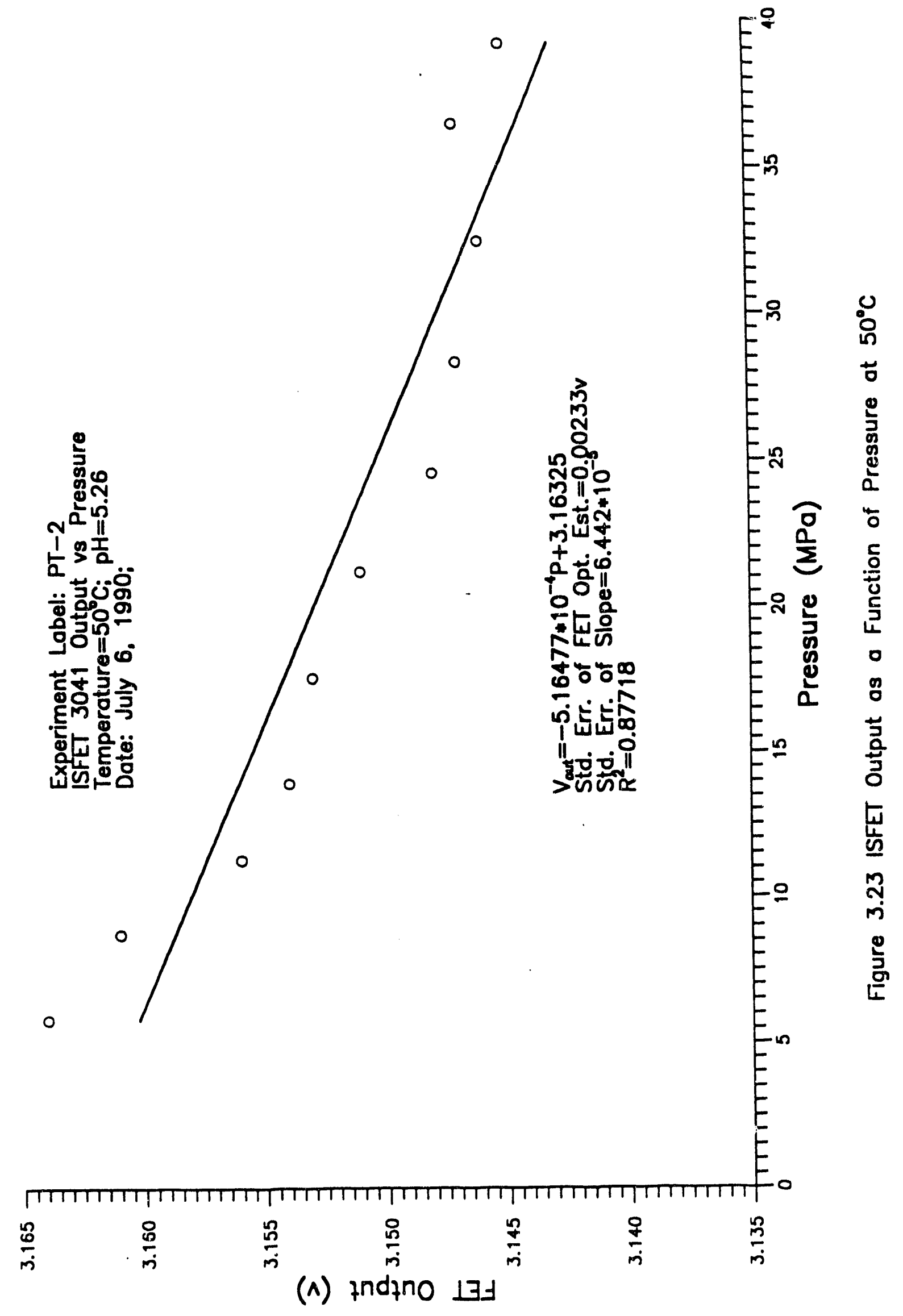




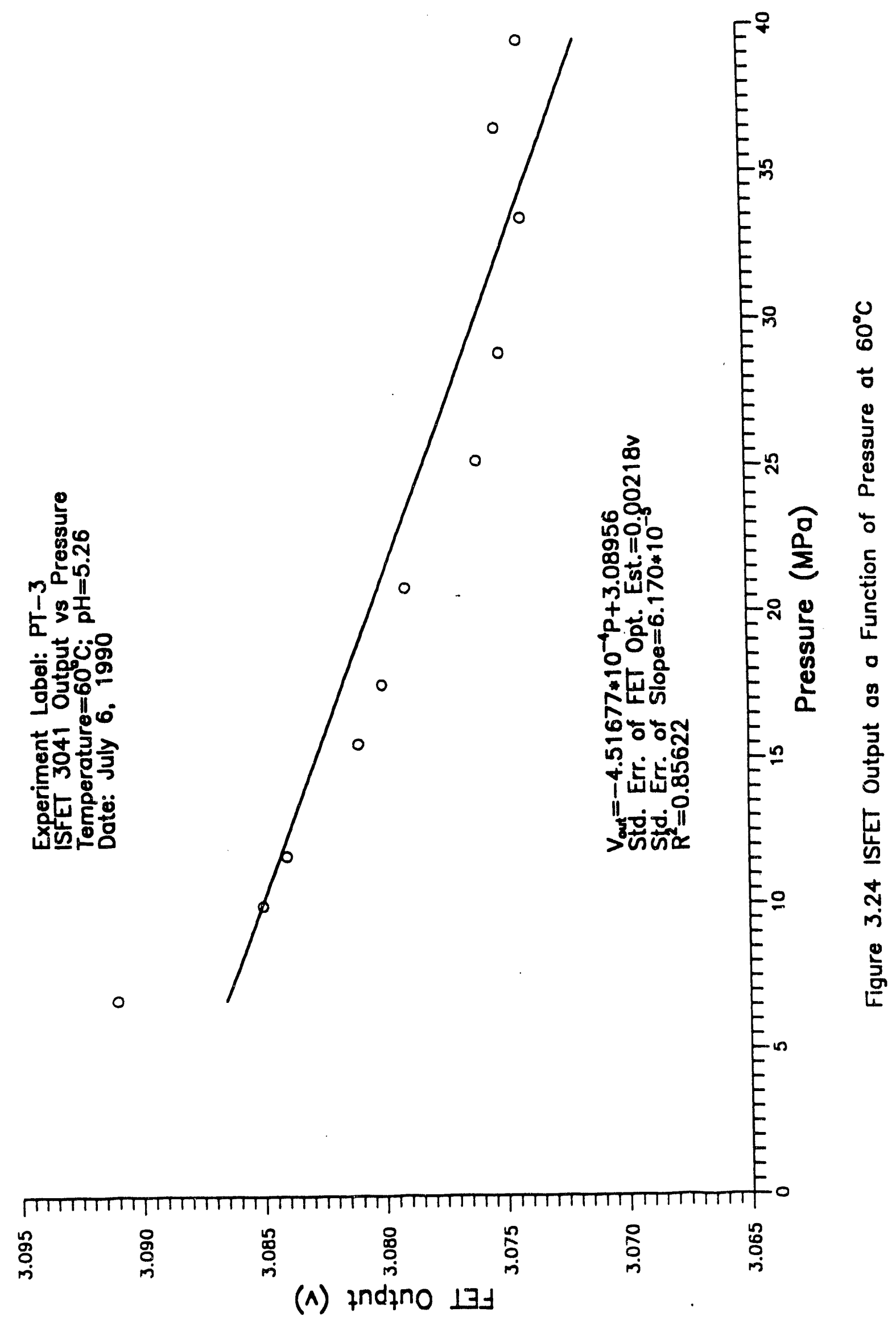




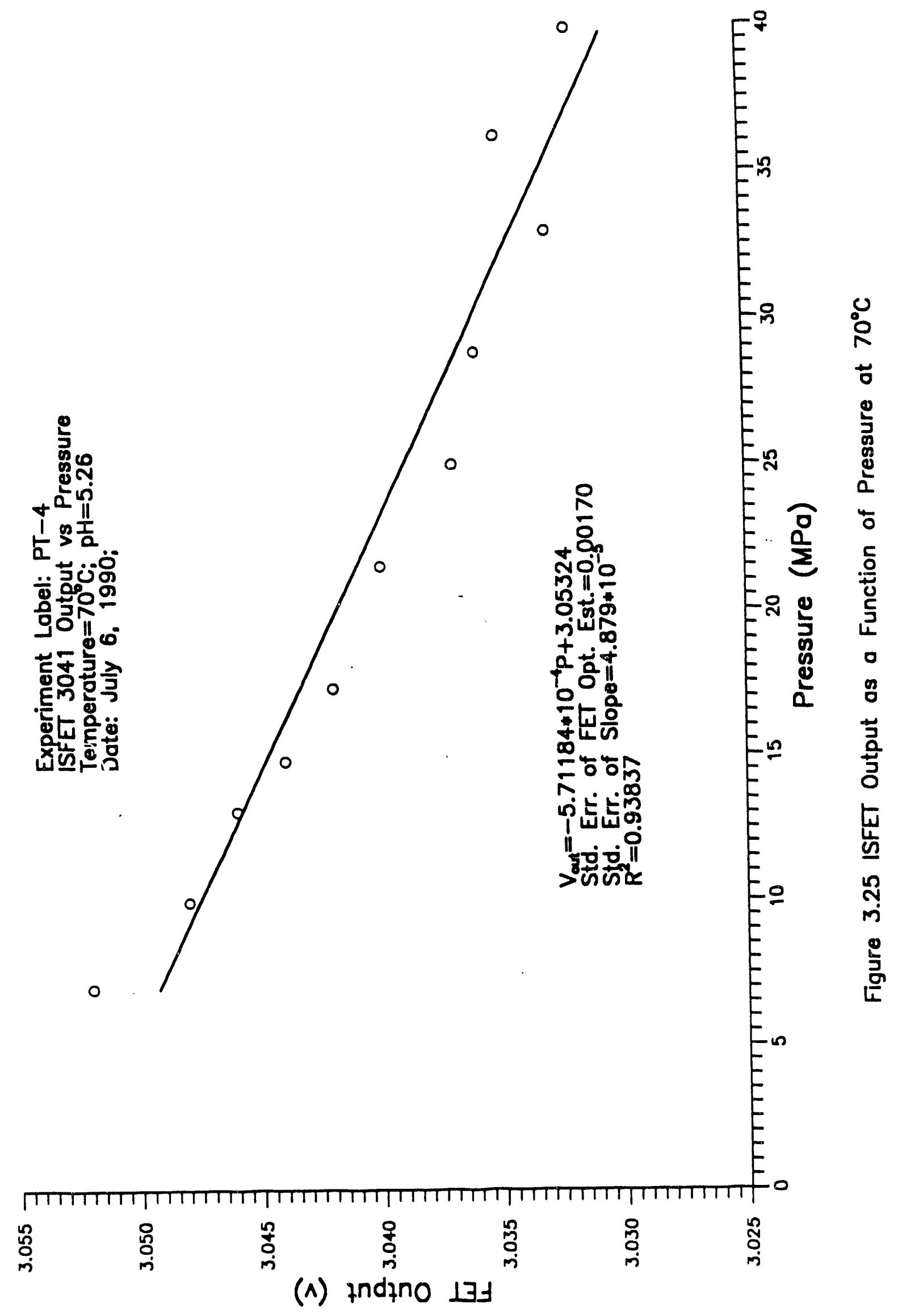




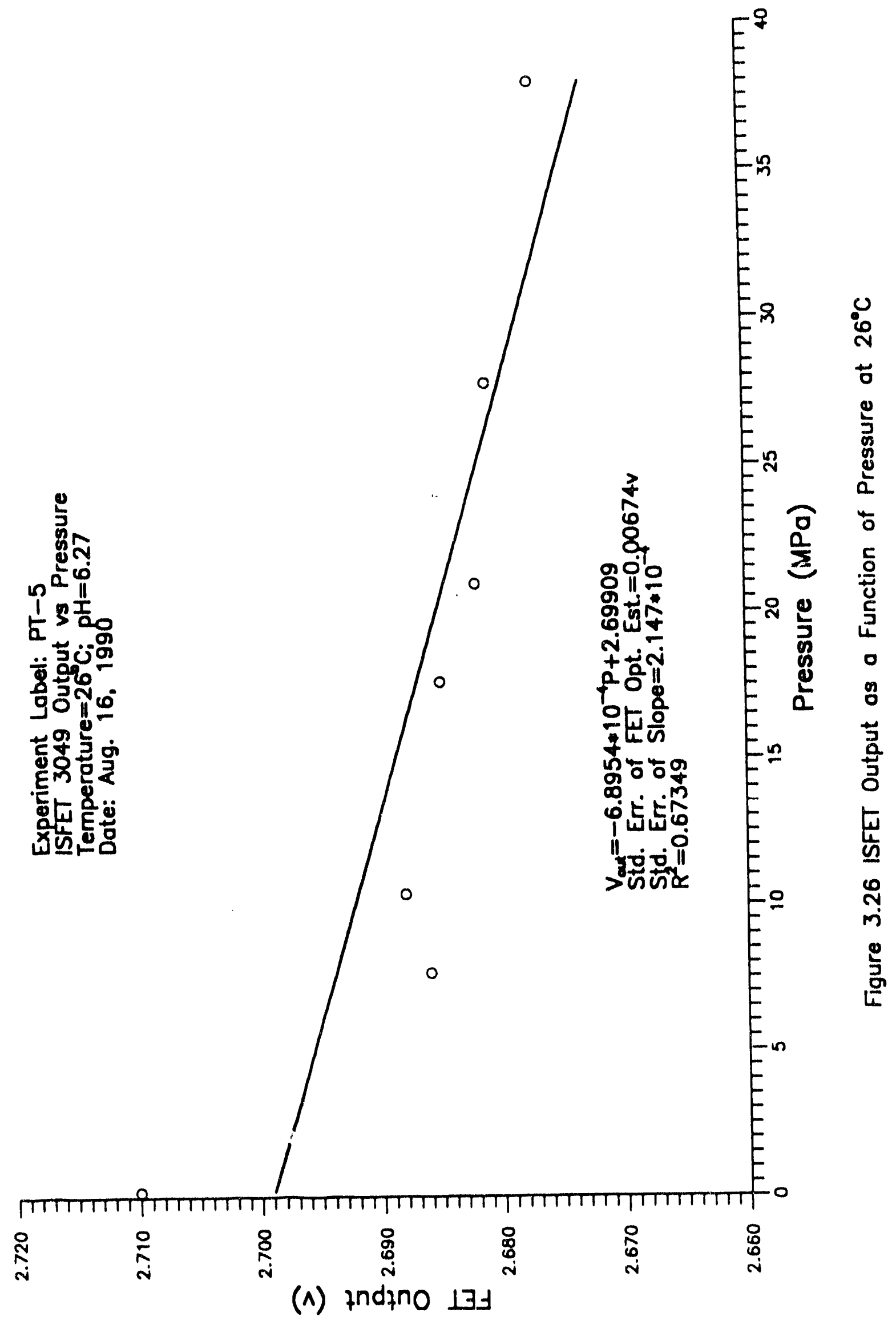




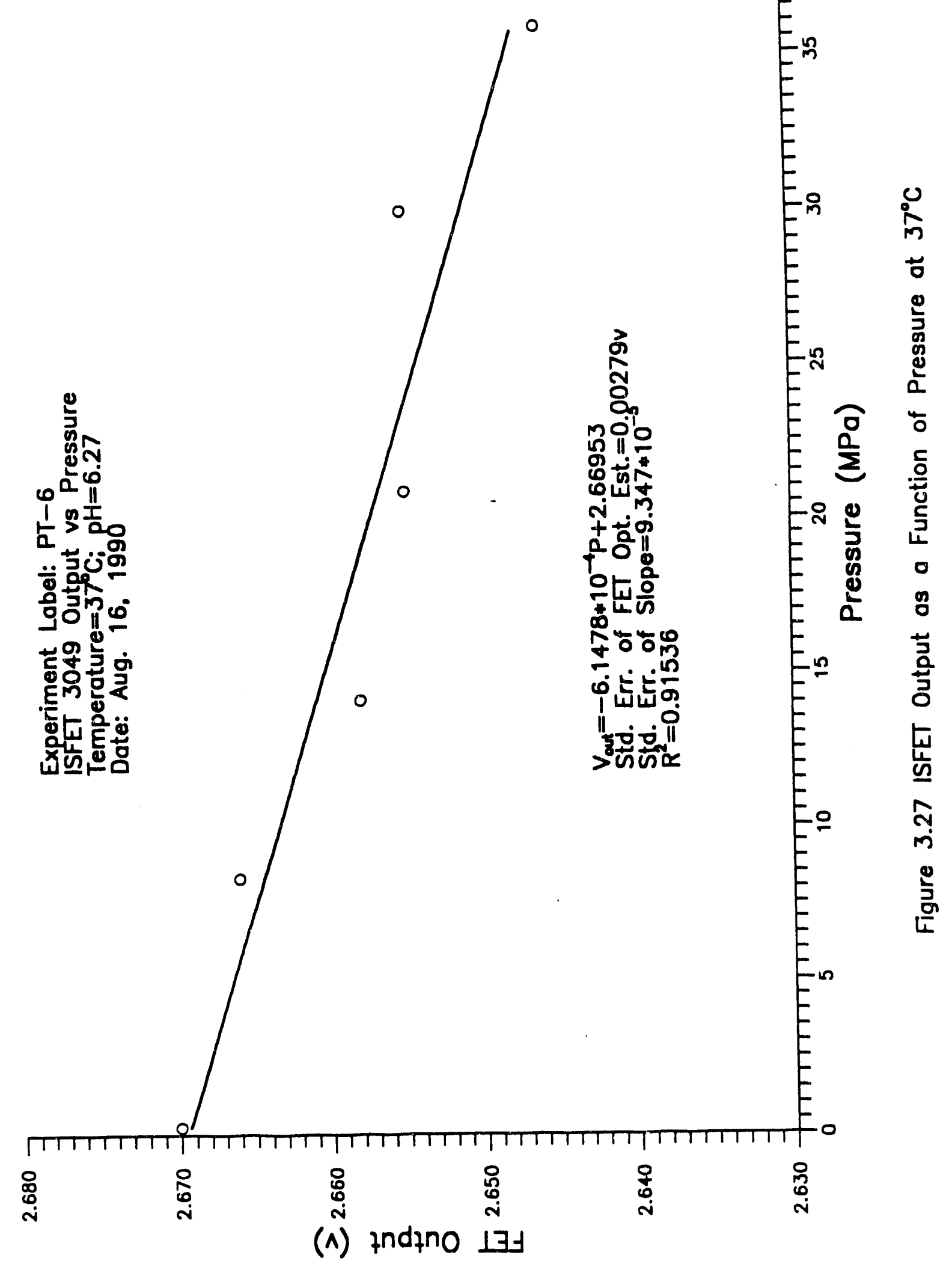



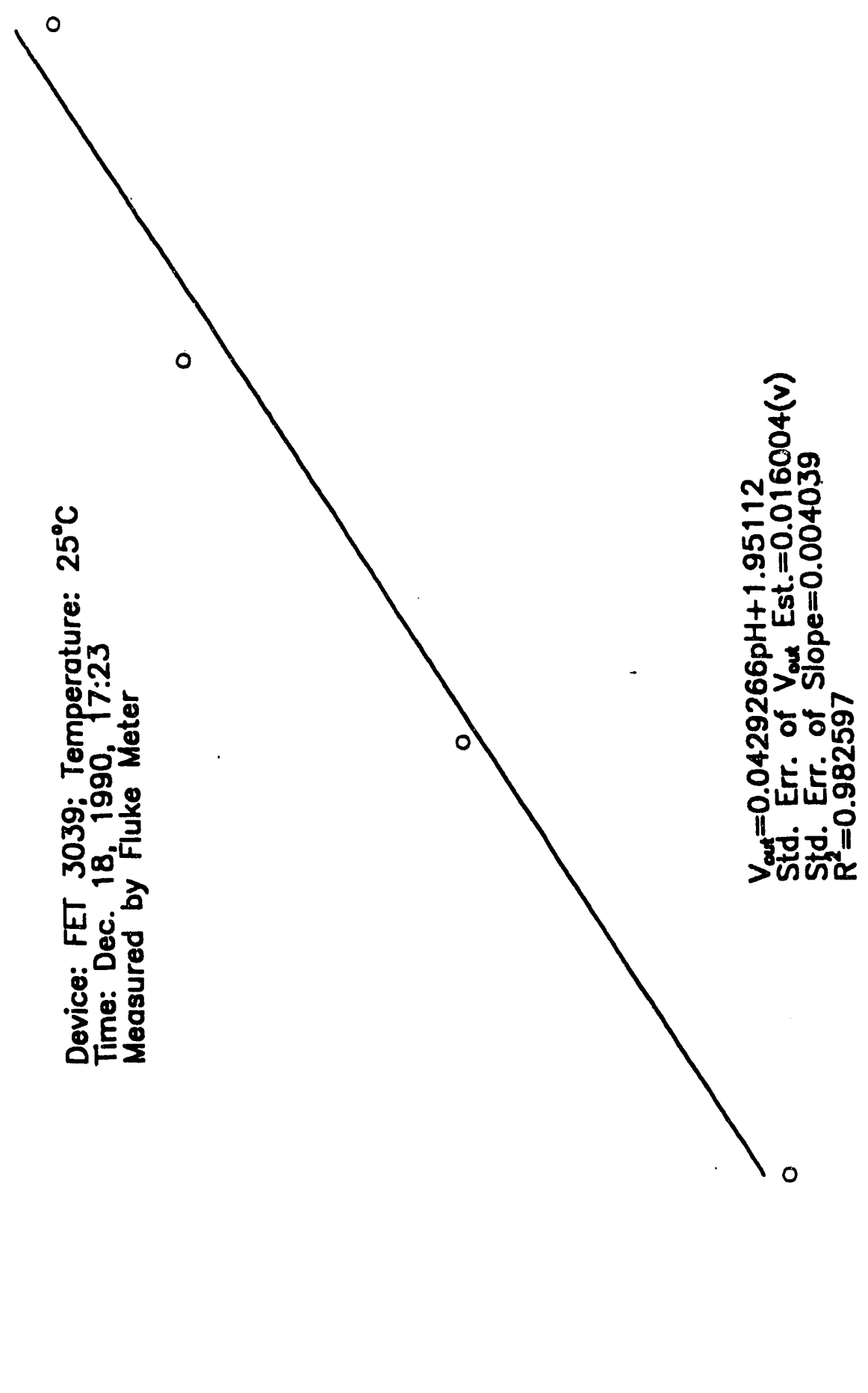

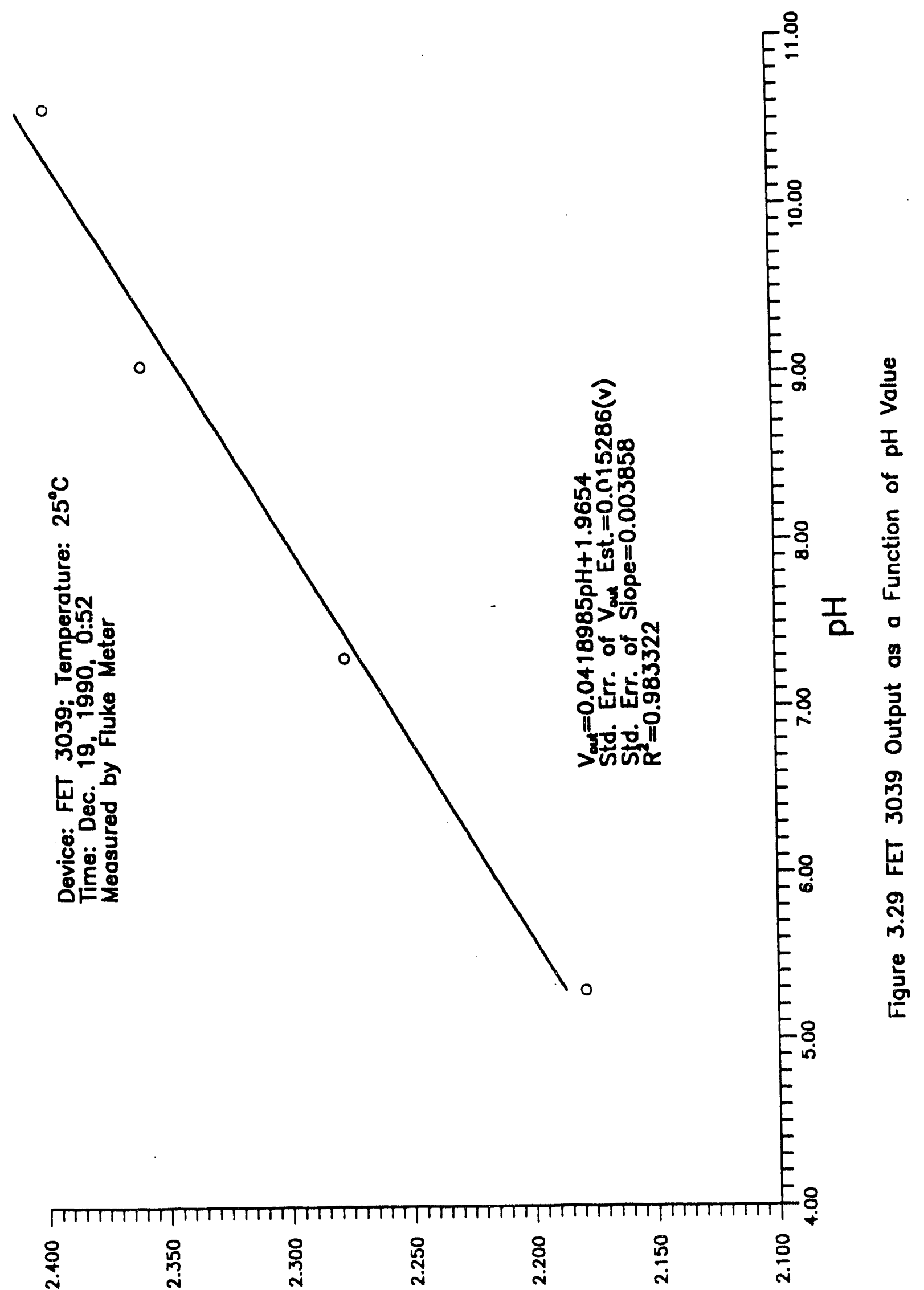

(^) zndino $1 \exists y$ 


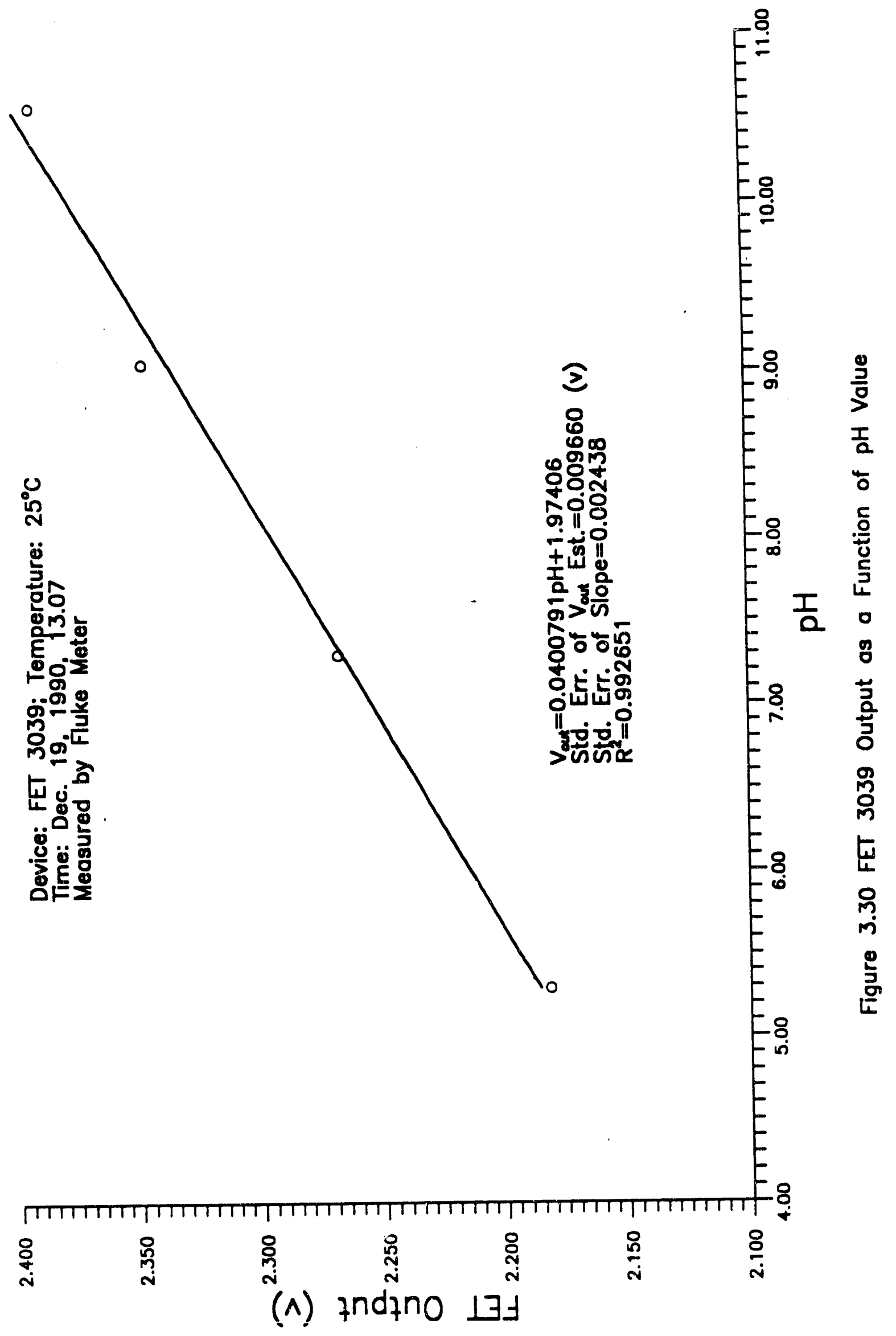



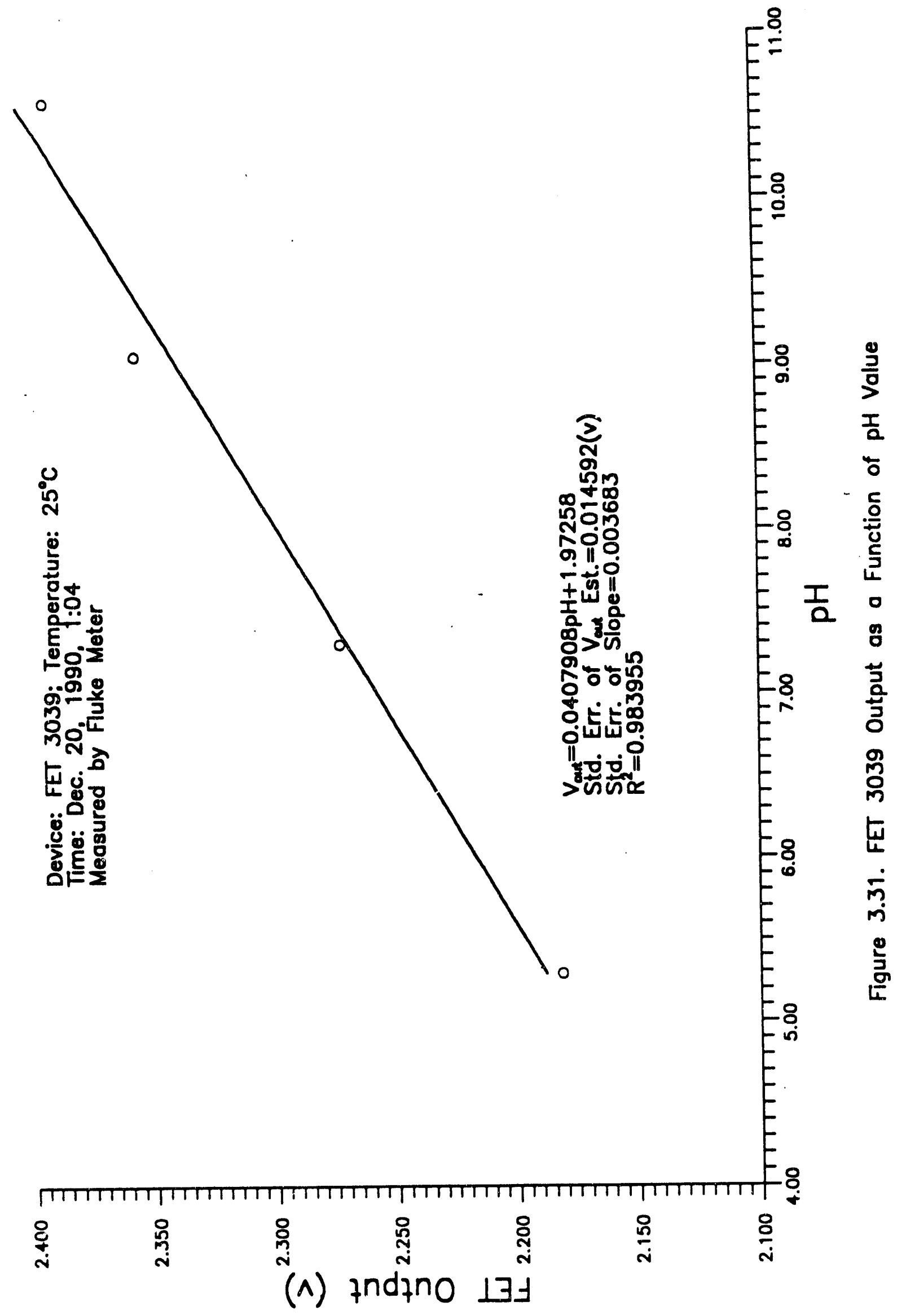

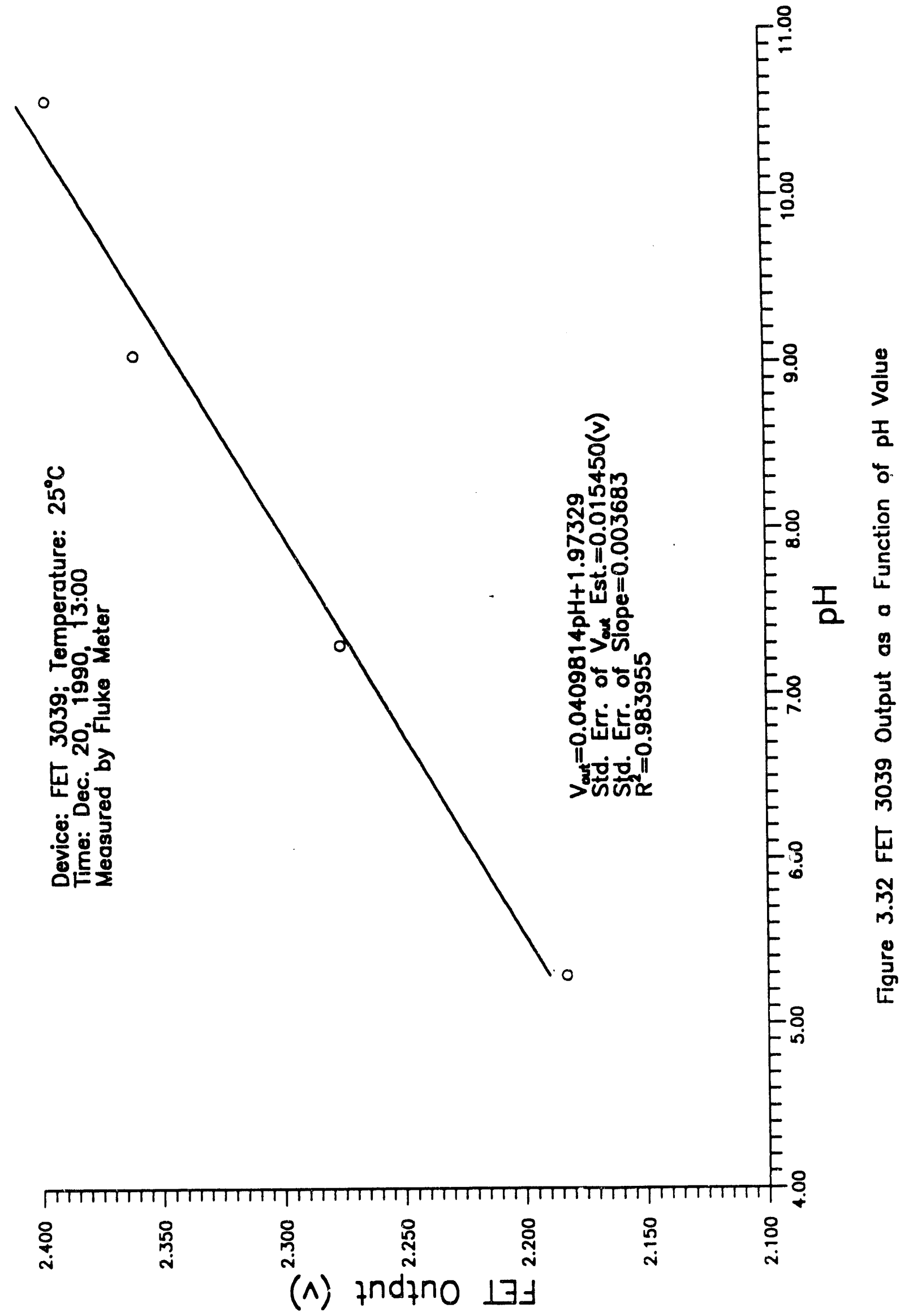


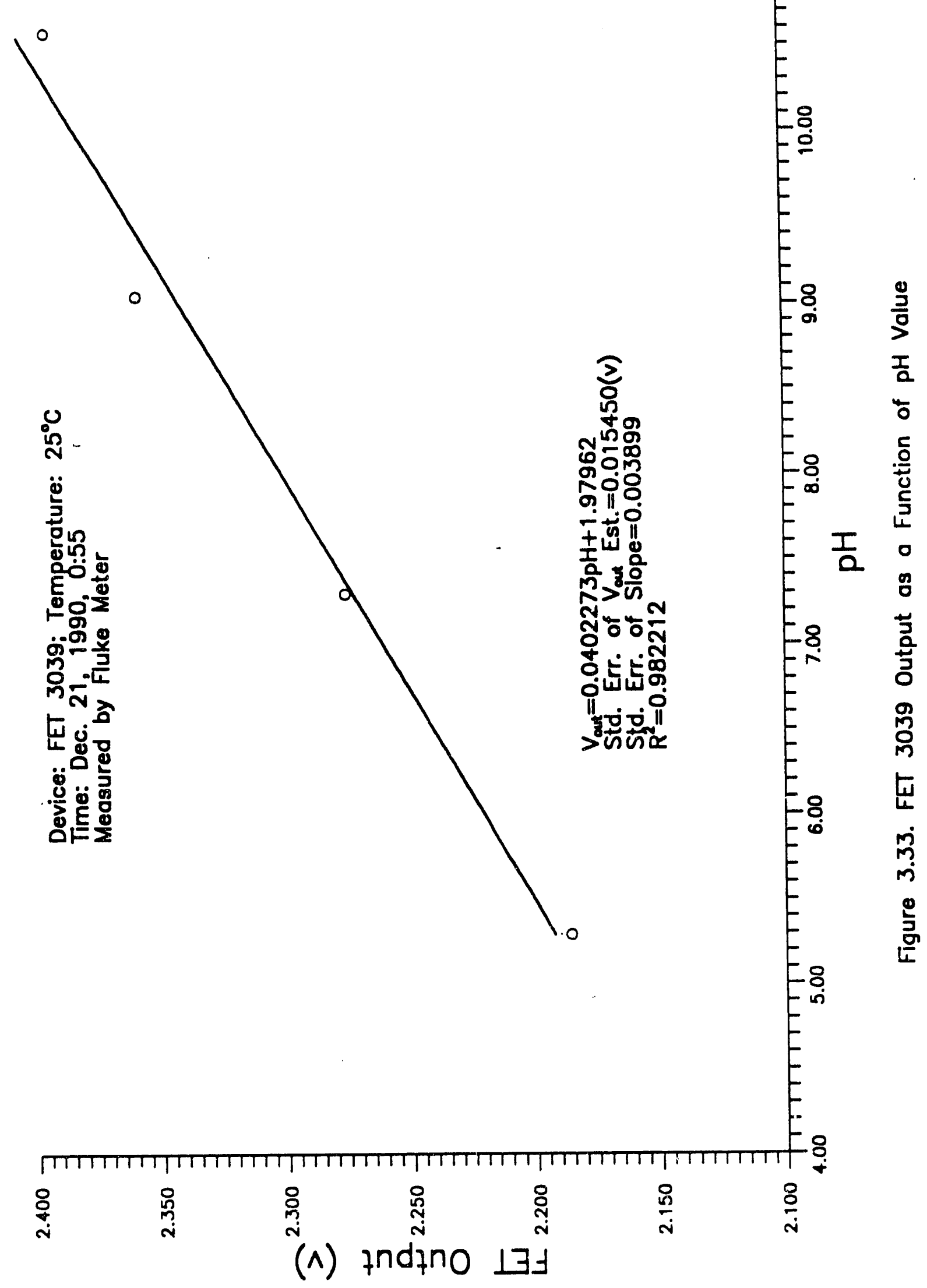




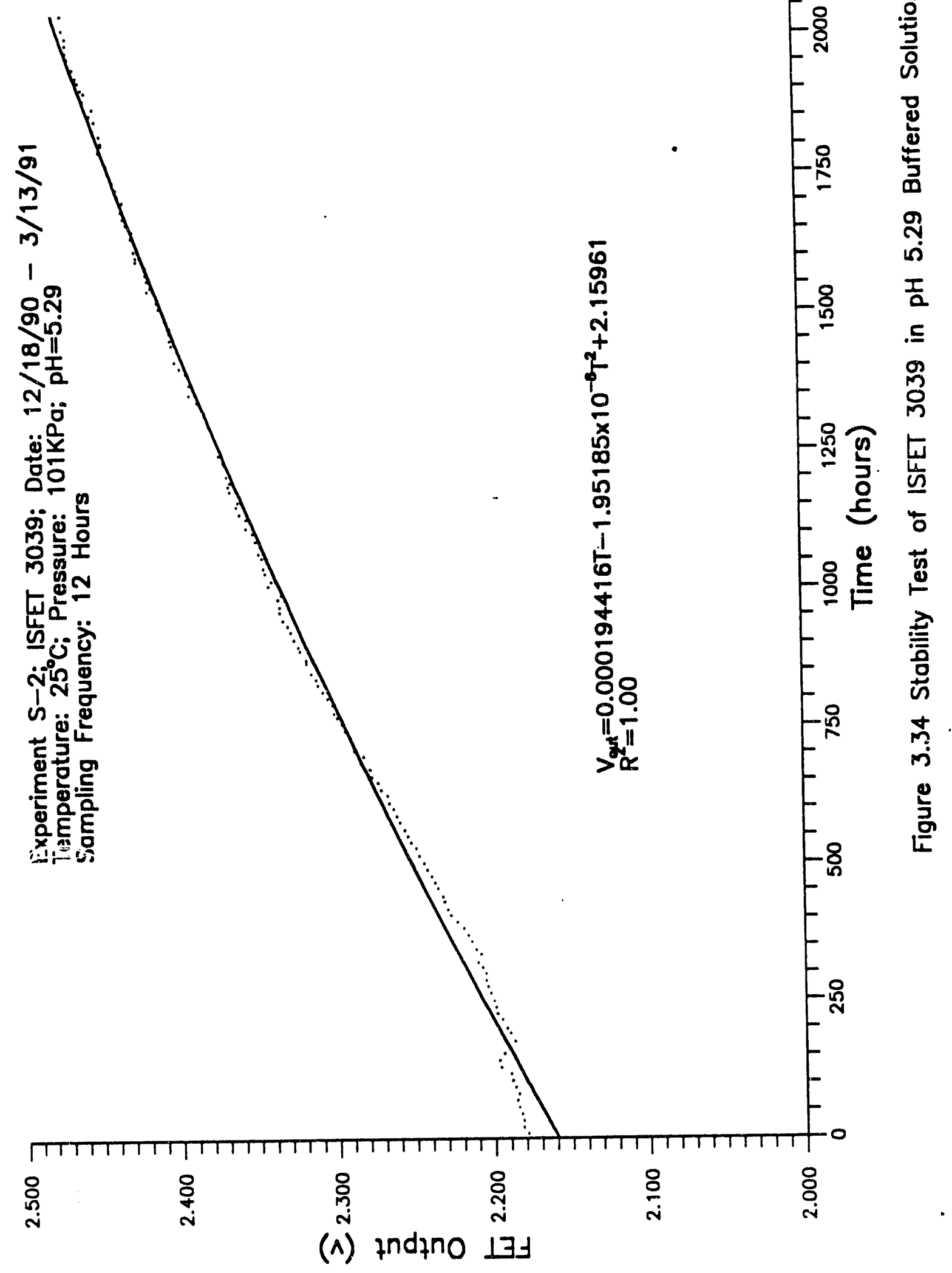




\section{REFERENCES:}

1. Benson, J., "New technology in $\mathrm{pH}$ analysis", American Laboratory, pp. 60-62, (March 1988).

2. Alean-Kirkpatrick, P. and Hertz, J. "An ion-selective field effect transistor for in-Situ $\mathrm{pH}$ monitoring of wet deposition" Intern. J.Environ. Anal. Chem., 37. pp. 149-159, (1989).

3. Knauss, K. G., Wolery, T. J. and Jackson, K. J., "A new approach to measuring $\mathrm{pH}$ in brines and other concentrated electrolytes". Geochimica et Cosmochimica Acta. 54. pp. 1519-1523, (1990).

4. Baxter, R. D., Phelan. D. M.; Clack, P. J. and Taylor, R. M.,"R\&D fabrication and testing of $\mathrm{pH}$ and $\mathrm{CO}_{2}$ sensors for geothermal brines", Leeds \& Northrup Company, North Wales, PA., (Mar. 1987).

5. Bergveld, P., IEEE Trans. BME-17, pp. 70, (1970).

6. Matsuo, T., Esashi, M., and Iinuma, K., Digest of joint meeting of Tohoku Sections of IEEEJ, (Oct. 1971).

7. Bergueld, P., IEEE Trans. BME-19, pp. 342, (1972).

8. Matsuo, T., and Wise, K. D., IEEE Trans. BEM-21, pp. 485, (1974).

9. Freiser, H., "Ion-selective electrodes in analytical chemistry", 2 Plenum Press, New York and London, (1981).

10. Zernel, J. N., Anal. Chem. 47, pp. 255A, (1975).

11. Moss, S. D., Janata, J., and Johnson, C. C., Anal. Chem. 47, pp. 2238, (1975).

12. Revesz, A. G., Thin Solid Films, 41, L43, (1977).

13. Buck, R. P., and Hackleman, D. E., Anal. Chem. 49, pp. 2315, (1977).

14. Morf, W. E., Oggenfuss, P., Simon, W., "New developments and consequences of the theory of ion-selective membranes" 4th Symposium on Ion-Selective 
Electrodes. Mátrafüred, (1984).

15. Janata, J., "Chemically sensitive field effect transistors: their application in analytical and physical chemistry" 4th Symposium on Ion-Selective Electrodes. Mátrafüred, (1984).

16. Van Der Schoot, B. H. and Bergveld, P., "The pH-static enzyme sensor" Analytica Chimica Acta, 199, pp. 157-160, (1987).

17. Sibbald, A., Covington, A. K. and Carter, R.'F., "Online patientmonitoring system for the simultaneous analysis of blood $\mathrm{K}^{\circ}, \mathrm{Ca}^{2 *}, \mathrm{Na}$ and $\mathrm{pH}$ using a quadruple-function CHEMFET integrated-circuit sensor" Medical \& Biological Engineering \& Computing, pp. 329-338, (July 1985).

18. Sibbald, A., Whalley, P. D. and Covington, A. K., "A miniature flowthrough cell with a four-function CHEMFET integrated circuit for simultaneous measurements of potassium, hydrogen, calcium and sodium ions", Analytica Chemica Acta., 159, pp. 47-62, (1984).

19. Sibbald, A., "A chemical sensitive integrated circuit: the operational transducer", Sensors and Actuators, 7, pp. 23-38, (1985).

20. Bousse, L., De Rooij, N. F. and Bergveld, P., "Operation of chemical sensitive field-effect sensors as a function of the insulator -lectrolyte interface", IEEE Transaction on Electron Devices, ED-30, No. 10. (Oct. 1983).

21. Li, Z. K., Reijn, J. M. and Janata, J., "Fluctuation phenomena. studies in chemically sensitive field effect transistors", J.Electrochem. Soc. (Mar. 1985).

22. Cakrt, M., "Optimization of experimental methods for determination of selectivity coefficients of known-addition techniques", 4th Symposium on Ion-selective Electrodes, Mátrafüred, (1984).

23. Van Der Spiegel, J., Lauks, I., Chan, P., Babic, D., "The extended gate 
chemically sensitive field effect transistor as malt-species microprobe", Sensors \& Actuators, 4, pp. 292, (1983).

24. Janata, J., "Chemical selectivity of field effect transistors", Analytical Proceedings, pp. 326-328, (Nov. 1987).

25. Braun, R. D.,"Introduction to instrumental analysis", pp. 697-720, McGraw-Hill Book Company, (1987).

26. Mann, L. Jr. "Applied engineering statistics for practicing engineers", pp. 113-134, Branes \& Noble, Inc., New York, (1970).

27. Volk, W., "Applied statistics for engineers", pp. 268, McGraw-Hill Book Co., (1969). 
For a Thesis

Chen, Jie, University of Southwestern Louisiana, 1991

Master of Science, Summer 1991

Major: Physics

Title of Thesis: Ion Sensitive Field Effect Transistors Applied to the Measurement of the $\mathrm{pH}$ of Brines

Thesis Directed by Dr John R. Meriwether

Pages in Thesis, 84; Words in Abstract, 125.

Abstract: In this research, Ion Sensi.ive Field Effect Transistors were used as the $\mathrm{pH}$ probes for brine solutions. A silver-silver chloride coated wire electrode was used as the reference electrode. Several $\mathrm{pH}$ values of buffer solutions containing sodium chloride were prepared as calibration and test solutions. The high pressure and high temperature conditions found in geothermal/geopressured reservoirs were maintained on the test solutions by a temperature and pressure control system. Measurements of ISFET's output, $\mathrm{V}_{\text {out, }}$ as a function of $\mathrm{pH}$, temperature, and pressure were performed. Linear relationships between $\mathrm{V}_{\text {out }}$ and $\mathrm{pH}, \mathrm{V}_{\text {out }}$ and temperature, and $\mathrm{V}_{\text {out }}$ and pressure were obtained and studied. The ISFETs were stable and reliable up to at least $40 \mathrm{MPa}$, but generally failed at temperatures in excess of about $60^{\circ} \mathrm{C}$. 


\section{Biographical Sketch}

Jie Chen, born in Xiamen, China on May 1, 1964, obtained his B.S. degree in physics at Jilin University, China in July, 1985. Working as an assistant engineer with Xiamen Photo. Materials Co. Ltd. from August, 1985 to December, 1988, he was charged with the analysis of photographic particles using an electromicroscope. In the Spring of 1989, he began his graduate study at the University of Southwestern Louisiana, USA.. While studying at USL, he was first a graduate teaching assistant and then during the Summer of 1989 he became a research assistant for Dr. John R. Meriwether and Dr. Dean F. Keeley at the Acadiana Research Laboratory. 

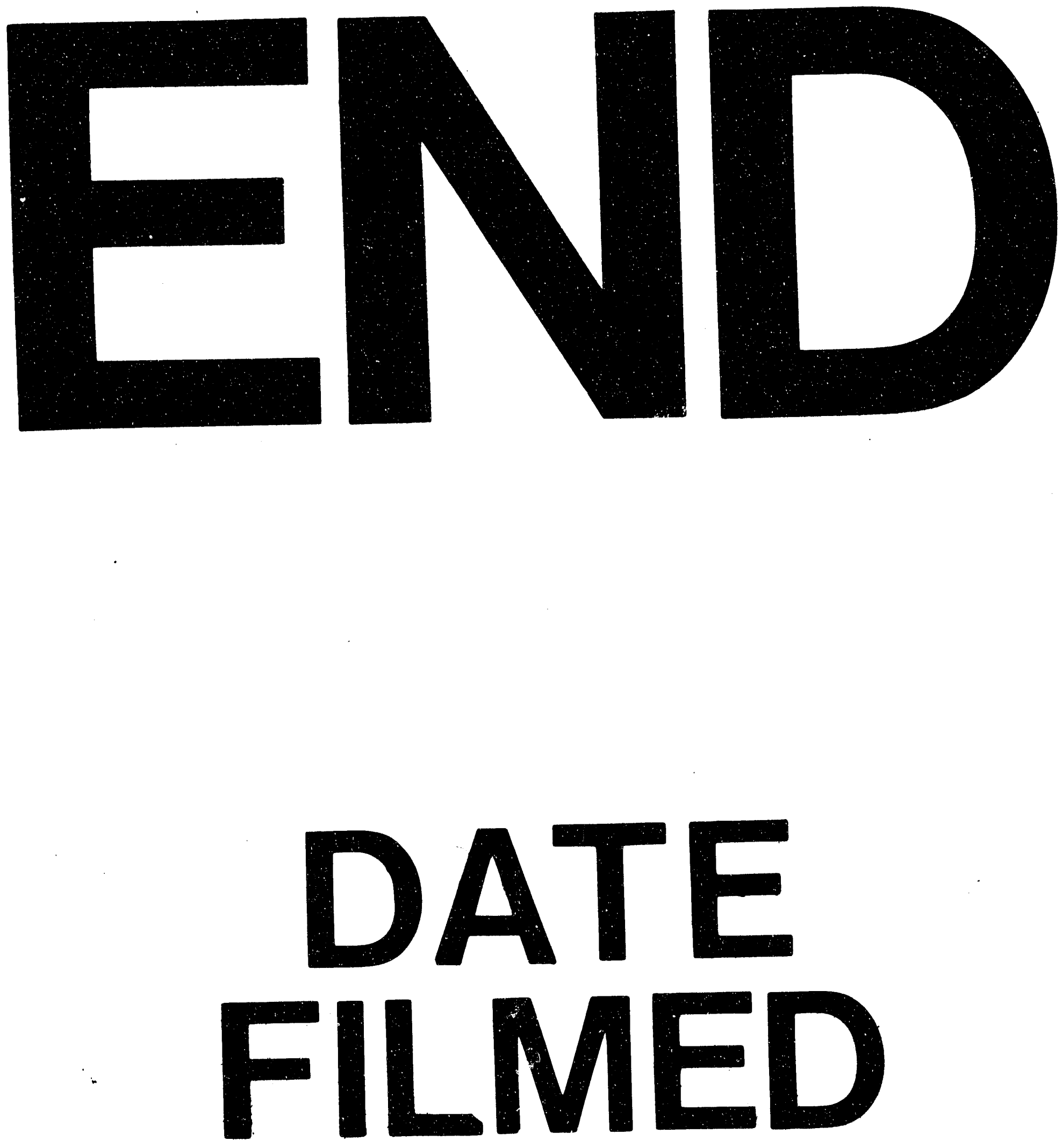

I
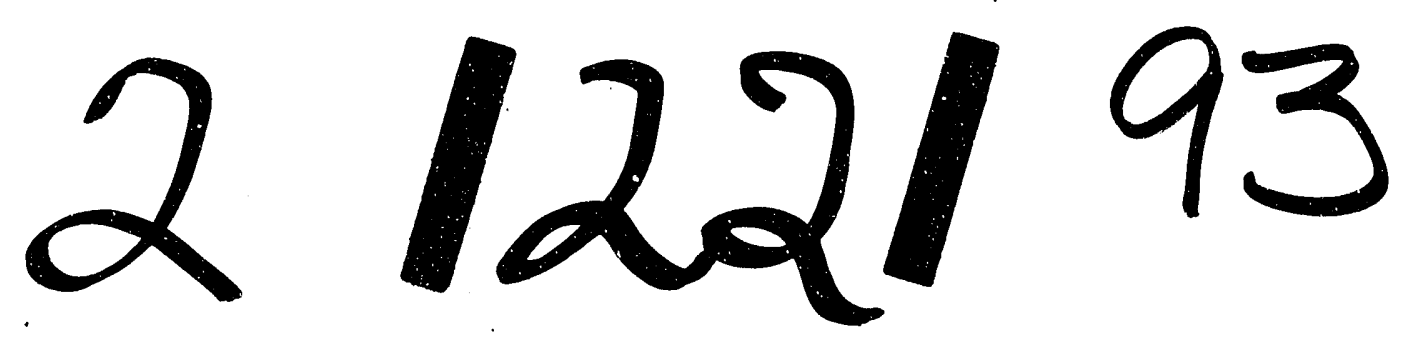
An 